\title{
Price Formation and the Measurement of Market Power on the International Dairy Markets
}

\author{
Dissertation \\ zur Erlangung des Doktorgrades \\ der Fakultät für Agrarwissenschaften \\ der Georg-August-Universität Göttingen
}

vorgelegt von

Markus Fahlbusch

geboren in Duderstadt

Göttingen, Februar 2014 
D 7

1. Referent: Prof. Dr. Bernhard Brümmer

2. Korreferent: Prof. Dr. Stephan von Cramon-Taubadel

Tag der mündlichen Prüfung: 5. Februar 2014 
For my family 


\section{Contents}

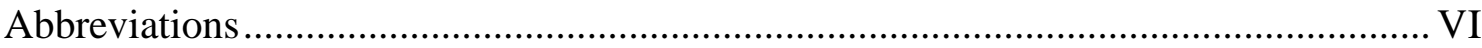

Acknowledgements............................................................................................... VII

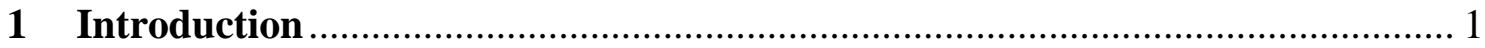

2 Overview of research papers ...................................................................... 5

2.1 Pricing-to-Market in a Perfect World: Is a Correct Estimation Possible?........... 5

2.2 Pricing-to-Market in an Oligopoly: An Alternative Approach to Measuring Marginal Cost

2.3 Measuring Market Power on the World Dairy Markets: A Residual Demand

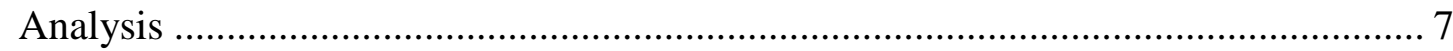

3 Pricing-to-Market in a Perfect World: Is a Correct Estimation Possible?......... 9

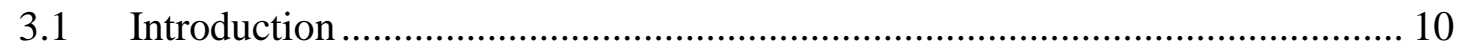

3.2 Detection of PTM: The Knetter model ........................................................ 13

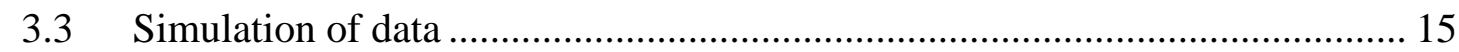

3.4 Estimation results for the simulated data .................................................. 22

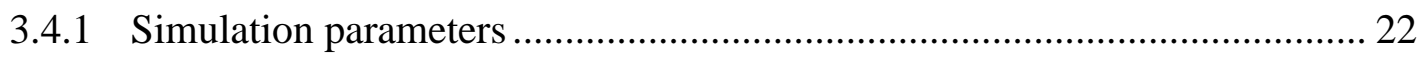

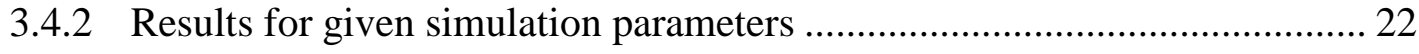

3.4.3 Results for varying simulation parameters .......................................... 25

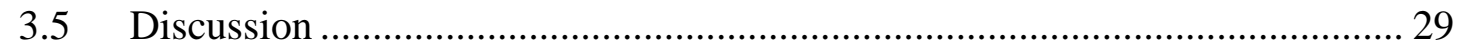

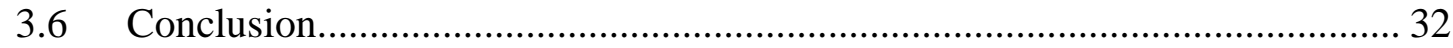

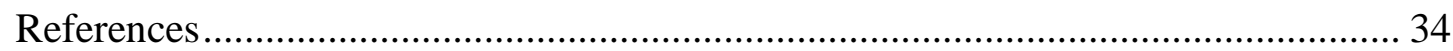

Appendix 3.1: Estimated PTM coefficients for the model in first differences ........... 38

Appendix 3.2: Estimated PTM coefficients for the model in levels.......................... 38

Appendix 3.3: Estimated PTM coefficients for different supply elasticities.............. 39

Appendix 3.4: Estimated PTM coefficients for different imported factor shares ...... 39

4 Pricing-to-Market in an Oligopoly: An Alternative Approach to Measuring

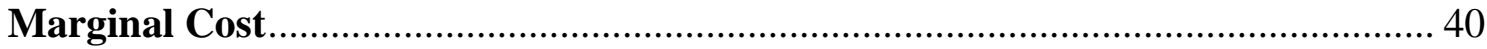

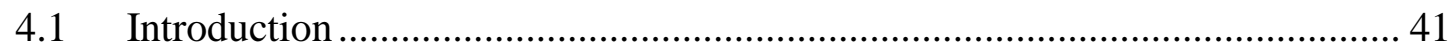

4.2 A theoretical model of pricing-to-market in an oligopoly ............................. 43

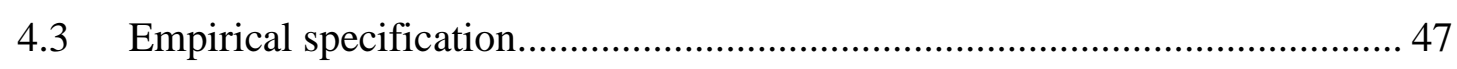

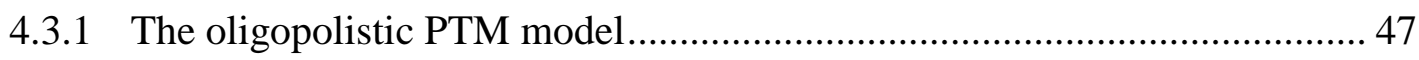

4.3.2 Estimation of the marginal cost .............................................................. 50 


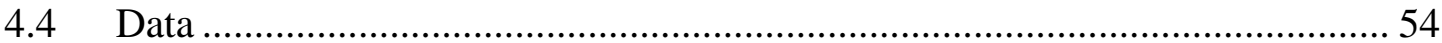

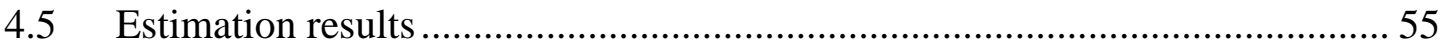

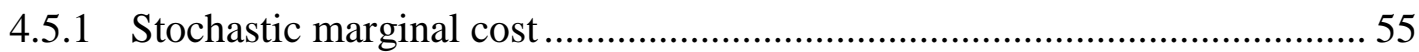

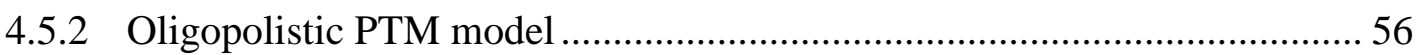

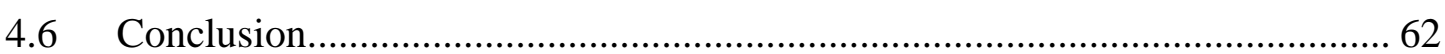

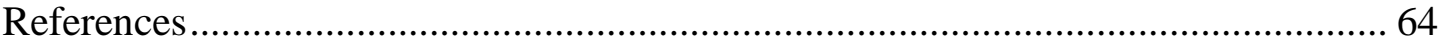

Appendix 4.1: Derivation of the theoretical model ..................................................... 66

Appendix 4.2: SMC series for New Zealand (in 1000 NZ\$) ..................................... 70

Appendix 4.3: SMC series for the EU (in $1000 €$ ) ..................................................... 70

5 Measuring Market Power on the World Dairy Markets: A Residual Demand

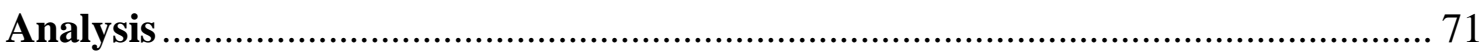

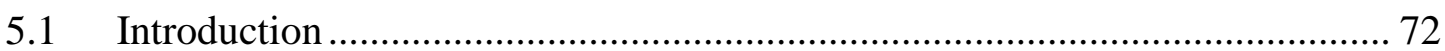

5.2 The residual demand and its connection to market power ............................. 74

5.3 Empirical specification and estimation problems …..................................... 78

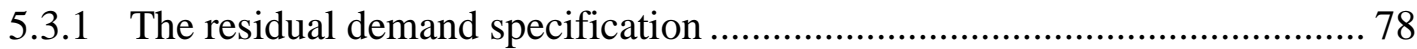

5.3.2 Instrumentation problems and cost shifting variables .............................. 79

5.3.3 A measure of the marginal cost as an alternative .................................... 81

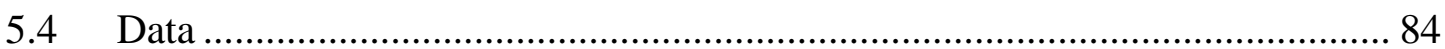

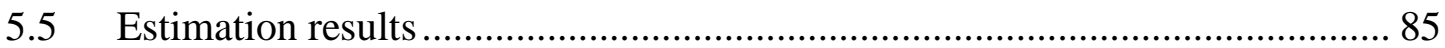

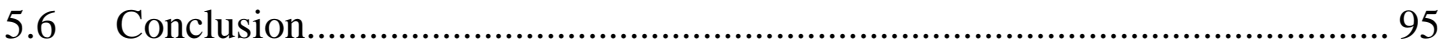

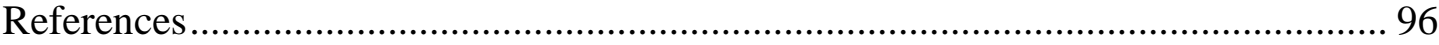

Appendix 5.1: Sample characteristics and SMC estimation results .......................... 98

Appendix 5.2: SMC series for Australia (in 1000 AU\$) ........................................... 98

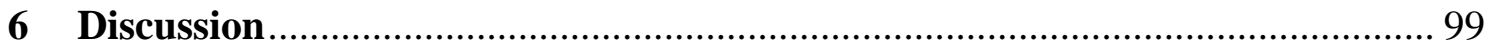

6.1 A note on the stochastic marginal cost....................................................... 99

6.2 The connection between PTM and the residual demand ............................. 103

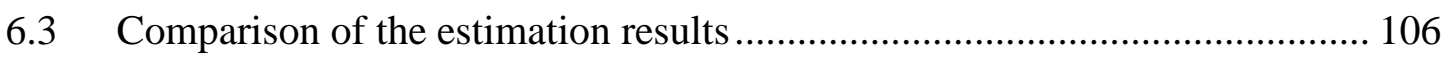

6.4 Implications for the international dairy markets ......................................... 110 


\section{Abbreviations}

2SLS two step least squares

3SLS three step least squares

AIC Akaike information criterion

BIC Bayesian information criterion

CPI consumer price index

ER bilateral exchange rate

ERPT exchange rate pass-through

FD-ERC first difference exchange rate correlation

GDP gross domestic product

GTA Global Trade Atlas

HAC heteroskedasticity and autocorrelation consistent

HQC Hannan-Quinn information criterion

IMF International Monetary Fund

IV instrumental variables

MC marginal cost

OLS ordinary least squares

PTM pricing-to-market

RDE inverse residual demand elasticity

SLPF stochastic lower price frontier

SMC stochastic marginal cost

SMP skimmed milk powder

SUR seemingly unrelated regressions

UV unit value

WMP whole milk powder 


\section{Acknowledgements}

This $\mathrm{PhD}$ thesis would not have been possible to complete without the general or specific support of several people. Firstly, I would like to thank my supervisor Prof. Dr. Bernhard Brümmer. His supervision and my appointment as a research assistant at his Chair for Agricultural Market Analysis allowed me to conduct the research necessary for this thesis. He is a great teacher and I learned a lot from him; the discussions we had along with his comments and feedback proved immensely helpful for me, and provided an important contribution to this thesis. Furthermore, he always had an open ear, supported me where he could and gave me the space to follow my research interests. In general, the time at his chair was a valuable experience in my life.

In addition, I am very grateful to Prof. Dr. Stephan von Cramon-Taubadel for being my second supervisor. I always enjoyed his lectures which influenced my way of economic thinking or just helped me to write good papers. Furthermore, I would like to thank Prof. Dr. Achim Spiller for joining the board of the examination committee. Since 2008, we have enjoyed an annual mutual cooperation in order to complete the annual dairy market article for the German Journal of Agricultural Economics.

Dr. Oleksandr Perekhozhuk and Dr. Sascha Alexander Weber were my discussants in the progress reports of the doctoral seminar. I would like to thank both of them for valuable hints and suggestions. Additionally, Dr. Oleksandr Perekhozhuk provided me with data from International Financial Statistics and Dr. Sascha Alexander Weber is part of a cooperation with the Thünen Institute which shapes the "milchtrends.de" project. He and all other colleagues of the project deserve my thanks for their fruitful cooperation and the interesting discussions we shared. The same is true for my colleagues at the Chair of Agricultural Market Analysis. In particular, I would like to emphasize the contributions of Dr. Martin Pfeuffer and Jonathan Holtkamp. Discussions with both Martin and Jonathan helped me to sharpen the content of my research. Further thanks go to Jonathan for the time we both enjoyed as office mates.

Furthermore, I am very grateful to Adam Walker who - as a native speaker - did the English editing for this thesis. He was always available when I needed his help and spent a lot of time on this, especially in the final phase. In addition, two student assistants aided me a lot during my time at the chair - Matthias Kuhn and Jurij Berger. Nina Enke, Monika Scholz, Bianka Rieck, Dagmar Krendl, Birgit Gerschewski and Wolf- 
gang Peinemann always provided a warm atmosphere at the department and often helped me with organizational tasks. I owe my thanks to all of them.

Special thanks go to my family: My parents always supported me in my studies. Without the support of my beloved wife, Olga, many things would not have been possible. She helped me where she could and managed the private framework that allowed me to do my research. In addition, she always had an understanding when the night once again became the day. Furthermore, my son Jan Richard - who was born in 2013 - gave me a kind of support that can only be understood by those who also have children. He is my pride and joy and reminds me of how special life is.

Göttingen, February 2014

Markus Fahlbusch 


\section{Introduction}

Due to an increased degree of price volatility, the international dairy markets have been the focus of public attention more and more in the past years. Historically, the European Union was able to protect itself from price developments on the international markets but this will be no longer possible in the future. The export subsidies which are necessary for this undertaking for a net export country have been suspended since 2009 and are unlikely to be reintroduced for a long period of time, in light of pressure from the WTO negotiations. Furthermore, import tariffs are continually under pressure. As a result, the international dairy markets and their development are of huge importance for the whole dairy value chain as well as for European and German policy. In this situation, information with regard to price formation on the international dairy markets is of primary interest. In this context, the question of imperfect competition and market power is a central issue. MCCORRISTON (2002) argues that imperfect competition should matter in general for agricultural economists since it is a) more pronounced in the agricultural sector than often assumed, b) important for how markets are working and c) has implications for policy analysis. Indeed, the preference for certain market policy instruments or even conceptual issues with regard to the Common Agricultural Policy can be influenced by imperfect competition. Market power has additional implications with regard to the regulatory policy that are insufficiently solved in an international context.

In fact, signs exist for some degree of imperfect competition on the international dairy markets, with the supply side particularly highly concentrated. Only four export countries (New Zealand, the EU, Australia and the US) account for $80 \%$ to $90 \%$ of the dairy exports when measured in milk equivalent. In contrast, the demand side is much less concentrated. However, even when the focus is shifted away from the country level to the firm level, concentration remains strong. The most important player on the markets is the New Zealand dairy co-operative Fonterra. The Fonterra Co-operative Group Ltd. was established in 2001 and developed from the two biggest dairy co-operatives - New Zealand Dairy Group and Kiwi - as well as from the New Zealand Dairy Board, which had an export monopoly on dairy products up to the merger. After the merger, the new dairy co-operative Fonterra was responsible for $95 \%$ of New Zealand's dairy exports (ARMENTANO et al. 2004: 41). This equals roughly one third of the total exports on the international dairy markets in milk equivalent. When single dairy products are considered, this share is - in some cases - markedly higher. 
However, in addition to New Zealand's dairy exports, Fonterra also controls - directly or indirectly - significant quantities of dairy exports from other export countries (BLAYNEY et al. 2006: 13-15). This is possible through a number of foreign subsidiaries, partnerships, joint ventures and agreements. The most important of these with regard to the international markets are agreements with Dairy America (export of US skimmed milk powder) and the Argentinian dairy co-operative SanCor (export of Argentinian milk powder and cheese) as well as an ownership stake in the Australian dairy company Bonlac. These kinds of operations further strengthen Fonterra's market position. Even without considering them, the company already dominates the markets, particularly for milk powder and butter with world market shares of around 50\%. The market shares are even higher in Asian and Southeast Asian destinations. However, a basic limitation for the exercise of market power should be the status as a co-operative; that is, the supply quantity is determined by the independent and competitive production decisions of the member farms (SEXTON \& LAVOIE 2001: 877). It may therefore be difficult for Fonterra to supply less quantity in order to charge an overall higher price. A much more likely possibility to exercise market power in this case is to practice price discrimination with respect to the destination countries.

For the analysis of market power, a number of different approaches are available. The New Empirical Industrial Organization (NEIO) offers structural approaches that allow the estimation of behavioral or market power parameters. An overview of a wide range of different models and applications can be found for example in BRESNAHAN (1989), Sexton \& Lavoie (2001) and Wohlgenant (2001). However, as GoldBerg \& KNETTER (1999: 32) argue, most of these models have an enormous need for data especially in the framework of international markets. For each destination country, a complete oligopoly model would have to be specified with price and quantity data needed for each firm that is selling in the market. Unfortunately, this data is usually not available - at least not at a reasonable cost. Approaches that avoid these data requirements - and are therefore intensively used when international markets are analyzed are the pricing-to-market (PTM) approach as well as the residual demand approach.

The PTM approach is based on the observation of KRUGMAN (1986) that import prices do not change by the same proportion at which exchange rates change. When this observation is not caused by a change in the overall marginal cost of the export country, markups are adjusted in order to smooth price changes in the destination country. This is exactly the behavior that is defined as PTM. The most important empirical model to 
detect PTM is introduced by KNETTER (1989; 1993). When PTM is detected, this is a proof that a markup must exist, at least in some time periods; otherwise it cannot be adjusted downwards. The residual demand approach, however, rests on the estimation of the inverse residual demand whose elasticity with regard to quantity is a direct indication of market power and is even equal to the Lerner index under some conditions. In contrast to the market demand, in the case of the "residual" demand, the reactions of competitors are already accounted for. The approach was developed by BAKER \& BRESNAHAN (1988) for single firms and adapted by GOLDBERG \& KNETTER (1999) for usage with international markets.

This thesis is built of three papers and considers both approaches by extending or modifying them. Afterwards, they are applied in order to analyze the New Zealand dairy exports with regard to market power. For the PTM model it is shown that the key feature of the model proposed by KNETTER $(1989 ; 1993)$ - namely, how it is controlled for the overall marginal cost of the export country - may pretend to eliminate a bias in the estimated PTM coefficients, but in fact only shifts this bias (first paper). Therefore, an alternative approach to control for the marginal cost is proposed - the usage of the socalled stochastic marginal cost - that additionally allows the inference of PTM through changes in the marginal cost. At the same time, the basic PTM model established by KNETTER $(1989 ; 1993)$ is extended to an oligopolistic model of PTM that a) provides an index of product differentiation and additionally b) identifies the source of PTM - a task that had not been solved until now (second paper). Furthermore, the stochastic marginal cost series is used in the residual demand model in order to replace cost shifting variables that often reflect only a small proportion of the marginal cost (third paper).

The thesis is structured as follows: Chapter 2 gives an overview of the three papers that constitute the core of this thesis. Chapters 3 to 5 represent the single papers. In Chapter 6 some overall issues are discussed, methods and results are compared and implications for the international dairy markets are considered. 


\section{References}

Armentano, L.E., Dobson, W.D., Jesse, E. V. \& Olson, N.F. (2004): The dairy sectors of New Zealand and Australia: A regional study. Babcock Institute Discussion Paper, 2004(3), pp. 1-64.

BAKER, J.B. \& BRESNAHAN, T.F. (1988): Estimating the residual demand curve facing a single firm. International Journal of Industrial Organization, 6, pp. 283-300.

Blayney, D.P., Gehlhar, M.J., Bolling, C.H., Jones, K., Langley, S., Normile, M.A. \& SomwarU, A. (2006): US dairy at a global crossroads. United States Department of Agriculture, Economic Research Service, ERR No. 28, pp. 1-44.

BRESNAHAN, T.F. (1989): Empirical studies of industries with market power. In Schmalensee, R. \& Willig, R., eds: Handbook of Industrial Organization, Vol. 2, No. 2. pp. 1011-1057.

GoldBerg, P.K. \& KNETTER, M.M. (1999): Measuring the intensity of competition in export markets. Journal of International Economics, 47(1), pp. 27-60.

KNETTER, M.M. (1993): International comparisons of pricing-to-market behavior. The American Economic Review, 83(3), pp. 473-486.

KNETter, M.M. (1989): Price Discrimination by U.S. and German Exporters. The American Economic Review, 79(1), pp. 198-210.

KRUGMAN, P. (1986): Pricing to market when the exchange rate changes. National Bureau of Economic Research (NBER), Working Paper No. 1926, pp. 1-43.

MCCORRISTON, S. (2002): Why should imperfect competition matter to agricultural economists? European Review of Agricultural Economics, 29(3), pp. 349-371.

Sexton, R.J. \& Lavoie, N. (2001): Food Processing and Distribution: An Industrial Organization Approach. In Gardner, B.L. \& Rausser, G.C., eds: Handbook of Agricultural Economics, Vol. 1, Part B - Marketing, Distribution and Consumers. Amsterdam: Elsevier, pp. 863-932.

Wohlgenant, M.K. (2001): Marketing Margins: Empirical Analysis. In Gardner, B.L. \& Rausser, G.C., eds: Handbook of Agricultural Economics, Vol. 1, Part B - Marketing, Distribution and Consumers. pp. 933-970. 


\section{Overview of research papers}

This chapter presents an overview of the three papers which constitute the core of this thesis. The basic ideas and results are summarized.

\subsection{Pricing-to-Market in a Perfect World: Is a Correct Estimation Possible?}

The first paper focusses on the specification of the Knetter model - which is the most important model to detect PTM - and shows by using simulated data that the model provides biased PTM estimates. This is shown to be the case, despite the fact that data is simulated under the theoretical conditions the Knetter model is built on.

When PTM is estimated, it is important to control for the marginal cost of the country whose exports are analyzed. Changes in exchange rates primarily influence the prices in the import country's currency, but when these changes lead to a considerable quantity reaction, the price in the export country's currency is affected too. This happens due to changes in the exporter's marginal cost. This means that exchange rates and the marginal cost are correlated and the omission of the marginal cost in a PTM model would lead to an omitted variable bias. PTM would be found more often and would be more pronounced since a part of the incompleteness of an exchange rate pass-through is due to a change of the exporter's marginal cost.

The basic problem concerns the fact that the marginal cost cannot simply be introduced in a PTM model because it is not observable. Furthermore, the usage of cost shifters would also lead to biased coefficients. Therefore, the Knetter model tries to infer an index of the marginal cost from price data. Since marginal cost is equal across all destination countries at the port of export, fixed time effects in a panel model should account for changes in the marginal cost. Nevertheless, this only works when the marginal cost also equally influences the prices across the destination countries (equal cost passthrough). Indeed, this cannot be expected to be the case. It can be theoretically shown that cost and exchange rate pass-through should be equal. When exchange rate passthrough is different across destination countries, cost pass-through is different too and the fixed effects only depict the average cost pass-through. As a result, the PTM coefficients can be expected to be biased toward the average PTM coefficient in the sample.

In order to prove the severity and the behavior of such a bias, we simulate idealized data of a monopolistic export country that delivers to ten destination countries and practices different degrees of PTM. The results confirm the bias in the coefficients and show that 
its extent is - under realistic conditions - around 50\% towards the sample mean. The extent depends heavily on the sample selection and is increased for large degrees of correlation of the exchange rates, small values of the supply elasticity as well as a high importance of foreign inputs. The influence of the supply elasticity makes this bias especially serious in the case of agricultural commodities.

\subsection{Pricing-to-Market in an Oligopoly: An Alternative Approach to Meas- uring Marginal Cost}

The second paper provides two innovations. Firstly, the PTM model proposed by Knetter is extended to an oligopolistic model of PTM that provides an index for the degree of product differentiation and allows the identification of the source of PTM. Secondly, since the first paper indicates biased PTM coefficients for the Knetter model, an alternative approach is developed to estimate a measure of the marginal cost (the stochastic lower price frontier) and is directly used to estimate the PTM model.

The PTM model established by Knetter is based on a monopolistic export firm that practices third degree price discrimination which directly leads to PTM behavior. Nevertheless, the model can also be used for an oligopolistic market structure but is not able to detect the source of PTM. In general, PTM can be caused by the convexity of the market demand schedule (that is the usual assumption) or by the existence of one or more oligopolistic competitors. In addition to the ordinary PTM coefficient, our theoretical extension of the model yields a competitor coefficient. This coefficient explains the influence of the competitor's cost on the firm's markup and is therefore an index for the degree of product differentiation that can be expected to lie between zero and the absolute value of the PTM coefficient. When this coefficient is zero, PTM is caused solely by the market structure; when it equals the absolute value of the PTM coefficient, PTM is caused solely by the existence of the respective competitor.

In this extended PTM model, the marginal cost is depicted by an estimate. The destination-specific export unit values that are already used in the Knetter model contain a lot of information regarding agreements of sale. They basically consist of the marginal cost, markups, quality premiums, measurement errors and expectation effects. By assuming that the other components follow certain distributions which can be estimated, we obtain the stochastic lower price frontier that is - under some conditions - an unbiased estimate for the marginal cost. We call this estimate the "stochastic" marginal cost. 
The empirical results of using the stochastic marginal cost in the oligopolistic PTM model support the validity of the approach with regard to the interpretation of the theoretical coefficients, as well as with regard to the usage of the stochastic marginal cost. In the case of the international dairy markets which are analyzed, a significant degree of PTM practiced by New Zealand is present; the only exception is the market for skimmed milk powder. The average degree of PTM implies that around 40\% of cost changes are smoothed out, whereas this number varies more across destinations than across products. Furthermore, the PTM found is mainly caused by the EU as a competitor region, especially when a larger number of lags are included.

\subsection{Measuring Market Power on the World Dairy Markets: A Residual Demand Analysis}

The third paper uses the concept of the stochastic marginal cost (which is introduced in the second paper) for the estimation of the residual demand faced by New Zealand in its most important destination countries. While in the first two papers theoretical and methodological questions are more the focus, in this paper we concentrate on the empirical application.

The residual demand (in its international market version) is the demand faced by an export country when the competing countries reaction is already accounted for. In the model, this reaction is depicted through the inclusion of cost shifting variables of the competing countries. Furthermore, cost shifting variables are usually used as instruments for the quantity as an endogenous right hand side variable. However, badly chosen or unsuitable cost shifters may cause a number of problems such as biased coefficients and standard errors as well as weak instruments. Since the stochastic marginal cost reflects the full range of changes in the marginal cost, it can be expected to be more appropriate - in addition to the exchange rate as the remaining cost shifter. Furthermore, the stochastic marginal cost series is always available when a certain number of destination-specific unit values is available too.

The estimation results show that the usage of the stochastic marginal cost does not solve the problem of weak instruments, but exhibits very precise estimates for the competitors that are much more often significant than the influence of their exchange rates. Since weak instruments are an overall problem, the estimation is done with SUR and the estimates of the inverse residual demand elasticity can therefore be seen as conservative. 
Nevertheless, the results show that in $56 \%$ of the equations, significant negative inverse residual demand elasticities are present with an average value that implies an optimal markup of about $8.6 \%$ of the price. This means that New Zealand (and therefore Fonterra) has a moderate degree of market power in most of the destination countries. Although there are some differences between the dairy markets analyzed, the estimates of the inverse residual demand elasticities differ much more across the destination countries than across the products analyzed. The most important competitors of Fonterra are Australia and the EU, whereas the US and domestic competitors in the destination country are, in most cases, unimportant. However, the extent of the market power implied by the estimated inverse residual demand elasticity cannot be attributed to the import market shares - neither those of the competitors nor those of New Zealand itself. Other factors such as the perceived degree of differentiation and different distribution channels seem to be of more importance. 


\title{
3 Pricing-to-Market in a Perfect World: Is a Correct Estimation Possible?
}

\begin{abstract}
The empirical model proposed by KNETTER $(1989 ; 1993)$ and its countless modifications represents an attempt to measure pricing-to-market for a given export country with respect to various destination countries. The key element of the model is the usage of a panel model with fixed time effects in order to control for the marginal cost. This procedure is based on the assumption that the marginal cost is equal for all destination countries at the port of export. Even if this is the case, the influence of the marginal cost on prices is not equal but instead depends on cost pass-through. When cost pass-through is not equal across the destination countries as theory suggests, the PTM coefficients of the Knetter model can be expected to be biased. In order to prove the existence, magnitude and the determinants of this bias, we simulate idealized data of a profit maximizing multi-market monopolistic export firm that practices pricing-to-market under the conditions that are assumed in the Knetter model. The estimation of the Knetter model for the simulated data shows that the PTM coefficients are indeed biased toward the average PTM coefficient in the sample. Under realistic conditions the extent of the bias is around $50 \%$ of the distance to the average PTM coefficient. In general, the extent is determined by some basic characteristics of the destination countries in the sample and the markets that are analyzed. For commodities especially, the bias can be expected to be large. The results therefore imply that a different approach is needed to estimate pricing-to-market unbiasedly.
\end{abstract}

Keywords: Pricing-to-market, exchange rate pass-through, Monte Carlo simulation 


\subsection{Introduction}

Since 2007, the Financial Crises and the Sovereign Debt Crises that followed in the US and the EU led to large fluctuations of exchange rates. This situation is somewhat similar to the one that the first authors of pricing-to-market studies faced. After the collapse of the Bretton Woods System, large exchange rate fluctuations took place in the 1970s and 1980s. These exchange rate fluctuations were an interesting experiment with regard to the price formation on markets. As long as the marginal costs do not change, one would expect that exchange rate changes are fully passed through to import markets. However, in the 1970s some authors already showed that this is often not the case and the exchange pass-through (ERPT) is, so-to-say, incomplete (GOLDBERG \& KNETTER 1997: 1249). The first authors who linked this observation to market power were MANN (1986), KRUGMAN (1986), DoRnBUSCH (1987) and BALDWIN (1988). The underlying idea is that exchange rate changes are (partly) offset through changes in the destinationspecific markups of the exporting firms. KRUGMAN (1986) labeled this behavior pricing-to-market (PTM). The first attempts to empirically detect PTM were made by KNETTER (1989) and MARSTON (1990). Both authors explain PTM as a result of the profit maximization of a monopolist when the demand curve in the destination country has a different curvature than that which a constant demand elasticity would lead to. In this case, the markup - which is determined through the demand elasticity - changes with the price.

The key feature of the PTM model established by KNETTER $(1989 ; 1993)$ is the way it is controlled for the marginal cost. The coverage of the marginal cost in the model is of importance because the marginal cost is correlated with exchange rates and its omission would lead to a bias in the estimated exchange rate coefficients which measure the degree of PTM. In addition to some other differences, in the ERPT literature and even in the model proposed by MARSTON (1990) the marginal cost is seen as observable and cost indices are used to display it. GOLDBERG \& KNETTER (1997: 1251) argue that these indices may be a good measure of the average cost but not of the marginal cost. Even worse, they lead to a form of measurement error which can be expected to be negatively correlated with the marginal cost and thus introduce a bias towards a finding of PTM. Therefore, KNETTER (1989) proposes an alternative way to control for changes in the marginal cost. He argues that for a given export country, the marginal cost should be equal across all destination countries when it is observed at the port of export. This means that when a panel model is estimated for the export country in question, the in- 
troduction of fixed time effects should effectively control for changes in the marginal cost and hence prevent a biased estimation. In fact, the usage of multiple transactions from a single source country does not only help to mitigate the cost measurement problem, it also ensures that the good under consideration is much more homogeneous as in the case when multiple export origins are used as in the ERPT literature (GOLDBERG \& KNETTER 1997: 1252).

In addition to the basic model specification of KNETTER (1989), a lot of modifications and extensions are made in the literature. Examples are the transformation in a first difference or an error correction representation (KNETTER 1993; GAGNON \& KNETTER 1995), a modification to study the symmetry of PTM with regard to the sign of exchange rate changes (KNETTER 1994; GIL-PAREJA 2000) and the addition of more independent variables. Such variables can be the exchange rate volatility or the exchange rate to an important competitor (e.g. PICK \& CARTER 1994; ZHANG et al. 2007), the offer price of said important competitor (GIL-PAREJA 2003; TANTIRIGAMA 2003), the market share of the export country under consideration (TANTIRIGAMA 2003) or the gross domestic product of the destination country (e.g. GIL-PAREJA 2003; GLAUBEN \& LOY 2003; ZHANG et al. 2007). The basic model proposed by KNETTER (1989) and its countless modifications are intensively used in the literature and applied to a wide variety of countries and sectors. Some examples for studies in the area of agricultural products are PiCK \& PARK (1991), PARK et al. (1996), CAREW (2000), GRIFFITH \& MULLEN (2001), Brown (2001), CAREW \& FlORKOWSKI (2003), GLAUBEN \& LOY (2003), XU \& SHELDON (2005) as well as JiN (2008).

Nevertheless, the PTM approach is also frequently criticized in the literature. Some general criticism is that the empirical proof for PTM is often done before markets are analyzed in regard to the plausibility of market power (SEXTON \& LAVOIE 2001: 886f). Other criticisms apply to the fact that it is not necessarily the adjustment of markups that the PTM coefficients measure. KASA (1992) shows that PTM can also be found due to adjustment cost. In order to avoid this effect, a higher temporal data aggregation can help. Furthermore, the usage of unit values in the PTM literature - which is common due to the need for destination-specific prices - can falsely lead to the finding of PTM as shown by LAVOIE \& LIU (2007). This is especially likely when the product under consideration is heterogeneous - i.e. an aggregation of different products. AUER \& CHANEY (2009) show that these effects are empirically not as serious as could be feared; nevertheless the use of disaggregated data seems to be reasonable. Further possible bi- 
ases of the PTM coefficients can occur in the case of menu costs, price stickiness and pricing in foreign currencies (e.g. GHOSH \& WOLF 1994; KNETTER 1997a; LARUE 2004). One response in the literature - to our knowledge only in the ERPT literature so far - to these kinds of problems is the usage of Threshold Cointegration techniques (e.g. AL-ABRi \& GOODWIN 2009; LARUE et al. 2010).

In this paper, we add a further piece of criticism to the PTM approach, more precisely to the PTM model proposed by KNETTER $(1989 ; 1993)$. This criticism applies to the key feature of the Knetter model: The way it is controlled for the marginal cost. An implicit assumption of the Knetter model is that a complete cost pass-through takes place or that the degree of cost pass-through is at least equal for all destination countries in the sample. When this assumption is violated, the estimated PTM coefficients can be expected to be biased. Indeed, such a violation is likely since the optimization condition of a monopolist - on which the Knetter model is built - implies that cost pass-through equals exchange rate pass-through. This is already described by KNETTER (1995) but without showing the theoretical implications for the estimation of the model. We therefore simulate data for a profit maximizing multi-market monopolistic export firm that exports to ten destination countries and practices third degree price discrimination. The demand that the firm faces in the destination countries reacts to price changes in such a way that constant PTM coefficients are given. In the next step, we use this data to estimate the underlying PTM coefficients with the Knetter model in order to detect the bias expected in the estimation and identify its determinants.

The paper is structured as follows: In Chapter 3.2 the concept of the Knetter model is presented. It is further argued that it can be expected to provide PTM coefficients that are biased toward the average PTM coefficient in the sample. Chapter 3.3 introduces the simulation model that is used to generate idealized data of a monopolistic export firm that practices PTM. In Chapter 3.4 the estimation results of the Knetter model with regard to the simulated data are presented and the determinants for the extent of the bias expected in the PTM coefficients are identified. The paper will close with a discussion of the results and a conclusion in Chapters 3.5 and 3.6. 


\subsection{Detection of PTM: The Knetter model}

The model proposed by KNETTER $(1989 ; 1993)$ is based on the first order optimization condition of a multi-market monopolistic export firm that practices third degree price discrimination across its destination countries. When this condition is solved for the export price $p_{i t}$ (in the export country's currency) the following equation appears:

$$
p_{i t}=M C_{t}\left(\frac{-\eta_{i t}}{-\eta_{i t}+1}\right) \quad \forall i, t
$$

where $M C_{t}$ is the firm's marginal cost that is equal for all destination countries and $\eta_{i t}$ is the absolute value of the own price elasticity of demand for the i-th destination country at period $t$. The condition states that the optimal export price the firm charges equals the overall marginal cost of the firm plus a destination-specific markup. This markup directly depends on the demand elasticity that in turn varies with the price. This means that when the price in the destination country changes, the optimal markup changes too. Such a price change can be due to a change in the exchange rate $\left(E R_{i t}\right)$ or due to a change in the marginal cost. Based on the optimization condition, GAGNON \& KNETTER (1995) derive the following theoretical relationship between the price and the marginal cost as well as the exchange rate:

$$
\ln p_{i t}=\alpha_{i}+\gamma_{i} \ln M C_{t}+\beta_{i} \ln E R_{i t}
$$

where the following symmetry condition applies for the coefficients:

$$
\gamma_{i}=\left(1+\beta_{i}\right) \quad \forall i
$$

The marginal cost and the exchange rate in equation (3.2) influence the price directly as well as indirectly. The direct effect is proportional (i.e. it equals one) and only appears for the marginal cost in equation (3.2) because $p_{i t}$ is measured in the export country's currency. Conversely, the indirect influence appears for both variables and is measured by $\beta_{i}$. This influence stems from the fact that the direct influence cause a price change that in turn influences the destination country's demand elasticity and therefore the optimal destination-specific markup. Since the marginal cost and the exchange rate - net of its effect on the marginal cost - affect the price in the destination country's currency equally, their influence on the destination-specific markup is equal too. FEENSTRA (1989) shows that this symmetry even holds for changes in import tariffs.

Unfortunately, in empirical applications the marginal cost cannot be directly observed and has to be estimated or displayed through proxy variables. KNETTER (1989) argues that the marginal cost is equal across the destination countries when observed at the port 
of export. Therefore, the author introduces a panel model that covers multiple destinations in which fixed time effects $\left(\theta_{t}\right)$ can account for (changes in) the marginal cost:

$$
\ln p_{i t}=\theta_{t}+\lambda_{i}+\beta_{i} \ln E R_{i t}+u_{i t}
$$

However, prices and exchange rates are often random walks that carry the risk of a spurious regression. Since this can be avoided through first differencing, KNETTER (1993) also proposes a version of the model in first differences:

$$
\Delta \ln p_{i t}=\theta_{t}+\beta_{i} \Delta \ln E R_{i t}+u_{i t}
$$

where $p_{i t}$ is again the export price to country $\mathrm{i}$ measured by destination-specific unit values (in the export country's currency), $\lambda_{i}$ is a fixed destination country effect in the version in levels that takes account of the different markup levels as well as quality differences, and $u_{i t}$ is the error term for which the usual assumptions apply.

In both versions of the model, the coefficient of interest is $\beta_{i}$. Although $\lambda_{i}$ could also give hints for price discrimination, it is usually only carefully interpreted in this way since it can be influenced by different degrees of quality. Only the value of the PTM coefficient $\beta_{i}$ is seen as a reliable indication for market power. When $\beta_{i}$ is smaller than zero, a rise in the exchange rate leads to a decrease of the export price. This means that price changes that are caused by exchange rate changes are smoothed out to a certain degree in the destination country's currency. When $\beta_{i}$ is minus one, price changes are perfectly smoothed out. In the PTM literature this is seen as proof for the existence of a markup. Conversely, a PTM coefficient of zero can be a sign for perfect competition but can also be caused by a constant demand elasticity in the destination country under the conditions of market power.

The problem with regard to the model proposed by KNETTER $(1989 ; 1993)$ is that the fixed time effects do not only measure just the marginal cost, but all kinds of variation that are common to the destination countries (KNETTER 1995: 8). Even if the marginal cost is equal for all destination countries, equation (3.2) shows that its influence on the export price is neither equal ${ }^{1}$ nor proportional as long as different degrees of PTM take place. The fixed time effects therefore actually measure the (change in) the marginal cost which is, on average, passed through to prices - in other words, the average effect of the marginal cost on prices in the sample. This means that the model only correctly controls for the marginal cost when the PTM coefficient of the respective destination

\footnotetext{
${ }^{1}$ KNETTER (1995) is aware of the destination-specific influence of the marginal cost that the symmetry condition implies, although he does not show the theoretical implications for the estimation of the model.
} 
country lies exactly at the mean of the sample coefficients. Since marginal cost and exchange rates are correlated, this can also be expected to bias the PTM coefficients. More exactly, as this correlation is probably negative and the symmetry condition implies that cost and exchange rate pass-through are equal, the PTM coefficients can be expected to be biased toward the mean of the PTM coefficients in the sample.

The purpose of the rest of the paper is to prove whether this hypothesized effect exists, how pronounced it is and which are the determinants - at least for the conditions under which the data is simulated. In order to estimate the Knetter model for the data simulated, we primarily use the model in first differences that is depicted in equation (3.4). This is because we want to emphasize that the bias is not caused by the spurious regression problem. However, both versions of the Knetter model are still in use in the PTM literature without further extensions or modifications.

\subsection{Simulation of data}

For the simulation of the data we assume a world consisting of a monopolistic export firm which is located in any country and produces a homogenous good. The firm is selling the good completely abroad to consumers located in $\mathrm{N}$ different destination countries. Each of the countries has its own currency whereby the exchange rates are freely fluctuating - i.e. are not fixed against one of the others. Trade is assumed to be costless and arbitrage to not be in action - that is, markets are fully geographically segmented. Under these circumstances, it would be profit maximizing for the firm to practice price discrimination across the destination countries according to the destination country's demand elasticities. Because the demand elasticities are not fixed but increasing in absolute value with the prices, an expected outcome of the firm's profit maximizing behavior is pricing-to-market.

\section{Demand conditions}

The demand of destination country $i$ in period $t$ is given by

$$
q_{i t}^{D}=f_{i}\left(\ddot{p}_{i t}\right) * v_{i t}
$$

where $q_{i t}$ and $\ddot{p}_{i t}$ are quantity and price (in the destination country's currency) respectively and $v_{i t}$ takes the changes of all other factors that have an influence on demand into account. In order to keep it simple and avoid modeling these factors, $v_{t}$ is assumed to be a random shift variable with the properties $v_{t} \sim N(1, \sigma)$. A suitable functional form for the demand has to take into account that the absolute value of the own price 
elasticity of demand $\left(\eta_{i}\right)$ should not be constant, but should vary with the price on the respective destination market. This condition is necessary in order to create a pricing-tomarket behavior in the model. Furthermore, the demand elasticity should behave in a way that the PTM coefficient $\beta_{i}$ is constant. This allows for a clear econometric proof of whether the coefficient is correctly identified by the Knetter model. It is therefore necessary to know exactly what is being measured by the PTM coefficient. KNETTER (1995: 5) shows this by taking the log of the firm's optimization condition (3.1) and totally differentiating the equation. In the resulting expression it is possible to see how the PTM coefficient is connected to the demand elasticity's curvature:

$$
\beta_{i}=\frac{\frac{\partial \ln \eta_{i}}{\partial \ln \ddot{p}_{i}}}{\left(-\eta_{i}+1\right)-\frac{\partial \ln \eta_{i}}{\partial \ln \ddot{p}_{i}}}
$$

Rearranging the expression yields:

$$
\frac{\partial \ln \eta_{i}}{\partial \ln \ddot{p}_{i}}=\left(-\eta_{i}+1\right)\left(\frac{1}{\beta_{i}}+1\right)^{-1}
$$

Expression (3.7) describes how the elasticity of the "demand elasticity" with respect to the price should look in order to create a constant PTM coefficient $\beta_{i}$. Unfortunately, this expression is neither analytically transferable into a function $\eta_{i}$ of price and the PTM coefficient, nor does it allows us to deduce a suitable functional form for the demand equation (3.5). Instead, both functions have to be numerically approximated in order to fulfill the condition of a given constant PTM coefficient. Examples for the resulting demand equations are presented in Figure 3.1.

Figure 3.1 shows four demand curves which differ with respect to the PTM coefficient. They are defined as having the same demand elasticity $\left(\eta_{i}=2\right)$ at a price of $\mathrm{p}=4,000$ and the same quantity demanded $(q=100,000)$ at this point. To the left of this point the absolute values of the elasticities are higher; to the right they are lower, respectively to a different degree. As the figure shows, the underlying PTM coefficient has an influence on the curvature of the demand curve whereby a larger absolute value of the PTM coefficient makes the demand curve less convex (or even makes it concave) than in the constant elasticity case. This influence on the curvature is well described and often mentioned in the literature (e.g. KNETTER 1993: 473), even if there have never been - at least to our knowledge - concrete demand curves depicted for given PTM coefficients. The case of concave demand curves for large absolute values of the PTM coefficients is also not explicitly reported in the literature. 
Figure 3.1: Demand functions with different PTM coefficients

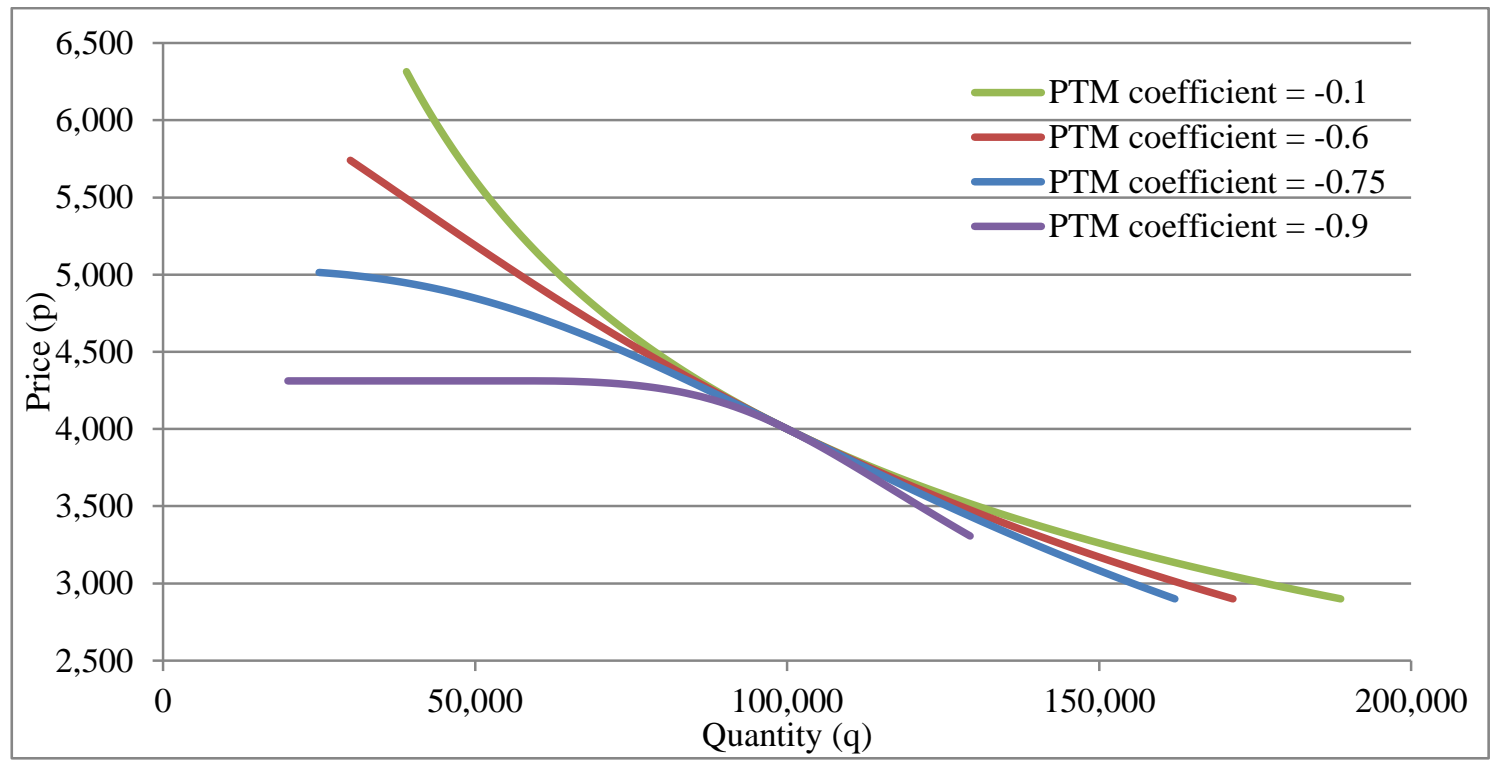

Source: own compilation

This, however, casts a bit more light on an unresolved issue in the literature: The connection between PTM and market power. Some authors argue that PTM behavior - or, in general, incomplete exchange rate pass-through - is an indication of competition rather than of market power (e.g. KIM et al. 2003). In view of the demand curve in Figure 3.1 with a very large absolute value of the PTM coefficient of -0.9 , this indeed seems plausible. This demand curve has a very flat section which seems to be comparable with a residual demand curve under perfect competition. However, if an export firm would only act in this flat part of the demand curve, the scope for PTM becomes very small. In this section, the absolute value of the demand elasticity is already very high and therefore the markup only lasts to offset very small exchange rate changes. A possible explanation for this shape of the demand curve would be monopolistic competition - i.e. an oligopolistic market structure with products of the respective suppliers differentiated among each other. If the differentiation is among export countries, this is also known as the Armington assumption (ARMINGTON 1969). In this case, each supplier has a certain space for price increases without instantaneously losing his buyers. However, even without heterogeneous products, an oligopolistic market structure can lead to PTM. This has already been shown by KRUGMAN (1986) and DORNBUSCH (1987) in their very basic articles for profit maximization under the conditions of a Cournot model. After all, a certain degree of competition seems to support PTM but it is still not possible without market power (KNETTER 1993: 473). BUGAMELLI \& TEDESCHI (2008) (among others) show that PTM is primarily prevalent in oligopolistic industries which sell in advanced economies. For the model described here, the underlying reasons for the actual form of 
the demand curve are seen as irrelevant. They are in a crystallized manner included in the assumed PTM coefficients.

\section{Exchange rates}

The export price to the i-th destination country in the destination country's currency $\ddot{p}_{i t}$ and the export price in the export country's currency $p_{i t}$ are connected through the exchange rate as followed:

$$
\ddot{p}_{i t}=E R_{i t} * p_{i t}
$$

where $E R_{i t}$ is the exchange rate between the export country and destination country $\mathrm{i}$ at period t (destination country's currency per unit of the exporter's currency). The exchange rates are modeled as autoregressive processes of the order 1, i.e. $\operatorname{AR}(1)$ :

$$
E R_{i t}=\alpha+\rho E R_{i t-1}+v_{i t}
$$

where $\rho$ is the autoregression coefficient, $\alpha$ is a constant which is set in a way that the long-run expected value of the process equals 1 and $v_{i t} \sim N(0, \sigma)$ is a random error. The parameter $\rho$ is set to a value of 0.9 in the model for a number of reasons. Firstly, this fits well to reality. Exchange rates are often very close to random walks $(\rho=1)$ or it cannot be ruled out empirically that they are random walks. Even real exchange rates often exhibit a high degree of serial correlation (e.g. BERGIN \& FEENSTRA 2001). When they have a unit root, it is also clear that they are spuriously correlated with each other in most of the cases. This kind of correlation can be eliminated through first differencing. However, typically the first differences of exchange rates between a given export country and numerous other destination countries are correlated too. This is because an exchange rate rise can be due to an appreciation of the export country's currency against all others or due to a depreciation of the respective counterpart's currency against all others. The first event is common to all destination countries and therefore introduces the correlation, whereas the second is not.

To illustrate this, Figure 3.2 shows the average correlation coefficient for each country represented. The correlation is between the first differences of exchange rates to all other countries listed in the International Monetary Fund (IMF) database in the period 1990 to $2011^{2}$. As discussed above, a low correlation coefficient implies that the worth of the currency of the respective country does not change a lot but the worth of the other country's currency does. This is the case for the United States in Figure 3.2, which was ex-

\footnotetext{
${ }^{2}$ These are in sum 169 countries and therefore 168 exchange rates, for which 14,028 bilateral correlation coefficients can be calculated.
} 
pected because the United States has a huge economy and the US-Dollar is the world's most important reserve currency. All other countries depicted have much higher correlation coefficients.

Figure 3.2: Average FD-ERC coefficients of selected countries

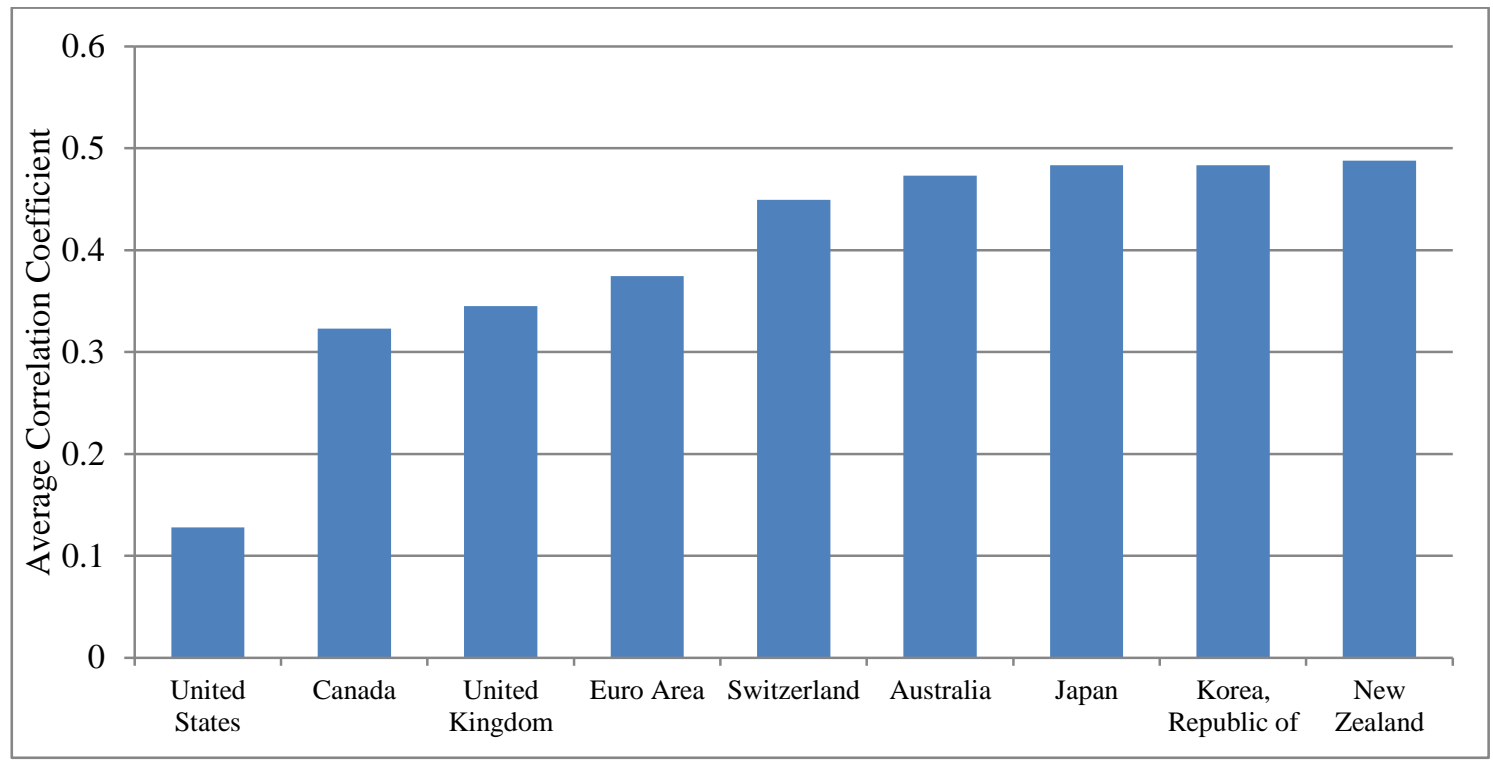

Source: IMF (2013)

The need to model this first difference exchange rate correlation (FD-ERC) is the second reason for defining the exchange rates through equation (3.9) as AR processes close to random walks. In the case of a random walk, the first difference of the process is $v_{i t}$. This means that the correlation of the first differences can be generated by creating random numbers which are correlated over i. In order to prevent the process exhibiting the typical properties of a random walk (increasing variance over $t$ and therefore a high chance for extreme numbers), a value of 0.9 for $\rho$ is seen as a good compromise.

\section{Cost and supply conditions}

The costs $C_{t}$ of the exporting firm (in export country's currency) at period t are given by

$$
C_{t}=C\left(\sum_{i=1}^{N} q_{i t}\left(E R_{i t} p_{i t}, v_{i t}\right)\right) * \xi_{t}
$$

As equation (3.10) shows, the cost depends on the sum of quantity demanded in the destination countries $q_{t}=\sum_{i=1}^{N} q_{i t}$ as well as on a random shift variable $\xi_{t}$ which takes changes of all other factors that influence the firm's cost into account. The first derivative of (3.10) with respect to quantity yields the marginal cost equation. For this equation the following functional form is assumed:

$$
M C_{t}=\alpha * q_{t}^{\delta} * \xi_{t}
$$


where $\alpha$ and $\delta$ are parameters to be determined. Inverting this expression yields

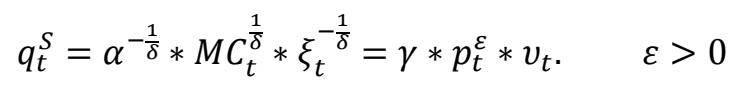

If the export firm would act in a competitive environment, equation (3.12) would be the individual supply function of the firm. In this case, $M C_{t}$ could be written as "price" (in the export country's currency) and $\varepsilon$ would be the own price elasticity of supply. In the case of market power, this is no longer valid. Nevertheless, for the sake of simplicity the parameter $\varepsilon$ is labeled as supply elasticity in this paper, even if it is in fact the elasticity of the marginal cost curve. As in demand equation (3.5), the random shift variable $v_{t}$ is assumed to have the properties $v_{t} \sim N(1, \sigma)$. This distribution assumption should not be too unrealistic. In the case of agricultural commodity markets, $v_{t}$ can be seen as a weather driven harvest variable (WILLIAMS \& WRIGHT 2005: 29). However, in all other cases this assumption is not critical. The case of markets in which a big part of the variation of $v_{t}$ comes from imported factors whose prices depend on exchange rates is additionally analyzed in Chapter 3.4 .

\section{Equilibrium}

At equilibrium, the monopolistic export firm maximizes its profit (П) in period t:

$$
\Pi_{t}\left(p_{1}, \ldots, p_{N}\right)=\sum_{i=1}^{N} p_{i t} q_{i t}\left(E R_{i t} p_{i t}, v_{i t}\right)-C\left(\sum_{i=1}^{N} q_{i t}\left(E R_{i t} p_{i t}, v_{i t}\right)\right) * \xi_{t}
$$

Substituting into demand function (3.5) and maximizing equation (3.13) with respect to prices yields the following rearranged first order conditions:

$$
p_{i t}=M C_{t}\left(\frac{-\eta_{i t}\left(\ddot{p}_{i t}, \beta_{i}\right)}{-\eta_{i t}\left(\ddot{p}_{i t}, \beta_{i}\right)+1}\right) \quad \forall i, t
$$

Equation (3.14) equals the first order condition (3.1) on which the Knetter model is based whereby the demand elasticity is a function of the price in the destination country's currency and the PTM coefficient. This means that the simulated export firm behaves in the same way as the Knetter model assumes. Furthermore, since the construction of the demand curve ensures a stable PTM coefficient, the simulated data can be perfectly described by the theoretical relationship depicted in equation (3.2) without any residual variation left. This means that the symmetry condition is fulfilled too. Although we used random numbers in the simulation model, these numbers do not have any influence on the fulfillment of the optimization condition but instead on the level of prices and quantities. 


\section{Simulation}

The model is applied in Microsoft Excel for $\mathrm{N}=10$ destination countries. The values of the demand elasticity and the PTM coefficient can be set for each destination country separately. In the initial starting period, the destination countries are defined as having the same number of quantity demanded for $v_{i 0}=0$ and therefore the same market share, which is $10 \%$. This means that at least in the starting period, all destination countries are equally important for the export country. How the market shares develop over time depends on the development of the exchange rates and the demand elasticities that react according to the respective PTM coefficients on price changes. The model is solved through the Excel solver which is an optimization add-on in Microsoft Excel. The Excel solver searches for the set of prices which fulfill the optimization condition (3.14) and thereby fixes both the marginal cost and the quantity traded. In the starting period, the quantity traded equals $1,000,000$ and the marginal cost is 2,000. In addition to the starting period, 100 periods are simulated. This number is used because it is close to existing PTM studies. In the literature, quarterly or even annual frequencies are often used. The problem with monthly data is that it often poorly represents equilibrium conditions. This is especially problematic in the Knetter model in first differences. KNETTER (1993: 476) states that even in the case of annual data, the PTM coefficient can still contain adjustment cost effects. This is why frequencies lower than monthly are the ones that are often used. Given the usage of quarterly data, the 100 periods simulated represent an observation period of 25 years. This is on the upper boundary of what is usually available in applications of the Knetter model. The original Knetter studies, for example, handle an observation period of between nine and fifteen years. 


\subsection{Estimation results for the simulated data}

\subsubsection{Simulation parameters}

We have to fix, at least for the initial conditions of the simulation, several parameters of the simulation model. In Chapter 3.4.3, these parameters are varied in order to monitor their influence on the estimated PTM coefficients. For the supply elasticity, a rather small value of 0.2 is chosen. This value lies in a range which is more or less typical for commodities. In the short and medium runs, the quantities supplied cannot change sharply and are therefore inelastic with regard to prices. Even in the case of products that typically have higher supply elasticities, these numbers should be much smaller for the rather short time periods that the Knetter model uses as frequencies. For the demand elasticities, an absolute value of 2 is chosen in the starting period for all destination countries. As a result, only the PTM coefficient values are different between the destination countries and are set in a range between 0 and -0.9 . An absolute value of 2 for the demand elasticity seems to be rather small as it implies a 100\% markup over marginal cost. However, it is chosen because of parameter stability. Even when the form of the demand function described above ensures stable parameters, this breaks down when the markup tends to zero - i.e. when the demand elasticity tends to infinity due to increased prices. The relatively low absolute value of the demand elasticity in the starting period efficiently prevents such cases.

The standard deviation of the shift variables was assigned to be 0.05 and the standard deviation of the error term associated with the exchange rates to be 0.075 . The latter equals the average standard deviation of the first log differences of the quarterly exchange rates of all countries in the IMF database between 1990 and 2011 - when extreme values are excluded. For the results presented in Chapter 3.4.2, the FD-ERC is considered to be 0.2 . This is a rather small value that is - at least on average - roughly the same as for the United States (Figure 3.2).

\subsubsection{Results for given simulation parameters}

Figure 3.3 shows the results of 200 simulations which are run under the described conditions. Each of the ten true PTM coefficients that are depicted in the figure is associated with an otherwise identical destination country. For each simulation, the coefficients for the ten destination countries are estimated with the Knetter model in first differences. In Figure 3.3, the mean and the dispersion of the estimates are displayed. If the Knetter model would be able to estimate the PTM coefficients unbiasedly, the mean 
should lie on the diagonal that represents the true coefficients. In addition, there should be no variation in the estimated PTM coefficients as the relationship that is depicted in equation (3.2) always holds perfectly in the simulated data. According to Figure 3.3, both conditions are not fulfilled. As hypothesized in Chapter 3.2, the estimated PTM coefficients are biased toward the average PTM coefficient in the sample ${ }^{3}$. The more a PTM coefficient deviates from the average PTM coefficient, the larger the extent of the bias is as well as the variance of the estimated PTM coefficients in absolute terms.

Figure 3.3: Estimated PTM coefficients versus true PTM coefficients ${ }^{4}$

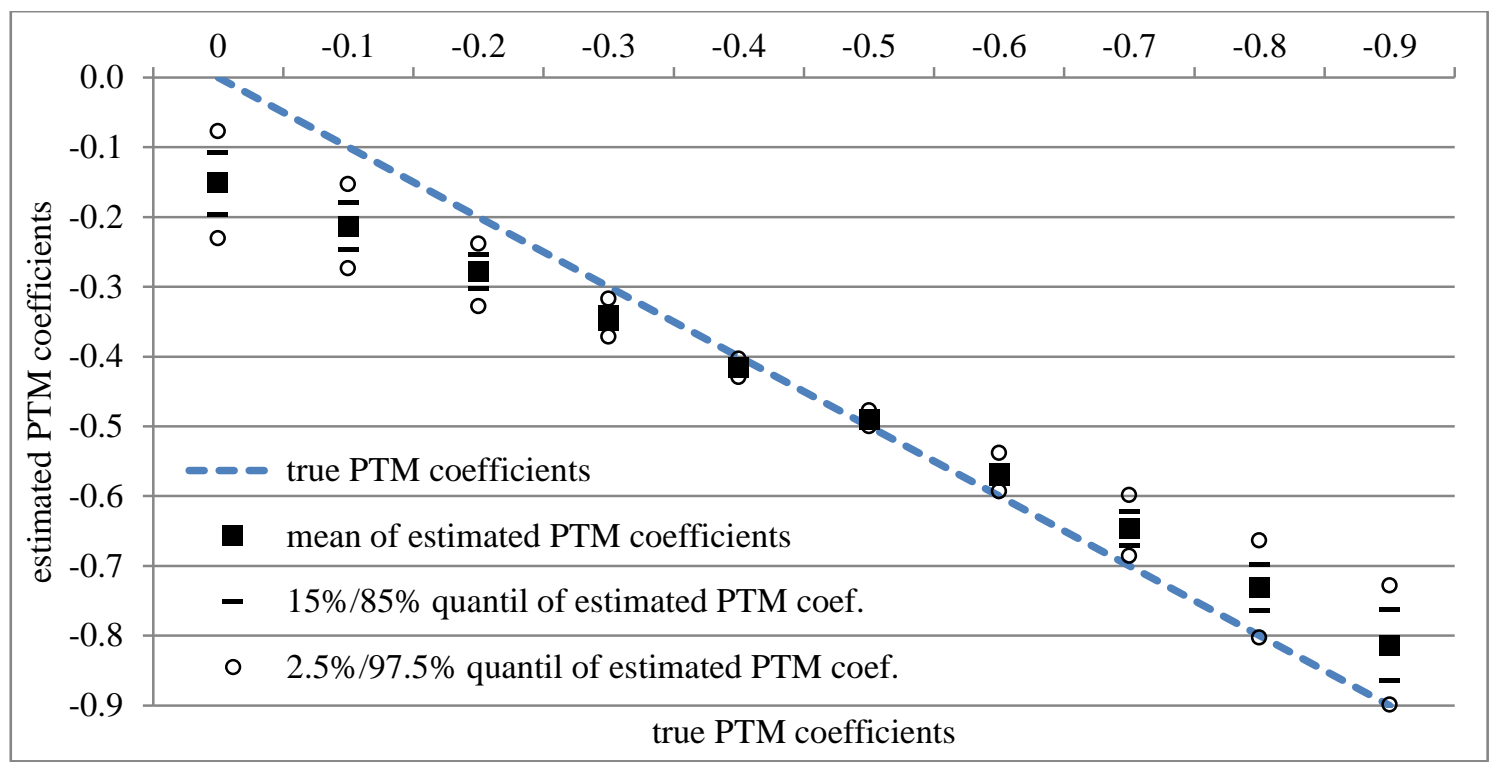

Source: Own compilation

This is because for PTM coefficients that lie far away from the average PTM coefficient, the cost pass-through (i.e. the influence of the marginal cost on the price) also lies far away from the average cost pass-through. Since the fixed time effects only control for the average cost pass-through, the bias is more pronounced in these cases. It is important to note that the relative extent of the bias depends on the correlation between the marginal cost and the exchange rate to the respective destination country. When this correlation is very pronounced, the estimated PTM coefficient is more affected by an incorrect control for (changes in) the marginal cost. Indeed, for a given correlation coefficient, the relative bias toward the average PTM coefficient is constant.

In fact, different degrees of correlation between the marginal cost and the respective exchange rates can explain two notable observations in Figure 3.3: Firstly, the dispersion of the estimated PTM coefficients and secondly, that for small absolute values of

\footnotetext{
${ }^{3}$ In the results presented here, the sample always covers the full simulation population. However, a narrower sample selection also exhibits PTM coefficients that are biased towards the sample mean.

${ }^{4}$ The results that are shown in this chapter are numerically displayed in Appendix 3.1 to 3.4.
} 
the PTM coefficients, the estimates are relatively more biased toward the average than the estimates for large absolute values of the PTM coefficients. The dispersion arises since the market shares of the destination countries develop away from the $10 \%$ in the starting period throughout each simulation. This is caused by different developments of the exchange rates. Different market shares, in turn, cause different degrees of correlation with the firm's marginal cost and therefore different extents of the bias. The differently pronounced bias for different PTM coefficients can be explained as well. A larger absolute value of the PTM coefficient implies that a larger proportion of changes in exchange rates or the marginal cost is smoothed out. This leads to a less pronounced demand response and therefore a smaller correlation with the marginal cost.

Taken together, Figure 3.3 exhibits a sobering result because the time dummies which should control for (changes in) the marginal cost are the key feature of the Knetter model. GOLDBERG \& KNETTER (1997: 1251) argue that without controlling for (changes in) the marginal cost, the PTM coefficients are biased upwards because exchange rates and the marginal cost are correlated. However, the same correlation leads to a bias in the PTM coefficients of the Knetter model when symmetry holds. Therefore, the Knetter model does not solve the problem of biased coefficients; it only changes the direction of the bias. As the symmetry condition implies, the basic problem is that the influence of the marginal cost on prices is not the same across the destination countries, although the marginal cost itself is. Even if the time effects would be a perfect proxy for changes in the marginal cost, this would not lead to unbiased PTM coefficients when cost passthough is incomplete. Instead, this would lead to a downward bias of the coefficients.

In the case of the Knetter model in levels, the effects mentioned are even more serious. Because exchange rates are close to random walks and the marginal cost is too ${ }^{5}$, spurious correlations can occur. The bias is more or less the same as for the Knetter model in first differences but the standard deviation of the estimated PTM coefficients is up to two times as high. Furthermore, the dispersion does not decrease when the degree of FD-ERC rises. In the case of the model in first differences, the full variation of estimated parameters lies between the true parameter and the average parameter in the sample (Figure 3.3). This is because correlation coefficients were always negative. However, in the case of the model in levels, a part of the variation lies in the opposite direction of the true parameter.

\footnotetext{
${ }^{5}$ In the model the "close to a random walk property" of the exchange rates often leads to a similar behavior of the marginal cost series, especially with an increasing degree of FD-ERC.
} 


\subsubsection{Results for varying simulation parameters}

\section{Exchange rate behavior}

As discussed above, the degree of correlation between the exchange rate to a destination country and the firm's marginal cost is an important determinant for the extent of the bias. This kind of correlation arises since changes in the exchange rate lead to price changes in the respective destination country and therefore also change the import demand of this country. In the case of the ten destination countries, each country's contribution to changes in the marginal cost is usually rather small. This results in low degrees of correlation and a moderate bias of the PTM coefficients. However, if exchange rates or their first differences are correlated, the picture changes dramatically. In this case, similar exchange rate changes take place simultaneously for more than one destination country. The correlation with each country's exchange rate and the overall marginal cost increases and therefore the bias of the PTM coefficients increases too. This is depicted in Figure 3.4. The figure shows the mean of the estimated PTM coefficients for different degrees of FD-ERCs while all other simulation parameters are unchanged. The correlation coefficients displayed hold for all bilateral FD-ERCs whereas the results for each correlation coefficient are based on 200 simulations.

Figure 3.4: Estimated PTM coefficients for different degrees of FD-ERC

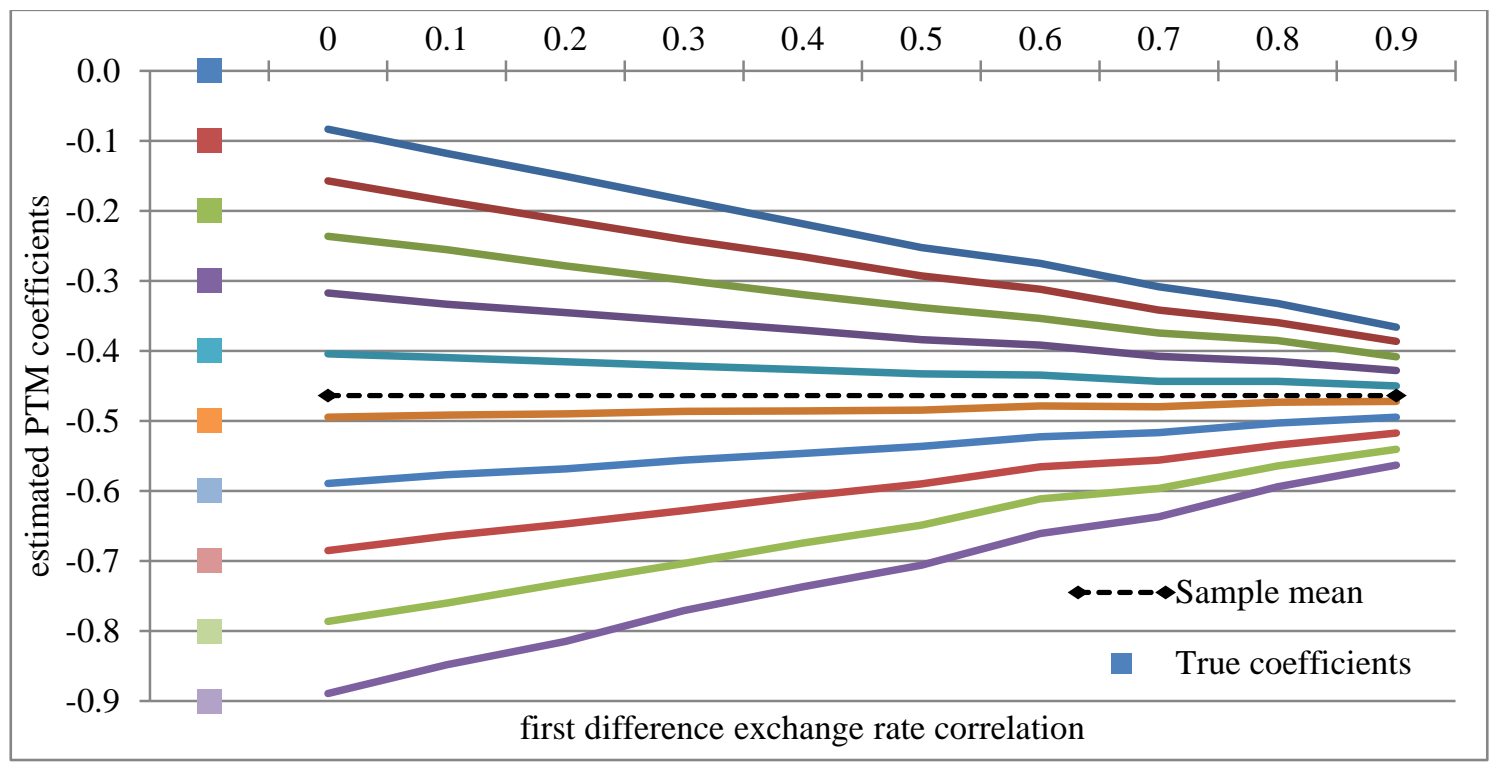

Source: Own compilation

If the Knetter model would correctly estimate PTM, the mean of the estimated PTM coefficients should exhibit the true coefficients. Even with no FD-ERC, this is not fulfilled but the bias is still moderate. However, with an increasing degree of FD-ERC the bias becomes more and more serious. For a correlation coefficient of 0.5 - which is 
close to the situation of the most developed countries (Figure 3.2) - the estimated PTM coefficients are already around 50\% biased toward the average PTM coefficient in the sample. The figure shows again that low absolute values of the true PTM coefficient go hand-in-hand with a larger bias in relative terms.

Of course, the FD-ERC empirically observed is not as uniform as assumed here. Some exchange rates are strongly correlated while others are not. The coefficients displayed in Figure 3.2 are average numbers. Unfortunately, these patterns are hard to model in the simulations. An attempt can be made by studying an extreme scenario of country groups whose exchange rates are correlated to varying degrees among the group but are not correlated between the groups. Indeed, similar patterns can be empirically observed. The results show that for the same average FD-ERC, the same correlation between exchange rates and marginal cost arises as in the uniform case. This means that the bias toward the average PTM coefficient in the sample is also the same as with a uniform FD-ERC. As a result, the degree of variation of the bilateral FD-ERC does not alter the results presented here - at least not in our simple simulation model that assumes equal market shares in the starting period.

\section{Different elasticity levels}

The degree of correlation between the marginal cost and exchange rates only reveals that there is a relationship between the variables but it does not say anything about the extent to which exchange rate changes lead to changes in the marginal cost - i.e. the slope of the relationship. This is exactly where the elasticity of the marginal cost curve - named as the supply elasticity here - comes into consideration. When the supply elasticity, for example, tends to infinity, the marginal cost will not change at all, although exchange rate changes may lead to changes in the quantity demanded. If a firm can produce each quantity with the same level of the marginal cost, we do not have to control for the marginal cost because it does not change. Conversely, small values of the supply elasticity cause larger adjustments of the marginal cost. This implies that we can expect smaller supply elasticities to cause larger extents of the bias in the PTM coefficient.

This hypothesis is supported by the results that are presented in Figure 3.5. The preceding results are based on an assumed supply elasticity of 0.2. Figure 3.5 shows the mean values of the estimated PTM coefficients for varying values of the supply elasticity (based on 200 simulations for each value of the supply elasticity depicted). For the FDERC, a value of 0.5 is assumed in Figure 3.5 as this is a typical value for most of the 
developed countries (Figure 3.2). Obviously, the bias of the estimated PTM coefficients is more serious in the case of small values of the supply elasticity. Conversely, a supply elasticity of 10 or more ensures almost no bias of the PTM coefficients. Moreover, in this case the variance of the estimated PTM coefficients is very small.

Figure 3.5: Estimated PTM coefficients for different supply elasticities

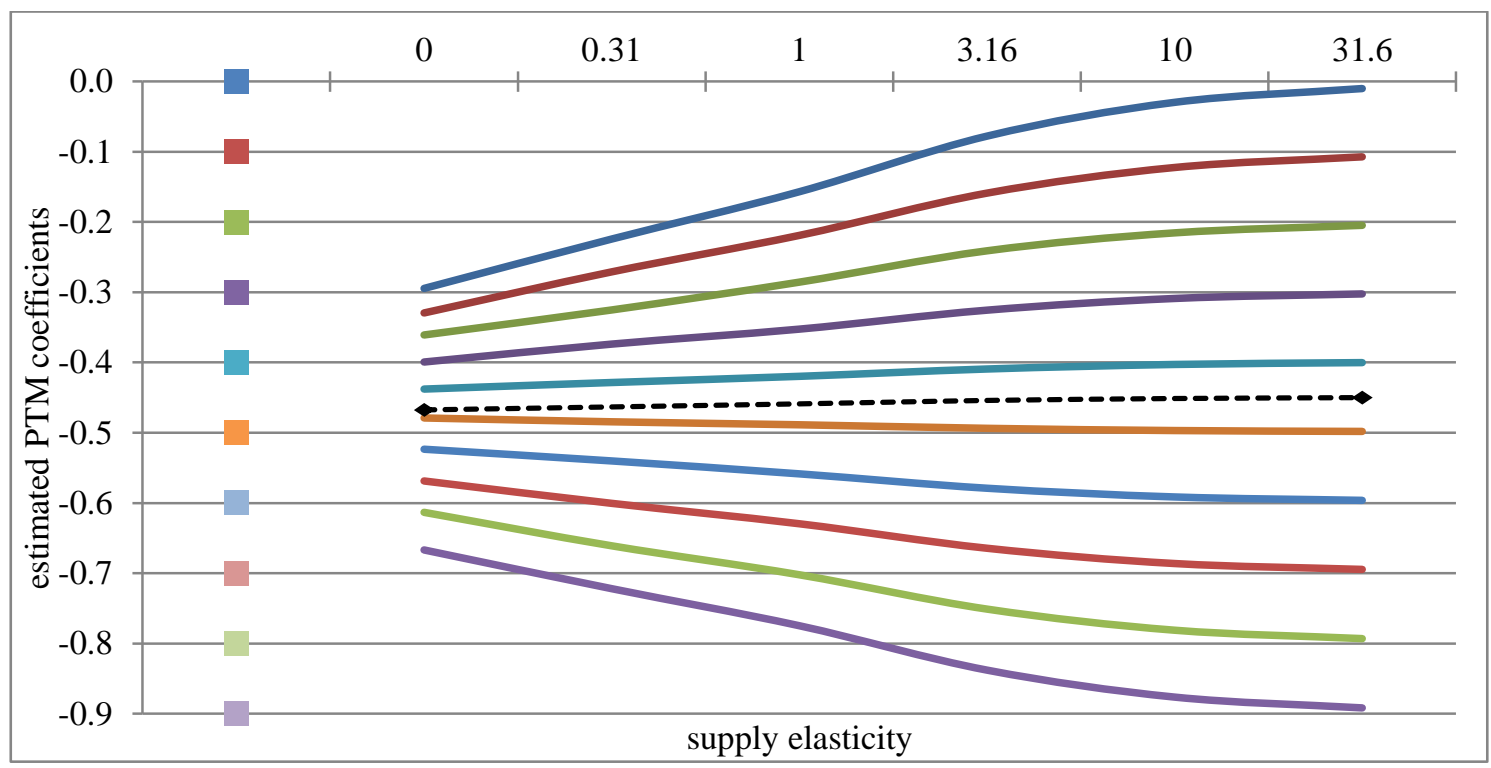

Source: own compilation

Note that in the simulation model, the export country's domestic supply elasticity and its export supply elasticity are the same because no domestic consumption is considered. In fact, the value of the export supply elasticity is essential for the result presented in Figure 3.5. This means that the higher the export share of the production of a country is, the smaller the elasticity is and the higher the bias is. The same holds for a higher absolute value of the export country's domestic demand elasticity. Even if the PTM coefficients in the Knetter model may not be seriously biased in the case of a large value of the supply elasticity, the coefficients would also not be seriously biased without controlling for the marginal cost at all.

Another important issue with regard to the supply elasticity is the assumed time length of the supply reaction. More precisely, short-run elasticities are often smaller than longrun ones. This has consequences for the usage of different frequencies in the Knetter model. If, for example, monthly data is used, the prices contain the short-run marginal cost reaction on exchange rate induced quantity changes. However, if annual data is used, the prices contain a longer-run or average reaction. Therefore, for shorter time lengths (or higher frequencies), the bias as well as the dispersion of the estimated coefficients should be larger. 
In contrast to the supply elasticity, the influence of the demand elasticity on the bias of the PTM coefficients is more ambiguous. For any destination country, a larger absolute value of its demand elasticity means that an exchange rate change causes a larger demand response. This results in a larger change in the marginal cost and therefore a more serious estimation bias. However, for all other countries, a higher absolute value of the demand elasticity allows for a better absorption of the considered country's demand response. Accordingly, if all demand elasticities are varied equally, the net effect is unclear. Unfortunately, a variation of the demand elasticity in the simulation model faces limitations. That is, high levels of the demand elasticity do not allow high degrees of PTM to take place and also endanger parameter stability in the model. Given the parameter assumptions inherent in the model, it is only possible to vary the absolute value of the demand elasticity between 1.5 and 5 . In this range, the demand elasticity has no significant influence on the bias of the PTM coefficients. Conversely, if the demand elasticity of a single destination country is varied, the bias of the respective PTM coefficient is clearly more serious in the case of a higher absolute value of the demand elasticity.

\section{Supply and demand side shocks}

Shocks to supply and demand, as introduced in the simulation models through random shift variables in equations (3.5) and (3.10), only have an effect on the level of the quantity, the marginal cost and the price. They do not have any influence on the optimization condition - i.e. the relationship displayed in equation (3.2) holds - and have no influence on the bias of the PTM coefficients. However, this only applies as long as these shocks are not correlated with the exchange rates. The crucial question is therefore whether these shocks are indeed not correlated with exchange rates and what happens if they are. On the demand side, KNETTER (1989: 202) states that "[...] exchange rates are at best weakly correlated with other macroeconomic variables". Of course, the exchange rate would be correlated with those of a foreign competitor and therefore with its offer price. However, a foreign competitor is not considered in the simulation model.

On the supply side, a correlation between shocks and exchange rates can arise when imported factors are of relevance for the production of the good. In this case, the exchange rate is positively correlated with the supply shock and therefore negatively correlated with the marginal cost. This leads to an amplification of the estimation bias in the Knetter model - provided that PTM does not take place for the imported factor. In order to analyze the importance of this amplification, we assume that the cost shifter in equation (3.10) depends directly on the exchange rates. That is, the export country pur- 
chases its inputs to an equal extent from the ten destination countries. For a FD-ERC of 0.5 and varying values of the supply elasticity, the mean values of the estimated PTM coefficients which are based on 200 simulations are depicted in Figure 3.6.

Figure 3.6: Results for different supply elasticities and imported factor shares

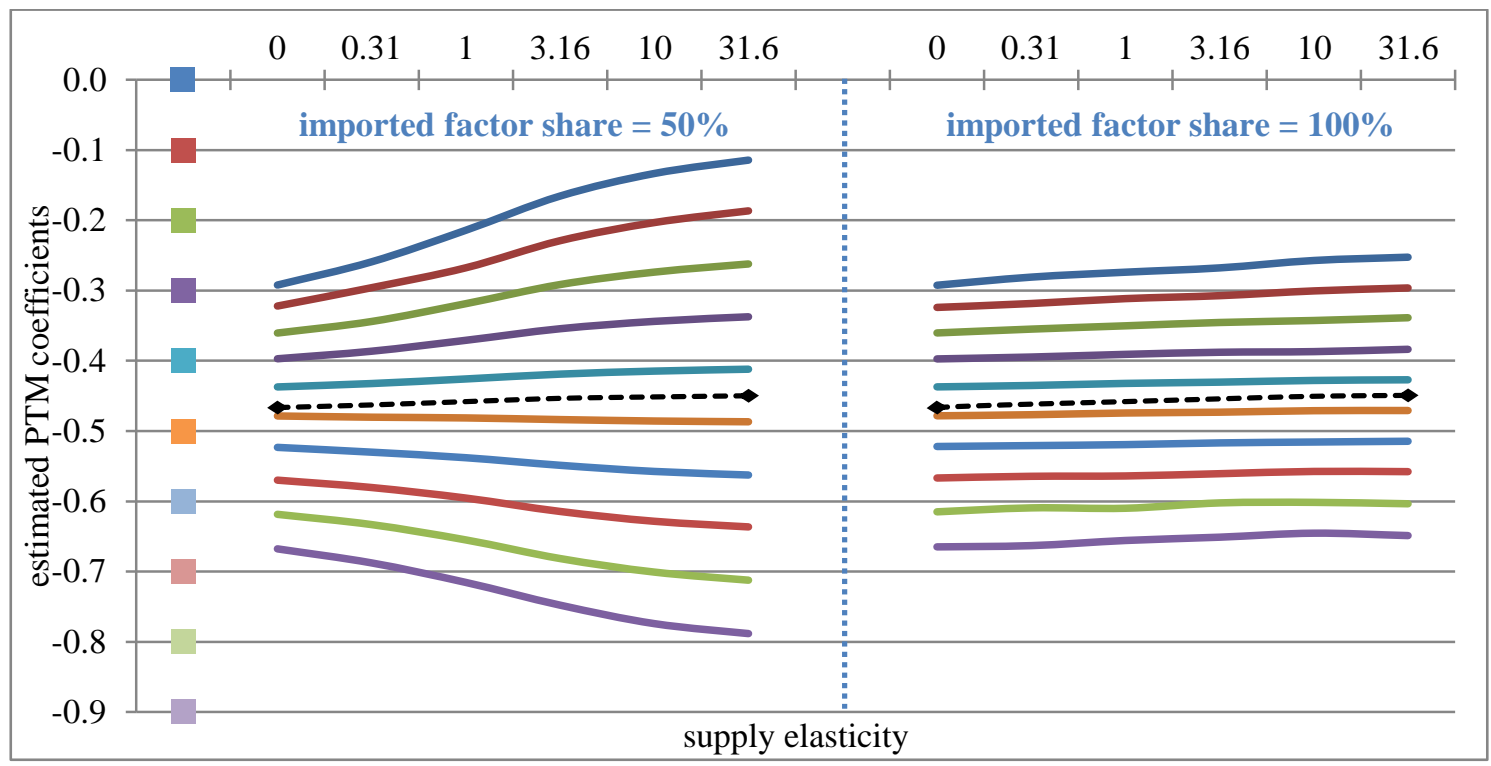

Source: own compilation

When Figure 3.6 is compared with Figure 3.5, it turns out that for a small value of the supply elasticity, an increasing share of imported factors only has a minor effect on the bias of the PTM coefficients - for a supply elasticity of zero there is no effect at all. This is due to the fact that a small supply elasticity leads to a strong influence of the quantity on the marginal cost and widely dampens the effect of changes in input prices; however, for a larger value of the supply elasticity, the influence of imported factors on the bias increases. If the supply shifter is completely determined by the influence of imported factors, this effect is so strong that the negative effect of the supply elasticity on the bias - which is shown in Figure 3.5 - is fully offset and the supply elasticity has literally no influence on the bias.

\subsection{Discussion}

In Chapter 3.4, it is shown that the Knetter model can be expected to be biased and that a number of parameters determine the extent of the bias. With regard to the FD-ERC, Figure 3.2 already revealed that a value of at least 0.5 seems to be common, when all countries of the IMF database are considered. However, in empirical applications only a restricted number of countries are relevant as destination countries. These groups of 
countries could expose very different average degrees of FD-ERC. This aspect alone makes it difficult to predict how serious the bias is in a specific case.

In contrast to the simulation model, in empirical applications individual destination countries could be of different importance for an export country with regard to market shares (i.e. share of export country's exports). Furthermore, they could exhibit very different values of the demand elasticity. This in turn results in very different degrees of correlation between the respective exchange rate and the marginal cost. When the degree of FD-ERC rises, these differences are smoothed out but do not disappear as long as exchange rates are not perfectly correlated. The consequences are as follows:

1. The bias can vary much more than reported in Chapter 3.4.

Consider, for example, a destination country whose imports correspond to a very high market share and in which the export country has no market power and cannot practice PTM. The exchange rate to this country can be expected to be highly correlated with the exporter's marginal cost. As a result, the Knetter model detects a significantly negative PTM coefficient although no PTM takes place. Furthermore, the extent of this bias is especially large when a large number of other countries in the sample exhibit markedly high PTM coefficients. This is because a country with a very small market share has the same leverage on the average PTM coefficient as a country with a huge market share.

2. The average PTM coefficient in the sample could be biased too.

The simulation results show that the average PTM coefficient is hardly biased. This is because of only moderate differences with regard to the correlation of exchange rates and the marginal cost across the destination countries. These differences are introduced by the different values of the true PTM coefficients. However, this cannot be expected for empirical applications anymore. If, for example, destination countries with low true PTM coefficients exhibit a high correlation between the exchange rate and the marginal cost, the average PTM coefficient is biased upwards in absolute terms.

The fact that the direction of the bias is the mean of the PTM coefficients in the sample (and not in the population) is a problem. It implies that for a given country, the estimated PTM coefficient depends heavily on the composition of the sample. However, the sample in PTM studies is often far away from a random selection. In the empirical application of the Knetter model, destination countries are typically chosen according to a) 
the completeness of unit value series, b) sufficiently high trade quantities and c) a sufficiently high variation of the exchange rate series. Indeed, significant changes of the estimated PTM coefficients when the sample selection is varied are a well-known phenomenon, when using the Knetter approach. The paper has a convincing explanation for this behavior.

The results in Chapter 3.4 also cast a bit more light on other phenomena that are described in the literature. It is often tested whether or not PTM coefficients are equal across destination countries which cannot typically be rejected. However, when coefficients are biased toward the sample mean, this test is pointless. Furthermore, an oftenobtained result in PTM studies is that the United States seems to reveal a different PTM behavior than all other countries. PTM is often found when the US is the destination country but often not found when they are the country of origin. This result could at least be influenced by the properties of the US with regard to the parameters that determine the extent of the bias. As Figure 3.2 shows, the US exhibits a very low average FD-ERC. Furthermore, as a large country they should have rather high export supply elasticities in a number of markets as well as a lower dependency on foreign inputs.

In fact, the only chance to avoid the bias when using the Knetter model seems to be choosing markets with high export supply elasticities and a low reliance on foreign factors - which would otherwise wipe out the effect of a larger elasticity. However, in such a scenario, the marginal cost would scarcely change at all and it is not necessary to control for it by using the Knetter model. Furthermore, this should be an uncommon scenario. In the case of agricultural commodity markets, the export supply elasticities can be expected to be rather low and therefore the bias to be serious. It could be argued that it is unclear whether the symmetry condition is fulfilled in empirical applications. Different implications for arbitrage, for example, speak against the symmetry condition. Even equal PTM coefficients usually change the price relations of the destination countries in a common currency and therefore trigger arbitrage - this is because exchange rates are not perfectly correlated. Conversely, an equal cost pass-through does not change the price relations and therefore does not trigger arbitrage. However, even when there are theoretical arguments against the symmetry condition, the bias only disappears if cost pass-through is equal across destination countries. Whether or not this is the case is an empirical question and should not be implicitly assumed in an empirical model. Instead, an empirical model should be robust against deviations from this assumption. 
It therefore requires a different methodological approach to achieve an unbiased estimation of PTM. Such an approach should allow the marginal cost to have different influences on prices across destination countries. For this purpose, KNETTER (1995) proposed a non-linear model that is still based on a panel approach with fixed time effects, but allows the time effects to exercise a destination-specific influence. An important disadvantage of this model is that it hinges on the validity of the symmetry condition. This means that it is not possible to test whether or not symmetry is fulfilled; in the case of non-fulfillment, the model results are again biased. This is a strong assumption and there is therefore no guarantee that the model produces better results. In actuality, the model is not followed up in the PTM literature.

An alternative would be the usage of an observable series as a measure of the marginal cost in order to estimate its destination-specific influence. Such a measure could be a non-destination-specific unit value series - a weighted average of the destinationspecific unit values. However, this series still contains cost and exchange rate passthrough effects and is therefore not appropriate. Instead, the wholesale prices in the exporting country can be used as a measure of the marginal cost. This measure is, for example, used by SAGHAIAN \& REED (2004) since they find strong multicollinearity between the exchange rates and the fixed effects in the Knetter model. However, this method comes with a number of possible problems. Firstly, the price series has to be available for a specific product or the specific variety of a product which is covered through the unit values series. Secondly, the domestic wholesale prices have to be uninfluenced by market power. However, when market power is supposed to be a problem in the export market, why should it not be a problem in the domestic market? And thirdly, in international trade the usage of (at least) medium-term contracts is often common. This means that the price information in unit values could be temporally lagged and therefore does not fit to wholesale prices. In Chapter 4, we propose an alternative method to construct a series which can be used as a measure of the marginal cost and therefore to control for it in a PTM model.

\subsection{Conclusion}

The empirical model proposed by KNETTER $(1989$; 1993) and its countless modifications are not able to measure pricing-to-market unbiasedly. The reason for this bias lies in the key element of the model, the way in which it controls for the marginal cost. The marginal cost is assumed to be identical across destination countries at the port of ex- 
port and it can therefore be approximated with the fixed effects of a panel model. However, even if the marginal cost is equal across destination countries, its influence on prices is not equal; instead, this influence depends on cost pass-through. Since cost and exchange rate pass-through are at least theoretically symmetrical, the PTM coefficients of the Knetter model are biased toward the average PTM coefficient in the sample. Even when symmetry does not hold, for an unbiased estimation cost pass-through must be equal across destination countries, which is rather unlikely to happen.

The severity and the determinants of the bias are analyzed in this paper by firstly generating data in simulations that are based on the assumptions of the Knetter model, and secondly using this data to estimate the Knetter model. It turns out that under realistic conditions, the extent of the bias is around $50 \%$ of the distance to the average PTM coefficient in the sample. In general, the extent of the bias is determined by a) the correlation between the export firm's marginal cost and the exchange rate to the respective destination country as well as b) the sensitivity of the marginal cost with regard to exchange rate changes. In addition to the market share and demand elasticity of the respective destination country, a) is determined by the degree of correlation between the first differences of the exchange rates of the destination countries. When this correlation increases, the destination countries act more and more as a unit with regard to the demand. Next to that, b) is driven by the export supply elasticity and the importance of foreign inputs. The bias tends toward zero only if the value of the supply elasticity is large (at least above 10) and foreign inputs do not play a role. However, in this case it is not necessary to control for the marginal cost at all, which is the main purpose of the Knetter model. In the case of agricultural commodity markets, the existing supply elasticities can be expected to cause a serious bias.

In summary, this means that the Knetter model delivers PTM estimates (mainly for single destination countries) that could be highly misleading as an implication of market power. The results are less problematic when the average degree of PTM in the sample is of interest, although in this case a bias can also occur. In any case, the results should be interpreted with caution. Furthermore, the model in first differences is superior to the model in levels. In order to achieve an unbiased estimation of PTM, an alternative method to measuring the marginal cost is needed. This method, as well as a differently specified PTM model that preserves the advantages of the Knetter approach, is presented in Chapter 4. 


\section{References}

AL-ABri, A.S. \& Goodwin, B.K. (2009): Re-examining the exchange rate pass-through into import prices using non-linear estimation techniques: Threshold cointegration. International Review of Economics \& Finance, 18(1), pp. 142-161.

Armington, P.S. (1969): The Geographic Pattern of Trade and the Effects of Price Changes. International Monetary Fund, Staff Papers, 16(2), pp. 179-201.

Auer, R. \& ChAney, T. (2009): Exchange Rate Pass-Through in a Competitive Model of Pricing-to-Market. Journal of Money, Credit and Banking, 41(1), pp. 151-175.

BALDWIN, R. (1988): Hysteresis in import prices: the beachhead effect. The American Economic Review, 78(4), pp. 773-785.

Bergin, P.R. \& FeEnstRA, R.C. (2001): Pricing-to-market, staggered contracts, and real exchange rate persistence. Journal of International Economics, 54(2), pp.333-359.

Brown, J. (2001): Price discrimination and pricing to market behavior of Canadian canola exporters. American Journal of Agricultural Economics, 83(5), pp. 13431349.

Bugamelli, M. \& Tedeschi, R. (2008): Pricing-to-Market and Market Structure. Oxford Bulletin of Economics and Statistics, 70(2), pp. 155-180.

CAREW, R. (2000): Pricing to market behavior: evidence from selected Canadian and US agri-food exports. Journal of Agricultural and Resource Economics, 25(2), pp. $578-595$.

CARew, R. \& Florkowski, W.J. (2003): Pricing to Market Behavior by Canadian and US Agriâ€• food Exporters: Evidence from Wheat, Pulse and Apples. Canadian Journal of Agricultural Economics, 51(2), pp. 139-159.

Dornbusch, R. (1987): Exchange Rates and Prices. The American Economic Review,, 77(1), pp. 93-106.

FEENSTRA, R.C. (1989): Symmetric pass-through of tariffs and exchange rates under imperfect competition: an empirical test. Journal of International Economics, 27(1-2), pp. 25-45.

GAGnON, J.E. \& KNetTER, M.M. (1995): Markup adjustment and exchange rate fluctuations: evidence from panel data on automobile exports. Journal of International Money and Finance, 14(2), pp. 289-310. 
GHosh, A.R. \& Wolf, H.C. (1994): Pricing in international markets: lessons from The Economist. National Bureau of Economic Research (NBER) Working Paper, No. 4806, pp. 1-20.

GIL-PAREJA, S. (2000): Exchange rates and European countries' export prices: An empirical test for asymmetries in pricing to market behavior. Weltwirtschaftliches Archiv, 136(1), pp. 1-23.

GIL-PAREJA, S. (2003): Pricing to market behaviour in European car markets. European Economic Review, 47(6), pp. 945-962.

Glauben, T. \& Loy, J.-P. (2003): Pricing-to-market versus residual demand elasticity analysis of imperfect competition in food exports: Evidence from Germany. Journal of Agricultural \& Food Industrial Organization, 1(1), p. 1-19.

GoldberG, P.K. \& KNETTER, M.M. (1997): Goods prices and exchange rates: What have we learned? Journal of Economic Literature, 35(3), pp. 1243-1272.

GRIFFITH, G. \& MULLEN, J. (2001): Pricing-to-market in NSW rice export markets. The Australian Journal of Agricultural and Resource Economics, 45(3), pp. 323-334.

IMF (2013): International Financial Statistics (IFS). International Monetary Fund.

JIN, H.J. (2008): Competitive structure of Canadian wheat exports in the world market. Applied Economics Letters, 15(13), pp. 1059-1064.

KASA, K. (1992): Adjustment costs and pricing-to-market theory and evidence. Journal of International Economics, 32(1-2), pp. 1-30.

KIM, M., Cho, G. \& Koo, W.W. (2003): Exchange Rate Pass-Through And Its Relation To Market Power: Reinterpretation Of The Degree Of Exchange Rate PassThrough. In American Agricultural Economics Association Annual Meeting, July 27-30. Montreal, Canada, pp. 1-30.

KNETTER, M.M. (1989): Price Discrimination by U.S. and German Exporters. The American Economic Review, 79(1), pp. 198-210.

KNETTER, M.M. (1993): International comparisons of pricing-to-market behavior. The American Economic Review, 83(3), pp. 473-486.

KNETTER, M.M. (1994): Is Export Price Adjustment Asymmetric?: Evaluating the Market Share and Marketing Bottlenecks Hypothesis. Journal of International Money and Finance, 13(1), pp. 55-70. 
KNeTTER, M.M. (1995): Pricing to Market in Response to Unobservable and Observable Shocks. International Economic Journal, 9(2), pp. 1-25.

KNETTER, M.M. (1997): The segmentation of international markets: evidence from The Economist. National Bureau of Economic Research (NBER) Working Paper, No. 5878, pp. 1-41.

Krugman, P. (1986): Pricing to market when the exchange rate changes. National Bureau of Economic Research (NBER) Working Paper, No. 1926, pp. 1-43.

Larue, B. (2004): Pricing-• to-• Market: Simple Theoretical Insights, Formidable Econometric Challenges. Canadian Journal of Agricultural Economics, 52(3), pp. 387-398.

LARUE, B., Gervais, J.-P. \& RANCOURT, Y. (2010): Exchange rate pass-through, menu costs and threshold cointegration. Empirical Economics, 38(1), pp. 171-192.

Lavoie, N. \& LiU, Q. (2007): Pricing-to-Market: Price Discrimination or Product Differentiation? American Journal of Agricultural Economics, 89(3), pp. 571-581.

MAnN, C.L. (1986): Prices, profit margins, and exchange rates. Federal Reserve Bulletin, 72, pp. 366-379.

Marston, R.C. (1990): Pricing to market in Japanese manufacturing. Journal of International Economics, 29(3-4), pp. 217-236.

PARK, T.A., Pick, D.H., Sheldon, I.M. \& ABbOTT, P.C. (1996): Imperfect competition and exchange rate pass-through in U.S. wheat exports. In Sheldon, I. M. \& Abbott, P. C., eds: Industrial organization and trade in the food industries. Westview Press, Inc., pp. 53-64.

PICK, D.H. \& CARTER, C.A. (1994): Pricing to market with transactions denominated in a common currency. American Journal of Agricultural Economics, 76(1), pp. 5560.

PICK, D.H. \& PARK, T.A. (1991): The competitive structure of US agricultural exports. American Journal of Agricultural Economics, 73(1), pp. 133-141.

SAghaian, S.H. \& REED, M.R. (2004): Integrating Marginal Cost into Pricing-to-market Models for US Agricultural Products. Current Agriculture, Food and Resource Issues, (5), pp. 187-203. 
Sexton, R.J. \& Lavoie, N. (2001): Food Processing and Distribution: An Industrial Organization Approach. In Gardner, B. L. \& Rausser, G. C., eds: Handbook of Agricultural Economics, Vol. 1, Part B - Marketing, Distribution and Consumers. Amsterdam: Elsevier, pp. 863-932.

TAntiRigama, M. (2003): Exchange Rate Pass-Through and Pricing-to-Market in the Internatioanl Trade market: The Study of New Zealand Exports. Annual Conference of NZ Association of Economists.

WiLliams, J.C. \& WRIGHT, B.D. (2005): Storage and Commodity Markets, Cambridge, MA: Cambridge University Press.

XU, Y. \& ShEldon, I.M. (2005): Pricing to Market, (Seasonal) Cointegration and US Agricultural Exports. In AAEA Annual meeting, July 24-27. Providence, Rhode Island, pp. 1-37.

Zhang, Q., Reed, M.R. \& Saghaian, S.H. (2007): Export Market Pricing Decisions and Market Power in World Grain Markets: A Duopoly Model for Soybeans. In Southern Agricultural Economics Association Annual Meeting, February 4-7. Mobile, Alabama, pp. 1-20. 
Appendix 3.1: Estimated PTM coefficients for the model in first differences

\begin{tabular}{|c|c|c|c|c|c|c|c|c|c|c|c|}
\hline & \multirow{2}{*}{$\begin{array}{l}\text { True PTM } \\
\text { coefficients }\end{array}$} & \multicolumn{10}{|c|}{ degrees of first difference exchange rate correlation (FD-ERC) } \\
\hline & & $\mathbf{0}$ & 0.1 & 0.2 & 0.3 & 0.4 & 0.5 & 0.6 & 0.7 & 0.8 & 0.9 \\
\hline \multirow{10}{*}{$\underset{\mathbb{\Xi}}{\stackrel{\Xi}{\Xi}}$} & 0.0 & -0.08 & -0.12 & -0.15 & -0.18 & -0.22 & -0.25 & -0.28 & -0.31 & -0.33 & -0.37 \\
\hline & -0.1 & -0.16 & -0.19 & -0.21 & -0.24 & -0.27 & -0.29 & -0.31 & -0.34 & -0.36 & -0.39 \\
\hline & -0.2 & -0.24 & -0.26 & -0.28 & -0.30 & -0.32 & -0.34 & -0.35 & -0.37 & -0.39 & -0.41 \\
\hline & -0.3 & -0.32 & -0.33 & -0.34 & -0.36 & -0.37 & -0.38 & -0.39 & -0.41 & -0.41 & -0.43 \\
\hline & -0.4 & -0.40 & -0.41 & -0.42 & -0.42 & -0.43 & -0.43 & -0.43 & -0.44 & -0.44 & -0.45 \\
\hline & -0.5 & -0.49 & -0.49 & -0.49 & -0.49 & -0.49 & -0.48 & -0.48 & -0.48 & -0.47 & -0.47 \\
\hline & -0.6 & -0.59 & -0.58 & -0.57 & -0.56 & -0.55 & -0.54 & -0.52 & -0.52 & -0.50 & -0.49 \\
\hline & -0.7 & -0.69 & -0.66 & -0.65 & -0.63 & -0.61 & -0.59 & -0.57 & -0.56 & -0.53 & -0.52 \\
\hline & -0.8 & -0.79 & -0.76 & -0.73 & -0.70 & -0.67 & -0.65 & -0.61 & -0.60 & -0.56 & -0.54 \\
\hline & -0.9 & -0.89 & -0.85 & -0.81 & -0.77 & -0.74 & -0.71 & -0.66 & -0.64 & -0.59 & -0.56 \\
\hline \multirow{10}{*}{ 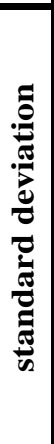 } & 0.0 & 0.039 & 0.041 & 0.042 & 0.045 & 0.046 & 0.039 & 0.046 & 0.044 & 0.047 & 0.046 \\
\hline & -0.1 & 0.031 & 0.030 & 0.032 & 0.036 & 0.035 & 0.035 & 0.034 & 0.035 & 0.038 & 0.041 \\
\hline & -0.2 & 0.023 & 0.026 & 0.024 & 0.025 & 0.027 & 0.027 & 0.026 & 0.029 & 0.029 & 0.034 \\
\hline & -0.3 & 0.014 & 0.013 & 0.015 & 0.017 & 0.018 & 0.017 & 0.020 & 0.019 & 0.023 & 0.030 \\
\hline & -0.4 & 0.005 & 0.006 & 0.007 & 0.008 & 0.009 & 0.011 & 0.013 & 0.014 & 0.017 & 0.027 \\
\hline & -0.5 & 0.005 & 0.005 & 0.006 & 0.006 & 0.007 & 0.009 & 0.012 & 0.014 & 0.016 & 0.028 \\
\hline & -0.6 & 0.014 & 0.013 & 0.015 & 0.014 & 0.015 & 0.013 & 0.019 & 0.019 & 0.021 & 0.030 \\
\hline & -0.7 & 0.022 & 0.025 & 0.024 & 0.024 & 0.026 & 0.023 & 0.027 & 0.029 & 0.027 & 0.037 \\
\hline & -0.8 & 0.031 & 0.036 & 0.037 & 0.034 & 0.037 & 0.034 & 0.036 & 0.037 & 0.035 & 0.042 \\
\hline & -0.9 & 0.041 & 0.044 & 0.047 & 0.046 & 0.043 & 0.045 & 0.049 & 0.048 & 0.043 & 0.048 \\
\hline \multicolumn{3}{|c|}{ Simulation parameter: } & $\begin{array}{l}\text { Supplye } \\
\text { Standarc } \\
\text { Standarc }\end{array}$ & ity $=$ & $\overline{D e m}$ & astic & star & $\begin{array}{l}\text { perioc } \\
05 \\
75\end{array}$ & & & \\
\hline
\end{tabular}

Source: Own calculations

\section{Appendix 3.2: Estimated PTM coefficients for the model in levels}

\begin{tabular}{|c|c|c|c|c|c|c|c|c|c|c|c|}
\hline & \multirow{2}{*}{$\begin{array}{c}\text { True PTM } \\
\text { coefficients }\end{array}$} & \multicolumn{10}{|c|}{ degrees of first difference exchange rate correlation (FD-ERC) } \\
\hline & & $\mathbf{0}$ & 0.1 & 0.2 & 0.3 & 0.4 & 0.5 & 0.6 & 0.7 & 0.8 & 0.9 \\
\hline \multirow{10}{*}{$\underset{\Xi}{\mathbb{\Xi}}$} & $\mathbf{0 . 0}$ & -0.08 & -0.11 & -0.15 & -0.19 & -0.21 & -0.25 & -0.27 & -0.31 & -0.34 & -0.37 \\
\hline & -0.1 & -0.16 & -0.18 & -0.22 & -0.24 & -0.26 & -0.30 & -0.31 & -0.34 & -0.37 & -0.39 \\
\hline & -0.2 & -0.24 & -0.26 & -0.28 & -0.30 & -0.31 & -0.34 & -0.35 & -0.37 & -0.39 & -0.41 \\
\hline & -0.3 & -0.32 & -0.33 & -0.35 & -0.36 & -0.37 & -0.38 & -0.39 & -0.41 & -0.42 & -0.43 \\
\hline & -0.4 & -0.40 & -0.41 & -0.42 & -0.42 & -0.43 & -0.43 & -0.44 & -0.44 & -0.45 & -0.45 \\
\hline & -0.5 & -0.49 & -0.49 & -0.49 & -0.49 & -0.48 & -0.48 & -0.48 & -0.48 & -0.48 & -0.47 \\
\hline & -0.6 & -0.59 & -0.57 & -0.57 & -0.56 & -0.55 & -0.53 & -0.53 & -0.52 & -0.51 & -0.50 \\
\hline & -0.7 & -0.68 & -0.66 & -0.65 & -0.63 & -0.61 & -0.59 & -0.57 & -0.55 & -0.54 & -0.52 \\
\hline & -0.8 & -0.78 & -0.76 & -0.72 & -0.71 & -0.67 & -0.64 & -0.62 & -0.59 & -0.57 & -0.54 \\
\hline & -0.9 & -0.89 & -0.85 & -0.82 & -0.77 & -0.74 & -0.70 & -0.67 & -0.63 & -0.60 & -0.57 \\
\hline \multirow{10}{*}{ 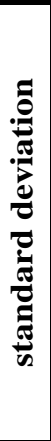 } & 0.0 & 0.047 & 0.057 & 0.062 & 0.068 & 0.064 & 0.069 & 0.060 & 0.056 & 0.057 & 0.052 \\
\hline & -0.1 & 0.036 & 0.043 & 0.049 & 0.053 & 0.054 & 0.053 & 0.054 & 0.052 & 0.049 & 0.047 \\
\hline & -0.2 & 0.025 & 0.033 & 0.038 & 0.043 & 0.044 & 0.040 & 0.043 & 0.048 & 0.041 & 0.037 \\
\hline & -0.3 & 0.016 & 0.020 & 0.027 & 0.029 & 0.030 & 0.032 & 0.034 & 0.035 & 0.036 & 0.037 \\
\hline & -0.4 & 0.009 & 0.013 & 0.015 & 0.018 & 0.018 & 0.022 & 0.024 & 0.027 & 0.032 & 0.033 \\
\hline & -0.5 & 0.005 & 0.006 & 0.009 & 0.012 & 0.014 & 0.019 & 0.021 & 0.024 & 0.029 & 0.033 \\
\hline & -0.6 & 0.014 & 0.015 & 0.018 & 0.020 & 0.022 & 0.026 & 0.023 & 0.028 & 0.030 & 0.034 \\
\hline & -0.7 & 0.028 & 0.028 & 0.036 & 0.038 & 0.034 & 0.038 & 0.037 & 0.041 & 0.036 & 0.038 \\
\hline & -0.8 & 0.038 & 0.047 & 0.049 & 0.047 & 0.045 & 0.055 & 0.051 & 0.047 & 0.044 & 0.044 \\
\hline & -0.9 & 0.051 & 0.055 & 0.059 & 0.076 & 0.067 & 0.073 & 0.062 & 0.057 & 0.059 & 0.049 \\
\hline \multicolumn{12}{|c|}{ Simulation parameter: } \\
\hline
\end{tabular}

Source: Own calculations 
Appendix 3.3: Estimated PTM coefficients for different supply elasticities

\begin{tabular}{|c|c|c|c|c|c|c|c|c|c|c|c|}
\hline & \multirow{2}{*}{$\begin{array}{c}\text { Supply } \\
\text { elasticity }\end{array}$} & \multicolumn{10}{|c|}{ True PTM coefficients } \\
\hline & & $\mathbf{0}$ & -0.1 & -0.2 & -0.3 & -0.4 & -0.5 & -0.6 & -0.7 & -0.8 & -0.9 \\
\hline \multirow{6}{*}{$\stackrel{\Xi}{\mathbb{E}}$} & $\mathbf{0}$ & -0.29 & -0.33 & -0.36 & -0.40 & -0.44 & -0.48 & -0.52 & -0.57 & -0.61 & -0.67 \\
\hline & 0.31 & -0.22 & -0.27 & -0.33 & -0.37 & -0.43 & -0.48 & -0.54 & -0.60 & -0.66 & -0.72 \\
\hline & 1 & -0.16 & -0.22 & -0.29 & -0.35 & -0.42 & -0.49 & -0.56 & -0.63 & -0.70 & -0.77 \\
\hline & 3.16 & -0.08 & -0.16 & -0.24 & -0.33 & -0.41 & -0.49 & -0.58 & -0.66 & -0.75 & -0.84 \\
\hline & 10 & -0.03 & -0.12 & -0.22 & -0.31 & -0.40 & -0.50 & -0.59 & -0.69 & -0.78 & -0.88 \\
\hline & 31.6 & -0.01 & -0.11 & -0.20 & -0.30 & -0.40 & -0.50 & -0.60 & -0.69 & -0.79 & -0.89 \\
\hline \multirow{6}{*}{ 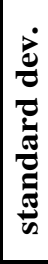 } & $\mathbf{0}$ & 0.053 & 0.040 & 0.029 & 0.021 & 0.011 & 0.011 & 0.019 & 0.032 & 0.039 & 0.053 \\
\hline & 0.31 & 0.036 & 0.031 & 0.024 & 0.016 & 0.010 & 0.008 & 0.015 & 0.022 & 0.034 & 0.040 \\
\hline & 1 & 0.027 & 0.022 & 0.016 & 0.011 & 0.007 & 0.006 & 0.010 & 0.016 & 0.025 & 0.026 \\
\hline & 3.16 & 0.012 & 0.011 & 0.008 & 0.006 & 0.003 & 0.003 & 0.005 & 0.008 & 0.012 & 0.013 \\
\hline & 10 & 0.005 & 0.004 & 0.003 & 0.002 & 0.001 & 0.001 & 0.002 & 0.003 & 0.005 & 0.005 \\
\hline & 31.6 & 0.002 & 0.001 & 0.001 & 0.001 & 0.000 & 0.000 & 0.001 & 0.001 & 0.002 & 0.002 \\
\hline \multicolumn{12}{|c|}{ Simulation parameter: } \\
\hline
\end{tabular}

Source: Own calculations

Appendix 3.4: Estimated PTM coefficients for different imported factor shares

\begin{tabular}{|c|c|c|c|c|c|c|c|c|c|c|c|c|}
\hline & \multirow{2}{*}{$\begin{array}{c}\text { Supply } \\
\text { elasticity }\end{array}$} & \multicolumn{10}{|c|}{ True PTM coefficients } \\
\hline & & & $\mathbf{0}$ & -0.1 & -0.2 & -0.3 & -0.4 & -0.5 & -0.6 & -0.7 & -0.8 & -0.9 \\
\hline \multirow{12}{*}{ 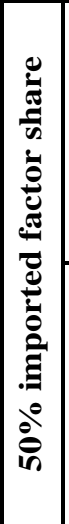 } & \multirow{6}{*}{$\stackrel{\Xi}{\text { ฮี }}$} & $\mathbf{0}$ & -0.29 & -0.32 & -0.36 & -0.40 & -0.44 & -0.48 & -0.52 & -0.57 & -0.62 & -0.67 \\
\hline & & 0.31 & -0.26 & -0.30 & -0.34 & -0.39 & -0.43 & -0.48 & -0.53 & -0.58 & -0.63 & -0.69 \\
\hline & & 1 & -0.21 & -0.27 & -0.32 & -0.37 & -0.43 & -0.48 & -0.54 & -0.60 & -0.66 & -0.72 \\
\hline & & 3.16 & -0.17 & -0.23 & -0.29 & -0.35 & -0.42 & -0.48 & -0.55 & -0.61 & -0.68 & -0.75 \\
\hline & & 10 & -0.13 & -0.20 & -0.27 & -0.34 & -0.41 & -0.49 & -0.56 & -0.63 & -0.70 & -0.77 \\
\hline & & 31.6 & -0.11 & -0.19 & -0.26 & -0.34 & -0.41 & -0.49 & -0.56 & -0.64 & -0.71 & -0.79 \\
\hline & \multirow{6}{*}{ 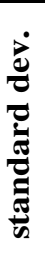 } & $\mathbf{0}$ & 0.036 & 0.030 & 0.024 & 0.015 & 0.011 & 0.009 & 0.015 & 0.021 & 0.029 & 0.037 \\
\hline & & 0.31 & 0.031 & 0.027 & 0.022 & 0.015 & 0.009 & 0.007 & 0.011 & 0.017 & 0.025 & 0.035 \\
\hline & & 1 & 0.026 & 0.021 & 0.017 & 0.012 & 0.008 & 0.006 & 0.010 & 0.015 & 0.021 & 0.029 \\
\hline & & 3.16 & 0.019 & 0.016 & 0.012 & 0.009 & 0.006 & 0.005 & 0.008 & 0.012 & 0.015 & 0.020 \\
\hline & & 10 & 0.030 & 0.024 & 0.018 & 0.011 & 0.005 & 0.005 & 0.011 & 0.017 & 0.025 & 0.031 \\
\hline & & 31.6 & 0.040 & 0.031 & 0.023 & 0.014 & 0.006 & 0.005 & 0.014 & 0.023 & 0.030 & 0.043 \\
\hline \multirow{12}{*}{ 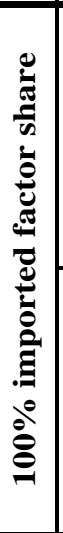 } & \multirow{6}{*}{ ⿷ี } & 0 & -0.29 & -0.32 & -0.36 & -0.40 & -0.44 & -0.48 & -0.52 & -0.57 & -0.62 & -0.66 \\
\hline & & 0.31 & -0.28 & -0.32 & -0.35 & -0.39 & -0.44 & -0.48 & -0.52 & -0.56 & -0.61 & -0.66 \\
\hline & & 1 & -0.27 & -0.31 & -0.35 & -0.39 & -0.43 & -0.47 & -0.52 & -0.56 & -0.61 & -0.66 \\
\hline & & 3.16 & -0.27 & -0.31 & -0.35 & -0.39 & -0.43 & -0.47 & -0.52 & -0.56 & -0.60 & -0.65 \\
\hline & & 10 & -0.26 & -0.30 & -0.34 & -0.39 & -0.43 & -0.47 & -0.52 & -0.56 & -0.60 & -0.65 \\
\hline & & 31.6 & -0.25 & -0.30 & -0.34 & -0.38 & -0.43 & -0.47 & -0.51 & -0.56 & -0.60 & -0.65 \\
\hline & \multirow{6}{*}{ 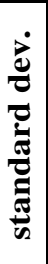 } & $\mathbf{0}$ & 0.031 & 0.026 & 0.021 & 0.015 & 0.010 & 0.008 & 0.012 & 0.020 & 0.025 & 0.037 \\
\hline & & 0.31 & 0.030 & 0.025 & 0.019 & 0.015 & 0.010 & 0.008 & 0.011 & 0.019 & 0.024 & 0.031 \\
\hline & & 1 & 0.029 & 0.026 & 0.019 & 0.013 & 0.008 & 0.008 & 0.012 & 0.018 & 0.023 & 0.032 \\
\hline & & 3.16 & 0.031 & 0.022 & 0.017 & 0.014 & 0.008 & 0.007 & 0.012 & 0.017 & 0.025 & 0.029 \\
\hline & & 10 & 0.031 & 0.023 & 0.016 & 0.012 & 0.008 & 0.007 & 0.012 & 0.016 & 0.025 & 0.029 \\
\hline & & 31.6 & 0.029 & 0.024 & 0.017 & 0.012 & 0.009 & 0.009 & 0.012 & 0.017 & 0.024 & 0.029 \\
\hline \multicolumn{13}{|c|}{ ulation paramete } \\
\hline
\end{tabular}

Source: Own calculations 


\title{
4 Pricing-to-Market in an Oligopoly: An Alternative Approach to Measuring Marginal Cost
}

\begin{abstract}
Pricing-to-market describes the phenomenon when an export firm adjusts its destination-specific markup in order to offset changes of the bilateral exchange rates that shift its marginal cost in the destination country's currency. For this behavior, the existence of a markup is necessary and therefore pricing-to-market is typically used as a method to analyze market power. However, an open question in the literature is whether pricing-to-market is caused by the characteristics of the market demand curve or by the market structure - i.e. the existence of oligopolistic competitors. The first innovation of this paper is the theoretical foundation of an oligopolistic model of pricing-to-market that allows the identification of its source. The second innovation is the proposal of an alternative approach to measuring marginal cost that avoids a biased estimation of pricing-to-market and also allows detection of it through changes in a firm's overall marginal cost. The oligopolistic PTM model is estimated for New Zealand's exports of the most important dairy products. The results support the validity of the approach proposed here and show that pricing-to-market is present on the analyzed market to a high degree due to the existence of the EU as main competitor.
\end{abstract}

Keywords: Pricing-to-market, exchange rate pass-through, international dairy markets 


\subsection{Introduction}

A possible way to detect imperfect competition and market power is to analyze the pricing behavior of firms - i.e. how prices react to changes in cost. For the international markets, a special kind of cost change can be directly observed. The change of the bilateral exchange rate between an export and an import country also changes the exporter's marginal cost in the import country's currency. Under conditions of perfect competition, the exporter's price has to change proportionally to the marginal cost but in the case of imperfect competition, it does not have to. If the price adjustment leads to a change of the perceived (residual) demand elasticity in the import country, a profit maximizing exporter will modify its markup and thus change the price more or less proportionally. This behavior is referred to in the literature as "pricing-to-market" (PTM), an expression KRUGMAN (1986) used for the first time. It can usually be expected that the (residual) demand elasticity increases with the price which implies that the price increases less than proportionally and leads to local-currency price stability (KNETTER 1993).

An open question in the literature is whether PTM is caused by the characteristics of the demand curve or by the market structure. KNETTER $(1989$; 1993) who presents the first empirical model to detect PTM considers a profit maximizing, multi-market monopolist. This approach is typically generalized by assuming that the demand elasticity the monopolistic firm faces can also be seen as residual demand elasticity. Hence, the model can also be used for an oligopolistic market structure although such a structure is usually not explicitly modeled ${ }^{6}$. The disadvantage of this procedure is that it is not possible to detect the source of PTM. Both the convexity of the market demand schedule as well as the presence of one or more oligopolistic competitors can change the elasticity along a residual demand schedule which is measured through the PTM coefficient. Other papers that analyze the connection between PTM and the market structure are either purely theoretical (e.g. FEENSTRA et al. 1996) or try to find a pattern between the market structure and the measured degree of PTM (e.g. BUGAMELLI \& TEDESCHI 2008).

In this paper, the theoretical framework of KNETTER (1995) - that is also used by GAGNON \& KNETTER (1995) in principle - is extended to an oligopolistic model of PTM which allows us to unravel whether PTM is caused by the characteristics of the market demand curve or by the market structure; this is the first innovation of the paper. The

\footnotetext{
${ }^{6}$ An exception is the empirical specification of GIL-PAREJA (2003) that assumes Bertrand competition and includes a competitor price index but without theoretically deriving the meaning of the coefficients.
} 
second innovation pertains to the way in which the marginal cost is depicted in the empirical application of the model. It is important to control for the marginal cost because it is correlated with the exchange rates and its omission would lead to biased PTM coefficients. In the empirical model proposed by KNETTER $(1989 ; 1993 ; 1995)$ and the later work that is based on this approach, for the marginal cost is controlled through the time effects of a fixed effects panel model. However, this procedure contains several disadvantages and it is simply no longer possible to apply it when it comes to the estimation of the oligopolistic PTM model. Instead we propose an approach that is based upon the estimation of a stochastic lower price frontier from the available unit value data which can - as we will argue - be used as a measure of the marginal cost. In the next step, this "stochastic" marginal cost series can be used to depict the marginal cost in the oligopolistic PTM model. A further advantage of this approach is that it also allows the detection of PTM through overall changes in the marginal cost.

The approach presented here is applied to the international markets for dairy products. These markets reveal a fairly high concentration on the supply side. The New Zealand dairy co-operative Fonterra accounts for approximately $95 \%$ of New Zealand's dairy exports and has a world market share of about $35 \%$ in milk equivalent (ME). For single dairy products, this share can be even higher - in some markets it lies well above $50 \%$. This is supported by the fact that Fonterra influences (directly or indirectly) huge parts of the dairy exports of other countries via international partnerships, joint ventures and foreign subsidiaries (ARMENTANO et al. 2004: 46f; DOBSON \& WILCOX 2002: 5). It is therefore fair to suppose that Fonterra has significant market power on the international dairy markets. In terms of export regions, the most important competitor of Fonterra (or New Zealand) is the European Union with almost the same market share in ME.

This paper is structured as follows: In Chapter 4.2 the theoretical oligopolistic PTM model is developed. In Chapter 4.3 the empirical specification of the model as well as the procedure to measure the marginal cost is presented. In Chapter 4.4 the data is discussed. Chapter 4.5 contains the estimation results for New Zealand's dairy exports and Chapter 4.6 finalizes the paper with a conclusion. 


\subsection{A theoretical model of pricing-to-market in an oligopoly}

Consider an exporting firm located in any country which sells any good in $\mathrm{N}$ different destination countries. It is assumed that the firm is able to segment the destination markets so that arbitrage does not need to be taken into account. In each destination country, the firm faces a third-country firm that competes with it and therefore limits its market power in the respective country. For simplicity, other competitors are not considered for the moment but it is possible to generalize the approach presented here to more than one foreign competitor. With regard to the type of oligopolistic competition, price competition with product differentiation is assumed. Similar to KNETTER (1995), no assumptions are necessary with regard to functional forms of cost or demand functions. The profits of the firm under consideration are given by:

$$
\Pi\left(p_{1}, \ldots, p_{N}\right)=\sum_{i=1}^{N} p_{i} q_{i}\left(E R_{i} p_{i}, E R_{i}^{C} p_{i}^{C}, Y_{i}\right)-C\left(q=\sum_{i=1}^{N} q_{i}\left(E R_{i} p_{i}, E R_{i}^{C} p_{i}^{C}, Y_{i}\right), W\right)
$$

where $p_{i}$ is the export price (in the export country's currency) and $q_{i}$ is the quantity sold to the destination country i, $E R_{i}$ is the real ${ }^{7}$ bilateral exchange rate (destination market currency per unit of the exporter's currency), $p_{i}^{C}$ is the real export price of the competing firm (in the competing firm's currency), $E R_{i}^{C}$ is the real bilateral competitor exchange rate (destination market currency per unit of the competing firm's currency), $Y_{i}$ is the real income in the destination country i, $W$ is the input price and $C(\cdot)$ is the cost function of the export firm. For simplicity, time arguments are suppressed in (4.1). Profit maximizing with respect to export prices yields the following first order conditions:

$$
p_{i}=M C(q, W)\left(\frac{-\eta_{i}\left(E R_{i} p_{i}, E R_{i}^{C} p_{i}^{C}, Y_{i}\right)}{-\eta_{i}\left(E R_{i} p_{i}, E R_{i}^{C} p_{i}^{C}, Y_{i}\right)+1}\right) \quad \forall i \in\{1, \ldots, N\}
$$

where $M C(\cdot)$ stands for the marginal cost and $\eta_{i}$ denotes the absolute value of the residual demand elasticity in the destination country i. As equation (4.2) shows, the optimal export price for a destination country should equal the marginal cost multiplied by a bracket term that depends on the residual demand elasticity and determines the markup. Both marginal cost and markup depend on the variables which determine the quantity demanded. While the marginal cost is equal across the destination countries, the residual demand elasticity and thus the markup is not equal. In order to show how the export price changes when these determinants change, the logarithm of equation (4.2) is taken and the result is totally differentiated with respect to the firm's and competitor's export

\footnotetext{
${ }^{7}$ The variables are divided through the price level in the respective destination market.
} 
price and exchange rate as well as the firm's input price and income in the destination country. This results in the following equation:

$$
\begin{aligned}
\frac{d p_{i}}{p_{i}} & =\frac{\frac{\partial M C(\cdot)}{\partial q}\left(\sum \frac{\partial q_{i}}{\partial \ddot{p}_{i}}\left(E R_{i} d p_{i}+p_{i} d E R_{i}\right)+\frac{\partial q_{i}}{\partial \ddot{p}_{i}^{C}}\left(E R_{i}^{C} d p_{i}^{C}+p_{i}^{C} d E R_{i}^{C}\right)+\frac{\partial q_{i}}{\partial Y_{i}} d Y_{i}\right)+\frac{\partial M C(\cdot)}{\partial W} d W}{M C(\cdot)} \\
& +\frac{\frac{\partial \ln \eta_{i}(\cdot)}{\partial \ln \ddot{p}_{i}}}{\left(-\eta_{i}(\cdot)+1\right)} *\left(\frac{d p_{i}}{p_{i}}+\frac{d E R_{i}}{E R_{i}}\right)+\frac{\frac{\partial \ln \eta_{i}(\cdot)}{\partial \ln \ddot{p}_{i}^{C}}}{\left(-\eta_{i}(\cdot)+1\right)} *\left(\frac{d p_{i}^{C}}{p_{i}^{C}}+\frac{d E R_{i}^{C}}{E R_{i}^{C}}\right)+\frac{\frac{\partial \ln \eta_{i}(\cdot)}{\partial \ln Y_{i}}}{\left(-\eta_{i}(\cdot)+1\right)} * \frac{d Y_{i}}{Y_{i}}
\end{aligned}
$$

where $\ddot{p}_{i}=E R_{i} p_{i}$ and $\ddot{p}_{i}^{C}=E R_{i}^{C} p_{i}^{C}$ denote the firm's and the competitor's export prices respectively in the destination country's currency. On the right hand side of the equation, the numerator of the first fraction depicts how the marginal cost changes through changes in the determinants. In total, the fraction shows the relative change of the marginal cost when the considered determinants change. In contrast, the next fractions depict in sum the relative change of the markup and illustrate how relative changes in particular determinants affect the markup and therefore the export price. However, in equation (4.3) the relative export price change still appears on the right hand side. Solving for the relative price change, simplifying the first fraction and introducing symbols for the coefficients yields:

$$
\frac{d p_{i}}{p_{i}}=\left(1+\beta_{i}\right) \frac{d M C}{M C}+\beta_{i} \frac{d E R_{i}}{E R_{i}}+\delta_{i}\left(\frac{d p_{i}^{C}}{p_{i}^{C}}+\frac{d E R_{i}^{C}}{E R_{i}^{C}}\right)+\omega_{i} \frac{d Y_{i}}{Y_{i}}
$$

where

$$
\begin{gathered}
\beta_{i}=\frac{\frac{\partial \ln \eta_{i}}{\partial \ln \ddot{p}_{i}}}{\left(-\eta_{i}+1\right)-\frac{\partial \ln \eta_{i}}{\partial \ln \ddot{p}_{i}}} \\
\delta_{i}=\frac{\frac{\partial \ln \eta_{i}}{\partial \ln \ddot{p}_{i}^{C}}}{\left(-\eta_{i}+1\right)-\frac{\partial \ln \eta_{i}}{\partial \ln \ddot{p}_{i}}} \\
\omega_{i}=\frac{\frac{\partial \ln \eta_{i}}{\partial \ln y_{i}}}{\left(-\eta_{i}+1\right)-\frac{\partial \ln \eta_{i}}{\partial \ln \ddot{p}_{i}}}
\end{gathered}
$$

Equation (4.4) represents an extension of the theoretical PTM equation KNETTER (1995) derived and tried to estimate ${ }^{8}$. The difference is that the derivation of KNETTER (1995) just leads to the first half of equation (4.4), i.e. the influence of the firm's marginal cost and exchange rate on the export price. In this part, equation (4.4) - including the coefficient from (4.5) - is identical to his results.

\footnotetext{
${ }^{8}$ For the complete derivation of the theoretical model see Appendix 4.1.
} 
The important insight given by equation (4.4) is that the five determinants affect the firm's export prices through three channels or coefficients. These coefficients explain the influence of the determinants on the residual demand elasticity and therefore the influence on the markup. For all coefficients, the denominator in the fraction is the same (equation (4.5) to (4.7)). We can usually expect this denominator to be negative: The residual demand elasticity itself cannot be smaller than one when profits are maximized - this holds independent of the market structure. Additionally, the second term - i.e. the elasticity of the "residual demand elasticity" with respect to the firm's export price in the destination country's currency $\left(\ddot{p}_{i}\right)$ - should usually be positive. This implies that the residual demand elasticity should increase with the price level and result in a residual demand curve which is less convex than the constant elasticity form. While this may be plausible - but not necessarily - for a market demand curve, it is clearly evident in the case of a residual demand curve. When the firm's price level changes, this creates a difference between its price and the competitor's price.

Given that the elasticity of the "residual demand elasticity" with respect to $\ddot{p}_{i}$ is positive, the PTM coefficient $\beta_{i}$ is negative and lies between zero and minus one ${ }^{9}$. The more the residual demand curve differs from the constant elasticity form, the higher the absolute value of the PTM coefficient. As already revealed by KNETTER (1995), the coefficient $\beta_{i}$ applies for changes in both the firm's marginal cost and the exchange rate - net of the effect an exchange rate change has on the marginal cost - since they influence $\ddot{p}_{i}$ in the same way. In equation (4.4) the influence of marginal cost and exchange rates on the export prices differs by one because price changes are measured in the export country's currency. Equation (4.4) reveals that this symmetry of the influences also holds for changes in the competitor's price and the competitor's exchange rate.

In contrast to $\beta_{i}$, the coefficient $\delta_{i}$ can be expected to be positive since the numerator in (4.6) - i.e. the elasticity of the "residual demand elasticity" with respect to the competitor's export price in the destination country's currency $\left(\ddot{p}_{i}^{C}\right)$ - is certainly negative. This means that when the competitor's price has any influence on the firm's residual demand elasticity, then a higher price will reduce it and allow a higher markup. In essence, $\delta_{i}$ can be viewed as an indication of the degree of product differentiation. When the market demand curve is not more convex than the constant elasticity form, $\delta_{i}$ can be ex-

\footnotetext{
${ }^{9}$ KNETTER (1995) also mentions the case of (residual) demand curves that are more convex than the constant elasticity form and imply positive PTM coefficients. However, this seems to be a rather theoretical consideration. The bulk of literature focuses on negative coefficients that lead to local-currency price stability (KNETTER 1993).
} 
pected to lie between zero and $\left|\beta_{i}\right|$. A value of zero means that either there is no common market (i.e. each of the firms has its own fully segmented market in the destination country) or the residual demand elasticity is already infinity (i.e. perfect competition takes place). In the case of perfect competition, the competitor's price influences the firm's price only via changes in the marginal cost. The other side of the range is a value of $\left|\beta_{i}\right|$ for $\delta_{i}$. In order to understand why this is the case, it is useful to consider the relation between $\beta_{i}$ and $\delta_{i}$ at first. They both depict changes in the residual demand elasticity when the respective price changes. When they are summed up, the result tells us how the residual demand elasticity changes, when the price of both firms changes to the same percentage. Since the price relation remains constant, this change in the residual demand elasticity must be due to a change in the market demand characteristics. This implies that the sum of the coefficients describes the convexity of the market demand curve, whereas $\beta_{i}$ describes the convexity of the residual demand curve. The knowledge of $\delta_{i}$ therefore enables us to unravel whether PTM comes from the shape of the market demand curve or from the market structure. However, when it is assumed that the market demand curve is not more convex than the constant elasticity form, $\delta_{i}$ cannot be larger than the absolute value of $\beta_{i}$. If the coefficients are exactly equal, the effects on the residual demand elasticity are mutually balanced out and the market demand curve therefore has to have a constant elasticity shape.

The third coefficient $\omega_{i}$ can be expected to be positive because the numerator in (4.7) i.e. the elasticity of the "residual demand elasticity" with respect to income in the destination country - is probably negative. This is because the Engel curve predicts that the income elasticity will decrease with an increase in the income. Since demand functions are homogenous of degree zero with respect to prices and income, this also leads to a smaller absolute value of the demand elasticity. Therefore, the effect which is measured by $\omega_{i}$ could be called "Engel effect". However, it could be questioned whether or not this effect is large enough in order to be detected empirically. In actuality, the PTM model proposed by KNETTER $(1989 ; 1993 ; 1995)$ is periodically expanded with an income variable (e.g. KNETTER 1997b) but its coefficient is almost never significant.

An important disadvantage of equation (4.4) is that it is empirically not estimable - at least not without a bias ${ }^{10}$. This is because when the competitor follows a similar function to (4.4), its price is no longer exogenous in (4.4). In order to avoid this endogeneity

${ }^{10}$ GIL-PAREJA (2003) includes a competitor price index in the model but without considering a possibly arising endogeneity bias. 
problem, equation (4.4) must also be considered for the competing firm. Solving the resulting system of equations again for relative export price change of the firm under consideration yields:

$$
\frac{d p_{i}}{p_{i}}=\left(1+\frac{\left(\beta_{i}+\delta_{i} \delta_{i}^{C}\right)}{\left(1-\delta_{i} \delta_{i}^{C}\right)}\right) \frac{d M C}{M C}+\frac{\left(\beta_{i}+\delta_{i} \delta_{i}^{C}\right)}{\left(1-\delta_{i} \delta_{i}^{C}\right)} \frac{d E R_{i}}{E R_{i}}+\frac{\delta_{i}\left(1+\beta_{i}^{C}\right)}{\left(1-\delta_{i} \delta_{i}^{C}\right)}\left(\frac{d M C^{C}}{M C^{C}}+\frac{d E R_{i}^{C}}{E R_{i}^{C}}\right)+\frac{\left(\omega_{i}+\delta_{i} \omega_{i}^{C}\right)}{\left(1-\delta_{i} \delta_{i}^{C}\right)} \frac{d Y_{i}}{Y_{i}}
$$

where the subscript $\mathrm{C}$ indicates that the respective variable or coefficient belongs to the competing firm. Introducing symbols for the newly composed coefficients simplifies equation (4.8) to:

$$
\frac{d p_{i}}{p_{i}}=\left(1+\tau_{i}\right) \frac{d M C}{M C}+\tau_{i} \frac{d E R_{i}}{E R_{i}}+\varphi_{i}\left(\frac{d M C^{C}}{M C^{C}}+\frac{d E R_{i}^{C}}{E R_{i}^{C}}\right)+\varpi_{i} \frac{d Y_{i}}{Y_{i}}
$$

Equation (4.8) illuminates how the coefficients in equation (4.4) change, when the competitor's reactions are already accounted for; instead of the competitor's price, its marginal cost appears in the equation. When $\delta_{i}$ is zero in (4.8), the equation simplifies to the short version of equation (4.4) which KNETTER (1995) already derived (plus the income term). In general, larger values of the coefficients $\delta_{i}$ and $\delta_{i}^{C}$ lead to smaller absolute values of the coefficient $\tau_{i}$ in comparison to the absolute value of $\beta_{i}$. This is evident because the larger $\delta_{i}^{C}$ is, the more the competitor reacts to the firm's price changes and the larger $\delta_{i}$ is, the more the firm reacts in turn to the adjusted price of the competitor. For the influence of the competitor's marginal cost and exchange rate, two effects are important. Firstly, the extent of its own PTM coefficient $\beta_{i}^{C}$ and secondly, the magnitude by which its price influences the firm's price via the optimal markup - i.e. $\delta_{i}$. Furthermore, the coefficient $\varpi_{i}$ contains a direct effect that income changes have on the price of the firm and an indirect effect via its effect on competitor price.

\subsection{Empirical specification}

\subsubsection{The oligopolistic PTM model}

Equation (4.9) constitutes the framework for an econometric time series model in first differences that explains export price changes to a certain destination country:

$$
\Delta \ln p_{t}=\alpha+\zeta \Delta \ln M C_{t}+\tau \Delta \ln E R_{t}+\psi \Delta \ln M C_{t}^{C}+\varphi \Delta \ln E R_{t}^{C}+\varpi \Delta \ln Y_{t}+u_{t}
$$

where $\alpha$ is a constant, $p_{t}$ is the firm's export price for the destination country in period $\mathrm{t}$ measured by destination-specific export unit values (in the export country's currency), $M C_{t}$ is the firm's marginal cost (in the export country's currency), $E R_{t}$ is the real bilateral exchange rate (destination market currency per unit of the exporter's currency), 
$M C_{t}^{C}$ is the competitor's marginal cost (in the competitor country's currency), $E R_{t}^{C}$ is the real bilateral competitor exchange rate (destination market currency per unit of the competitor's currency), $Y_{t}$ is the real income in the destination country (measured by the real GDP) and $u_{t}$ is the error term for which the usual assumptions apply.

If the focus is turned to the investigated product as a whole, rather than individual destination countries, equation (4.10) can be estimated in a non-destination-specific manner. This requires only a slightly different definition of the variables so that $p_{t}$ is the firm's overall export price (non-destination-specific unit values are used), $E R_{t}$ is the effective exchange rate (i.e. the exchange rate is a weighted average of those of the major destination countries) and $Y_{t}$ is the weighted average GDP. In this case, the weights for the exchange rates and the GDP are the respective export shares. This procedure could be a first step before analyzing single destinations countries, when PTM is found to be an overall phenomenon in a certain product market.

The estimation of the non-destination-specific version of equation (4.10) has an important advantage but also a possible disadvantage. The advantage is that false detection of PTM due to quality changes in the underlying trade flow of the unit value (LAVOIE \& LIU 2007) should be rather unlikely. Marked quality changes in the production would require exporters to have a high degree of flexibility. Conversely, the disadvantage is that there could be an endogeneity bias in the non-destination-specific model. As the first fraction in equation (4.3) already shows, the marginal cost depends on the prices that the firm charges in the destination countries. When prices are increased, the quantity demanded decreases and the marginal cost decreases too, when it is a function of quantity. The marginal cost can therefore be classed as endogenous and the resulting endogeneity bias tends in the direction of a finding of PTM through the marginal cost coefficient. The severity of the bias depends on several characteristics of the market analyzed such as the value of the residual demand elasticity, the share of the exports for which the price applies and the elasticity of the marginal cost with respect to quantity. However, when the model is estimated for single destinations whose imports hardly influence the marginal cost, a possible endogeneity bias should be negligible. Even if this were not the case, the PTM model proposed by KNETTER (1989; 1993) basically faces the same problem despite using time dummies to control for the marginal cost.

Regardless of the model version, under the conditions of perfect competition, $\zeta$ would equal one and all other coefficients would be zero; this means that the firm's price is 
fully explained by its marginal cost. The same result would apply under imperfect competition and a constant residual demand elasticity. Similar to KNETTER (1993; 1995), it is not possible to distinguish between these two cases with the approach presented here. In contrast, when the absolute value of the residual demand elasticity increases due to a rise in the firm's price, $\zeta<1$ and $\tau<0$ would apply, whereby the effects should be equal so that $(\zeta-1)=\tau$ (first symmetry condition). Additionally, when the residual demand elasticity is influenced by the competitor price, $\psi$ and $\varphi$ should be significantly positive and equal according to theory (second symmetry condition). The relation between $\zeta$ and $\tau$ as well as between $\psi$ and $\varphi$ reveals whether PTM occurs primarily due to the market structure (i.e. the existence of the competitor) or due to the convexity of the market demand curve. If PTM occurs solely due to the market structure, $\tau$ and $\varphi$ should sum up to zero (and $\zeta$ and $\psi$ should sum up to one). The smaller the absolute value of $\varphi$ in comparison to $\tau$, the more the convexity of the market demand curve causes PTM.

Due to the fact that the theoretical coefficients $\beta_{i}, \delta_{i}$ and $\omega_{i}$ reveal the pure effects which were illuminated in Chapter 4.2 , they are of more interest. There are different ways that allow the identification of these coefficients. When a complete price series is available for the competitor too, equation (4.10) can simply be estimated for both firms. In this case, $\delta_{i}$ can be obtained via the division of $\psi_{i}$ from the firm's equation by $\zeta_{i}^{C}$ from the competitor's equation or via a division of $\varphi_{i}$ by $\left(1+\tau_{i}^{C}\right)$. When a complete price series is not available for the competitor, the theoretical coefficients can only be identified when it is assumed that the coefficients of the firms are equal. In this case, $\delta_{i}$ can be obtained via the division of $\psi_{i}$ by $\zeta_{i}$ or similarly $\varphi_{i}$ by $\left(1+\tau_{i}\right)$. With regard to the PTM coefficients, this assumption implies that the firms are facing residual demand curves with the same curvature in the destination country. It is unclear how critical this assumption actually is. At least with respect to $\delta_{i}$, equal coefficients do not seem to be very critical since they are a measure of the degree of product differentiation. This implies that equal $\beta_{i}$ coefficients could be an uncritical assumption too, at least in the case when PTM takes place only due to the market structure - that is, $\left|\beta_{i}\right|$ equals $\delta_{i}$.

When the empirical data reveals that in a certain market, the competitor's marginal cost and exchange rate have an influence on the firm's price, the model proposed by KNETTER $(1993$; 1995) which does not consider these variables suffers an omitted variable bias - the marginal cost and exchange rate of the competitor are omitted but correlated with those of the firm. Furthermore, the model estimates $\tau$ instead of $\beta$. 
A final modification of equation (4.10) is appropriate when contracts play a role in the respective market. On markets for agricultural commodities, contracts are common especially on the dairy markets which can have contracts of up to nine months in length. Contracts basically create time periods of various lengths between price setting and delivering of the products. Their usage implies that the export unit value reflects prices negotiated in different time periods - the present as well as the past. In order to incorporate this into the model, a number of lags of the right hand side variables in (4.10) can be introduced. According to MARSTON (1990: 226), in this case the coefficients are generally a product of two effects. That is, the share of the exported quantity subject to price-setting lag-length $\mathrm{j}\left(s_{j}\right)$ multiplied with the respective coefficient for this laglength (e.g. $\zeta_{j}$ for the coefficient of the marginal cost). Summing up the contemporaneous as well as lagged coefficients yields the weighted average influence of the variable over all contract lengths - that is $\zeta=\sum_{j=0} s_{j} \zeta_{j}$ for the marginal cost; obviously, $s_{j}$ represents the weight and has to sum up to one over all lags. This procedure could also help to correct the influence of a pricing currency other than the exporter's currency ${ }^{11}$. When PTM is only caused by pricing in a different currency in conjunction with price rigidity, this effect should be corrected in the following periods.

\subsubsection{Estimation of the marginal cost}

When estimating equation (4.10), the problem arises that the marginal cost is not observable, at least not directly. The common practice of using cost indices as proxy variables is criticized by GOLDBERG \& KNETTER (1997: 1251) since this procedure can be expected to introduce a bias in the estimation. KNETTER $(1989 ; 1993)$ therefore uses the fixed country effects of a panel model as a measure of the marginal cost and is thus able to control for it. However, this approach is not applicable to (4.10) since the marginal cost of the competitor appears in the equation too. Furthermore, in Chapter 3 we show that when the first symmetry condition - which is already proposed by KNETTER (1995) - holds, the estimated PTM coefficients are biased toward the average PTM coefficient in the sample. This is because the marginal cost may be equal for all destination countries at the port of export; the influence of the marginal cost on prices is not equal ${ }^{12}$, but depends on the degree of PTM. The severity of this bias depends heavily on firm, prod-

\footnotetext{
${ }^{11}$ Pricing in a foreign currency together with price rigidity is a known source of falsely detected PTM.

12 KNETTER (1995) is aware of the destination-specific influence of the marginal cost that the symmetry condition implies, although he does not show the theoretical implications for the estimation of the model. Instead, KNETTER (1995) proposed a non-linear model of PTM that is based on the symmetry condition. However, this model has some disadvantages and is actually not followed up in the literature.
} 
uct and market characteristics as well as on sample selection. An infelicitously chosen sample can also introduce a huge amount of noise in the fixed effects. SAGHAIAN \& REED (2004) also criticize the usage of fixed effects since they find strong multicollinearity between the fixed effects and the exchange rates. Instead, they use wholesale prices in the exporting countries. However, the main problems with this procedure are a) such series have to exist and b) in order to be a good measure of the marginal cost they should be uninfluenced by market power. We propose an alternative measure of the marginal cost that is independent of sample selection and market power and is always available when a certain number of destination-specific unit values are available too.

The advantage of the availability of destination-specific export unit values is that they give a lot of information regarding a number of agreements of sale. In each period, there are unit values which contain various levels of markups or quality premiums and there are probably unit values which reflect more or less the marginal cost at the port of export. Furthermore, unit values contain measurement errors as well as expectations about future developments, when they - at least in part - consist of batches whose prices are arranged in long- or medium-term contracts. Essentially, the fixed effects of the Knetter model just take the average of the unit values of the sample in a given period while simultaneously correcting them for the estimated PTM. However, the underlying sample is often small and particular unit value series exhibit a high variation.

The alternative to this procedure that preserves the basic idea of KNETTER (1989; 1993; 1995 ) - that is, the usage of multiple transactions to estimate a measure of the marginal cost - would be a) to use all unit values available for a given period and b) not to apply a simple average with an artificial correction for the estimated PTM. Instead, the factors moving unit values away from the marginal cost can be expected to exhibit certain distributions. When these distributions can be estimated, an estimation of the marginal cost would be available too. This requires some basic distribution assumptions:

1. Measurement error and expectation effects

Both are assumed to be independently normally distributed with a mean of zero. This means that the sum of these effects should be normally distributed as well.

2. Markups and quality premiums

Both effects are assumed to reflect positive deviations from the marginal cost. This implies that the firm does not practice dumping and charges at least marginal cost. Since higher markups should not be as likely as smaller ones, a possible distribution for these effects could be a truncated normal distribution. 
Under these assumptions, the i-th observation for an export unit value (in the export country's currency) can be described as follows:

$$
p_{i t}=\theta_{t}+v_{i t}+u_{i t}
$$

where $\theta_{t}$ is a time specific constant and $v_{i t}+u_{i t}$ represents a composed error term. For the error components we assume:

$$
\begin{aligned}
& v_{i t} \sim \operatorname{iid\mathrm {N}}\left(0, \sigma_{v_{t}}^{2}\right) \\
& u_{i t} \sim \operatorname{iid\mathrm {N}^{+}}\left(\mu_{t}, \sigma_{u_{t}}^{2}\right)
\end{aligned}
$$

where $v_{i t}$ and $u_{i t}$ are moreover assumed to be independently distributed (KUMBHAKAR $\&$ LOVELL 2003: 169). The error component $v_{i t}$ displays measurement errors and expectation effects (see assumption 1) whereas $u_{i t}$ represents markups and quality premiums (see assumption 2). According to assumption 2, a truncated normal distribution (that is very flexible) is chosen for $u_{i t}$.

The model displayed in (4.11) is a stochastic frontier model without further explanatory variables. We can therefore call the fitted values of the model - i.e. $\theta_{t}-$ the stochastic lower price frontier (SLPF). When the distribution assumptions are fulfilled, the SLPF equals an unbiased estimation of the marginal cost that is hereafter called the "stochastic" marginal cost (SMC). The most critical point in this regard concerns the distribution of $u_{i t}$. If a certain unknown minimum markup exists, the normal distribution of $u_{i t}$ is not truncated at zero but instead at an unknown positive value. This implies that the SLPF lies above the true marginal cost. Since we cannot rule out such a case, one should be cautious to use the SLPF as an absolute measure of the marginal cost for the purpose of comparisons with price series. For the usage in the PTM model, the case is different. The question would be rather whether the SMC series is biased in a way that biases the coefficients of the model. If a possible minimum markup is constant over time, the coefficients in equation (4.10) are not biased. Similarly, a random fluctuation of this minimum markup over time would not bias the coefficients but create a larger standard error. If, however, this minimum markup is a function of the price level, the coefficient of the marginal cost could indeed be biased. The probable direction of this bias would be positive - i.e. against finding of PTM through the marginal cost coefficient. This is due to the fact that the certain minimum markup can be expected to be lower in case of a higher price level. It is further worth mentioning that the distribution assumptions imply that the analyzed good is homogenous in the sense that a certain standard quality with the possibility of quality premiums should exist. However, when 
the good is too heterogeneous and there is nothing even like a standard quality, then the approach could be invalid.

Given the distribution assumptions, equation (4.11) can be estimated via maximum likelihood. It can be estimated with cross sectional data $(\mathrm{T}=1)$ as well as (unbalanced) panel data ( $\mathrm{T}>1$ ). However, according to (4.12) and (4.13) it is assumed that $\sigma_{\nu}^{2}, \mu$ and $\sigma_{u}^{2}$ depend on $\mathrm{t}$. This implies that only the estimation with cross sectional data is valid because in the case of panel data, the parameters are estimated independently of t. Of course, when the parameters do not depend on $t$, the usage of panel data is possible too. However, in this case the SLPF series lies a constant value below the simple time specific mean series of the original data. This does not represent an improvement in comparison to the usage of the simple time specific mean as a measure of the marginal cost. Only the variability of parameters with respect to $t$ allows temporally non-constant deviations from the simple mean. The parameters can vary for different reasons: With regard to $v_{i t}$, it is conceivable that the measurement error is temporally constant but the expectation effects are probably not. For periods with rather unstable prices, they should be more important than otherwise. Similarly, the distribution parameters of $u_{i t}$ can change - for example, in the case of higher prices only smaller markups are optimal.

In summary, only an estimation of (4.11) with cross sectional data should be valid. However, this causes a disadvantage with regard to the efficiency of estimation: The observations for a single period (e.g. a month) are usually rather limited and the true parameters $\sigma_{v_{t}}^{2}, \mu_{t}$ and $\sigma_{u_{t}}^{2}$ may only change significantly with an increasing time interval. Under these circumstances, the estimation efficiency could be raised by expanding the period specific sample - for example, through the two temporally adjacent periods. This means that equation (4.11) is estimated as a panel model with $\mathrm{T}=3$ in a rolling window over the whole time span. As long as the true parameters are constant over the subsequent three time periods, this procedure triples the available observations and raises the estimation efficiency. Essentially, the choice of the value for $\mathrm{T}$ is a tradeoff between estimation efficiency and the most temporally flexible estimation. 


\subsection{Data}

For the empirical application of the model, the most important dairy products in terms of international trade are chosen which account for the majority of New Zealand's dairy exports. These products are skimmed milk powder (SMP, HS 040210), whole milk powder (WMP, HS 040221), butter (HS 040510) and cheddar cheese (HS 0406900011). Although three out of four are just on the 6-digit level, all of them reveal a high degree of homogeneity and can therefore be referred to as commodities. The destinationspecific unit values (export value divided by export quantity) of WMP are obtained from the Global Trade Atlas (GTA 2013) and are available from 1990 to 2012. The analyzed destination countries are chosen according to the completeness of the unit value series, having sufficiently high and continuous trade quantities and a sufficiently high variation of the exchange rate series.

As a competitor to New Zealand, the European Union (EU) is considered. Historically New Zealand and the EU (as well as Australia to a lesser extent) were the only important export countries in the international dairy market. Since the last decade, other countries such as the U.S. and Argentina have started to play an increasingly important role on the international dairy markets. Because cheddar is less important for the EU's exports, an aggregate consisting of Gouda, edam and cheddar (HS 04069021, HS 04069023, HS 04069078) is considered as a competing product for New Zealand.

The data frequency is monthly for the estimation of the SMC series, as this implies the least possible aggregation of price information. In contrast, for the estimation of equation (4.10), quarterly data is used. This is due to three different reasons: Firstly, calculating unit values on a quarterly basis reduces the influence of measurement errors, temporally varying qualities and the appearance of missing values. Secondly, quarterly data raises the chance that a possible adjustment process is finished to a higher degree than in the case of a monthly frequency. This argument is less valid when lags are included in the model but, nevertheless, for this reason it remains a commonly used frequency for PTM studies. Thirdly, consumer price indices (CPI) and real gross domestic products (GDP) are not available for frequencies higher than quarterly.

Bilateral exchange rates, CPIs and GDPs are obtained from the International Financial Statistics of the International Monetary Fund (IMF). Bilateral exchange rates and unit values of the EU before 1999 are based on the ECU as the predecessor of the Euro. The CPIs are used to correct the bilateral exchange rates for the destination country's price 
level. For the construction of the effective exchange rates, the bilateral exchange rates of the fifty most important destination countries (with exchange rates available) for the respective product are used; the countries' share of New Zealand's exports serves as weight in the calculation. It is assumed that the considered destination countries cover $100 \%$ of the exports, although this is only an approximation.

\subsection{Estimation results}

\subsubsection{Stochastic marginal cost}

The destination-specific unit values that are on average available per month lie between 41 and 110 whereas for the EU, the numbers are somewhat larger (Table 4.1). These observations reveal a fairly high variation with single observations far away from the average. As a result, an outlier correction was seen to be appropriate. In the first step, we excluded all observations which are based on less than a certain minimum quantity (Table 4.1). Furthermore, in the second step we excluded all observations that lay more than five standard deviations apart from the mean. This procedure reduces the number of observations available by $17 \%$ to $40 \%$; however, in all cases, this percentage belongs to less than $1 \%$ of the quantity exported.

Table 4.1: Sample characteristics and SMC estimation results ${ }^{13}$

\begin{tabular}{|c|c|c|c|c|c|c|c|c|c|c|c|}
\hline \multirow{3}{*}{$\begin{array}{l}\text { export } \\
\text { country }\end{array}$} & \multirow{3}{*}{ product } & \multirow{3}{*}{$\begin{array}{c}\text { observa- } \\
\text { tions per } \\
\text { month }\end{array}$} & \multicolumn{3}{|c|}{ outlier correction } & \multirow{2}{*}{\multicolumn{3}{|c|}{$\begin{array}{c}\text { distrubution } \\
\text { parameters }\end{array}$}} & \multicolumn{3}{|c|}{ average values } \\
\hline & & & \multirow{2}{*}{$\begin{array}{c}\text { min. } \\
\text { quant. }\end{array}$} & \multicolumn{2}{|c|}{ observ. used } & & & & \multirow{2}{*}{ SMC } & \multirow{2}{*}{$\begin{array}{c}\text { unit } \\
\text { values }\end{array}$} & \multirow{2}{*}{$\begin{array}{l}\text { UV sur- } \\
\text { charge }\end{array}$} \\
\hline & & & & abs. & $\%$ & $\gamma$ & $\mu$ & $\mathbf{s V}_{\mathrm{u}}$ & & & \\
\hline \multirow{4}{*}{$\begin{array}{c}\text { New } \\
\text { Zealand }\end{array}$} & SMP & 41.3 & 10 & 33.0 & $80 \%$ & 0.63 & -278 & $53 \%$ & 3096 NZ\$ & $3365 \mathrm{NZ \$}$ & $8 \%$ \\
\hline & WMP & 59.4 & 10 & 49.5 & $83 \%$ & 0.79 & -300 & $68 \%$ & 3121 NZ\$ & $3490 \mathrm{NZ \$}$ & $11 \%$ \\
\hline & Butter & 58.8 & 10 & 48.6 & $83 \%$ & 0.88 & -253 & $78 \%$ & $2780 \mathrm{NZ \$}$ & $3307 \mathrm{NZ \$}$ & $17 \%$ \\
\hline & Cheese & 53.0 & 5 & 38.8 & $73 \%$ & 0.81 & -623 & $68 \%$ & 3453 NZ\$ & 4048 NZ\$ & $16 \%$ \\
\hline \multirow{4}{*}{$\mathbf{E U}$} & SMP & 74.6 & 10 & 53.2 & $71 \%$ & 0.82 & -375 & $69 \%$ & $1598 €$ & $1859 €$ & $14 \%$ \\
\hline & WMP & 110.3 & 10 & 91.8 & $83 \%$ & 0.86 & -124 & $75 \%$ & $1879 €$ & $2309 €$ & $20 \%$ \\
\hline & Butter & 109.3 & 10 & 65.3 & $60 \%$ & 0.88 & -187 & $77 \%$ & $1843 €$ & $2215 €$ & $17 \%$ \\
\hline & Cheese & 99.6 & 5 & 59.9 & $60 \%$ & 0.89 & -26 & $81 \%$ & $2286 €$ & $2823 €$ & $20 \%$ \\
\hline
\end{tabular}

Source: Own calculations, GTA (2013)

The stochastic frontier estimation was done with cross sectional data at first. The results revealed that the distribution parameters vary a lot over time. However, they also follow autoregressive processes (AR), i.e. the larger the temporal distance is the more similar the distribution parameters are. We therefore decided to estimate the SMC series in a rolling window procedure with $\mathrm{T}=3$. As an example, the resulting time series for WMP is displayed in Figure 4.1 (all others are displayed in Appendix 4.2 and 4.3).

\footnotetext{
${ }^{13}$ The UV surcharge depicts the difference of unit value and SMC in relation to the unit value as average for the whole observation period. The UV surcharge can consist of a markup as well as quality premiums.
} 


\section{Figure 4.1: WMP unit values and the SMC series for New Zealand}

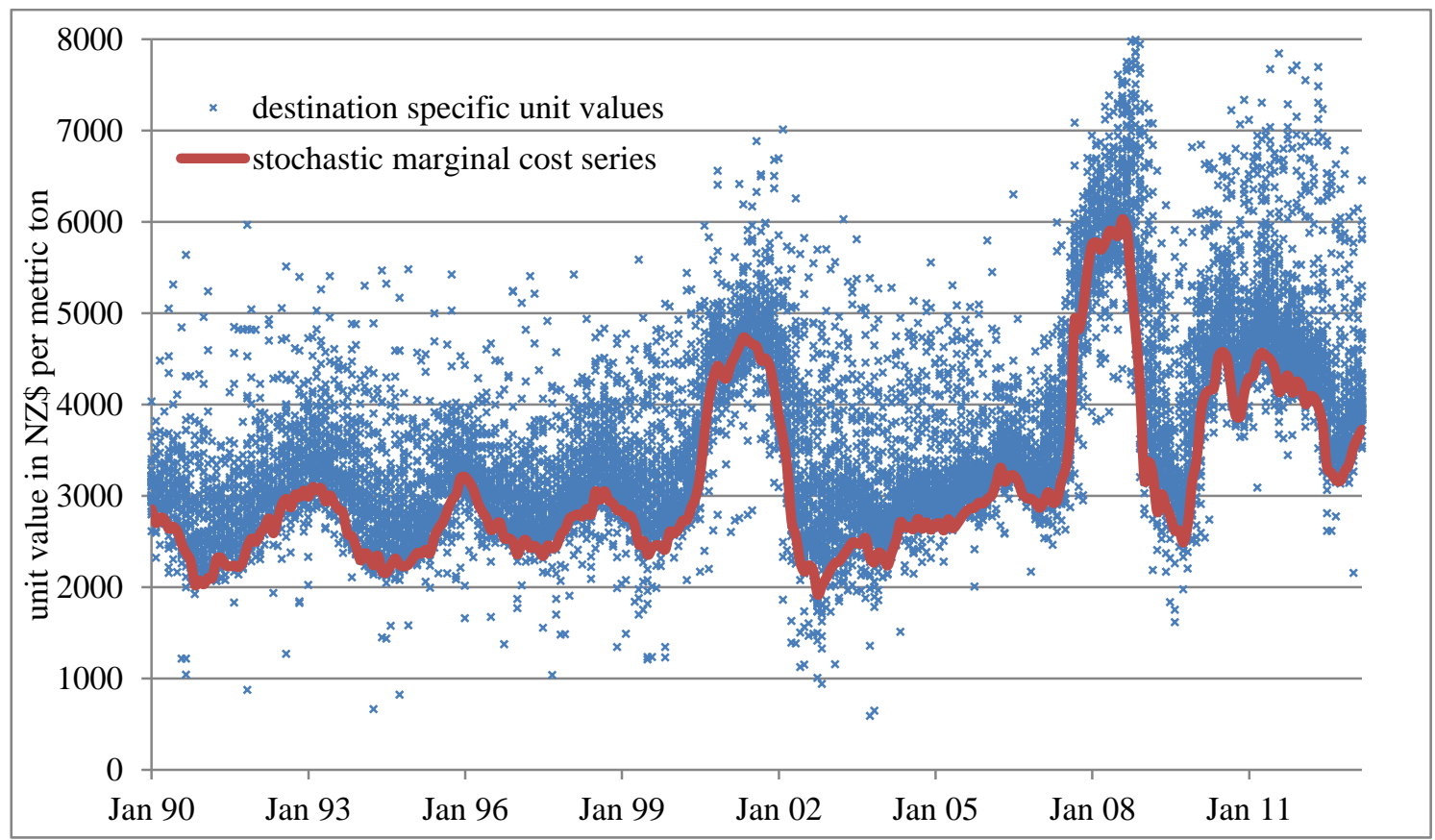

Source: Own compilation, GTA (2013)

Intuitively, the SMC series in Figure 4.1 lies on the lower edge of the area with the highest density of destination-specific unit value observations. In Table 4.1, the average distribution parameters from the stochastic frontier estimations of the SMC series are displayed, where $\gamma=\frac{\sigma_{u}^{2}}{\sigma_{v}^{2}+\sigma_{u}^{2}}$. However, since $\sigma_{u}^{2}$ is the variance parameter of a truncated normal distribution, it does not represent the actual variance of the error component $u_{i t}$. Therefore, $\gamma$ does not represent the share of the variance of $u$ in the total variance. Instead, this information is given by $\mathrm{sV}_{\mathrm{u}}$ in Table 4.1 . On average, around $70 \%$ of the total variance is due to markups and quality premiums $\left(u_{i t}\right)$, while only a small part is due to measurement errors and expectation effects $\left(v_{i t}\right)$. Table 4.1 shows that larger values of $\mathrm{sV}_{\mathrm{u}}$ go along with larger average surcharges of the non-destination-specific unit values on the SMC (UV surcharges) - at least roughly speaking. Furthermore, for each product the UV surcharge is larger for the EU than for New Zealand. This is not necessarily a sign for higher markups in the EU; it could also be attributed to more product heterogeneity because of a larger number of exporting firms.

\subsubsection{Oligopolistic PTM model}

The results presented in this chapter are based on estimating equation (4.10) in first logdifferences. We also tried to estimate (4.10) in log-levels but most of the time series exhibit a unit root and are typically not co-integrated. This result could be expected for various reasons. One reason is that the unit value series could be based on changing 
average qualities of the quantities traded over time. As the trade statistics do not contain information about quality, it cannot be controlled for quality changes in the model. It can only be hoped that possible quality changes are not correlated with the descriptive variables in the model (see LAVOIE \& LIU (2007) for possible problems in this regard). A second reason is that the export firm can change its destination-specific markup for reasons that are not represented in equation (4.10). Such reasons are often not observable and therefore cannot be modeled; they could include the appearance or disappearance of competitors, a changing competition strategy or changing trade cost - FEENSTRA (1989) shows that tariffs have the same influence on markups as exchange rates. These considerations make it seem implausible that the residuals of an estimation of (4.10) in levels are stationary. We tested all estimated models in first log-differences for heteroscedasticity (Breusch-Pagan test), autocorrelation (Breusch-Godfrey test) and parameter stability (CUSUM test). While parameter stability is almost always unproblematic, the other factors are not. Therefore a heteroskedastic and autocorrelation consistent (HAC) estimator of the standard errors is used. The number of lags is chosen according to the minimum of the usual information criteria; when the result is ambiguous, the higher number of lags is chosen.

Table 4.2 shows the results of the non-destination-specific estimation of equation (4.10). For each product, we estimated the model without lags and with the optimal lag number. The optimal lag numbers reveal that price corrections and contracts take place up to three (or in one case four) quarters. The explained variance is - even without lags - quite high and increases with the introduction of lags are only moderate. An exception is butter, for which the R-squared is much lower than for the other products.

The significant coefficients in Table 4.2 have, in all cases, the correct $\operatorname{sign}^{14}$ that is predicted by theory and change only slightly with the introduction of lags. The introduction of lags leads to the rejection of PTM behavior only in the case of SMP. This implies that $85 \%$ of the price changes can be explained with contemporaneous and lagged changes in the marginal cost. In actuality, this result is not surprising when PTM is seen as an indication of market power. Firstly, New Zealand has a lower world market share for SMP than for the other products; secondly, unlike the other products, SMP is more homogenous and intended more for industrial use than for the consumer; thirdly, Table 4.1 already shows that the UV surcharge is smaller than for the other products.

\footnotetext{
${ }^{14}$ Note that instead of $\zeta$ the displayed values and t-statistics in Table 4.2 belong to $\zeta-1$. This is because when a test has to be done for PTM with regard to marginal cost, $\zeta$ should be tested against one.
} 
Table 4.2: Estimation results of equation (4.10) as non-destination-specific version

\begin{tabular}{|c|c|c|c|c|c|c|c|c|c|c|c|}
\hline Product & 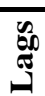 & $\sum \zeta-1$ & $\sum \tau$ & $\begin{array}{l}\text { test for } \\
\text { symmetry }\end{array}$ & $\sum \psi$ & $\sum \varphi$ & $\begin{array}{c}\text { test for } \\
\text { symmetry }\end{array}$ & $\sum \boldsymbol{\sigma}$ & $\mathbf{R}^{2}$ & $\beta$ & $\delta$ \\
\hline \multirow[b]{2}{*}{ SMP } & 0 & $\begin{array}{c}-0.23^{\text {*** }} \\
(-4.96)\end{array}$ & $\begin{array}{c}-0.27^{* * *} \\
(-2.24)\end{array}$ & $\begin{array}{c}0.10 \\
{[0.75]}\end{array}$ & $\begin{array}{c}-0.09 \\
(-0.88)\end{array}$ & $\begin{array}{c}-0.02 \\
(-0.11)\end{array}$ & $\begin{array}{c}0.11 \\
{[0.74]}\end{array}$ & $\begin{array}{l}2.76^{*} \\
(1.68)\end{array}$ & 0.78 & -0.23 & 0.00 \\
\hline & 3 & $\begin{array}{c}-0.12 \\
(-0.59)\end{array}$ & $\begin{array}{c}0.04 \\
(0.26)\end{array}$ & $\begin{array}{c}0.88 \\
{[0.35]}\end{array}$ & $\begin{array}{c}-0.03 \\
(-0.12)\end{array}$ & $\begin{array}{c}-0.21 \\
(-1.08)\end{array}$ & $\begin{array}{c}1.04 \\
{[0.31]}\end{array}$ & $\begin{array}{c}0.82 \\
(0.75)\end{array}$ & 0.85 & -0.00 & 0.00 \\
\hline \multirow{2}{*}{ WMP } & 0 & $\begin{array}{c}-0.41^{* * * *} \\
(-7.22)\end{array}$ & $\begin{array}{c}-0.51^{* * * *} \\
(-4.13)\end{array}$ & $\begin{array}{c}0.99 \\
{[0.32]}\end{array}$ & $\begin{array}{c}0.11^{*} \\
(1.93)\end{array}$ & $\begin{array}{c}0.13 \\
(1.37)\end{array}$ & $\begin{array}{c}0.02 \\
{[0.89}\end{array}$ & $\begin{array}{c}1.19 \\
(1.33)\end{array}$ & 0.84 & -0.44 & 0.19 \\
\hline & 4 & $\begin{array}{c}-0.39 * * * * \\
(-3.65)\end{array}$ & $\begin{array}{c}-0.41 \text { **** } \\
(-3.17)\end{array}$ & $\begin{array}{c}0.06 \\
{[0.81]}\end{array}$ & $\begin{array}{c}0.22^{*} \\
(1.85)\end{array}$ & $\begin{array}{l}0.24^{*} \\
(1.84)\end{array}$ & $\begin{array}{c}0.04 \\
{[0.84]}\end{array}$ & $\begin{array}{c}0.20 \\
(0.32)\end{array}$ & 0.91 & -0.47 & 0.36 \\
\hline \multirow{2}{*}{ Butter } & 0 & $\begin{array}{c}-0.45^{* * * *} \\
(-3.90)\end{array}$ & $\begin{array}{c}-0.56 \\
(-1,57)\end{array}$ & $\begin{array}{c}0.15 \\
{[0.69]}\end{array}$ & $\begin{array}{c}0.15 \\
(1.60)\end{array}$ & $\begin{array}{l}0.82^{* *} \\
(2.59)\end{array}$ & $\begin{array}{c}6.28 \\
{[0.01]}\end{array}$ & $\begin{array}{c}2.39 \\
(1.52)\end{array}$ & 0.47 & -0.52 & 0.35 \\
\hline & 3 & $\begin{array}{c}-0.43 * * \\
(-2.57)\end{array}$ & $\begin{array}{c}-0.18 \\
(-0.52)\end{array}$ & $\begin{array}{c}0.76 \\
{[0.39]}\end{array}$ & $\begin{array}{c}0.29 \\
(1.45)\end{array}$ & $\begin{array}{c}0.45 \\
(0.87)\end{array}$ & $\begin{array}{c}0.11 \\
{[0.74]}\end{array}$ & $\begin{array}{c}-1.08 \\
(-0.46)\end{array}$ & 0.63 & -0.56 & 0.49 \\
\hline \multirow{2}{*}{ Cheese } & 0 & $\begin{array}{c}-0.45^{* * * *} \\
(-8.41)\end{array}$ & $\begin{array}{c}-0.37 * * * * \\
(-2.68)\end{array}$ & $\begin{array}{c}0.53 \\
{[0.47]}\end{array}$ & $\begin{array}{c}0.11 \\
(1.54)\end{array}$ & $\begin{array}{c}-0.04 \\
(-0.36)\end{array}$ & $\begin{array}{c}1.19 \\
{[0.28]}\end{array}$ & $\begin{array}{c}0.01 \\
(0.01)\end{array}$ & 0.72 & -0.46 & 0.00 \\
\hline & 3 & $\begin{array}{c}-0.43 * * * * \\
(-4.92)\end{array}$ & $\begin{array}{c}-0.41 * * \\
(-2.00)\end{array}$ & $\begin{array}{c}0.00 \\
{[0.95]}\end{array}$ & $\begin{array}{c}0.27 * * * \\
(2.98)\end{array}$ & $\begin{array}{c}0.12 \\
(0.52)\end{array}$ & $\begin{array}{c}0.64 \\
{[0.43]}\end{array}$ & $\begin{array}{c}0.03 \\
(0.03) \\
\end{array}$ & 0.80 & -0.56 & 0.48 \\
\hline
\end{tabular}

Note: The numbers in parenthesis are heteroskedastic and autocorrelation robust t-statistics. Values and t-statistics of the coefficients refer to the sum of contemporaneous and lagged coefficients. The robust p-values appear in square brackets.

F-test for symmetry: The null hypothesis is that the effects are symmetric.

Source: Own calculations

For the remaining products, the introduction of lags often results in a higher or more significant influence of the competitor variables. This implies that competition is temporally lagged - a likely outcome when both export countries are using contracts and an outcome which is also found for the destination-specific estimates (Table 4.3). In contrast, the influence of the firm's variables hardly changes. Their estimated coefficients are around -0.4 for the three products - that is, $40 \%$ of changes in the marginal cost or the exchange rates are offset through changes in the markup. Furthermore, the F-test shows that the symmetry conditions are fulfilled in almost all cases. Unlike the other coefficients, the coefficient of the GDP is almost never significant.

According to the theoretical framework in Chapter 4.3, the theoretical coefficients $\beta$ and $\delta$ can be calculated from the estimated coefficients. Because the non-destinationspecific unit value series of the EU is not comparable with that of New Zealand, the equal coefficient assumption is applied. Furthermore, the required coefficients $\tau$ and $\varphi$ are taken from an estimation of equation (4.10), which is restricted for symmetry. The resulting numbers for $\beta$ and $\delta$ are listed in the last two columns of Table 4.2. With the exception of the results for SMP, the numbers reveal quite a high degree of PTM, when the EU's reaction is not considered. When lags are introduced, the absolute numbers are even higher; this is due to a larger value for the differentiation coefficient $\delta$. Since $\delta$ is close to the absolute value of $\beta$, the PTM behavior is primarily caused by the existence 
of the EU as a competitor. Nevertheless, the results are consistent with theory; i.e. $\delta$ is always smaller than the absolute value of $\beta$.

In addition to the non-destination-specific version of equation (4.10), we estimate the model for single destination countries and WMP. WMP is chosen since New Zealand has by far the largest world market share for this product. The results are depicted in Table 4.3. The variance explained by the model is above $50 \%$ for most of the destination countries and nearly all estimated coefficients have the correct sign. A striking exception is the Philippines, whose coefficients all have a value opposed to what theory predicts - although this is significant in just one case. This means that when the marginal cost of the EU increases, Fonterra lowers its price. This result could either be a sign of strategic behavior or an artifact with regard to quality changes in the unit value series; so, when the marginal cost of the EU increases, it sells less standard- and more premium-quality WMP, whereas Fonterra's export composition changes the other way around. Despite the unusual coefficient values, both symmetry conditions are fulfilled. Furthermore, the summing up conditions of the firm's and the competitor's coefficients are fulfilled in a way that when all variables change by the same percentage, there is local-currency price stability.

The remaining destination countries exhibit very different degrees of PTM. It is noticeable that nearly all marginal cost coefficients $\zeta$ are significantly smaller than one, whereas just four out of sixteen exchange rate coefficients $\tau$ are significant. This means that PTM is more often detected through changes in the marginal cost than through changes in the exchange rates. One reason that $\tau$ is less often significant could be the very stable exchange rate between New Zealand and the EU. This implies that New Zealand's exchange rates to the destination countries are highly correlated with those of the EU to the destination countries, which in turn influences the significance. Another reason is that the average absolute value of $\zeta-1$ is quite high compared to that of $\tau$ (Table 4.3). When the marginal cost in New Zealand increases, $46 \%$ of this increase is on average offset through a change in the markups, but only $37 \%$ of an increase in the real bilateral exchange rate is offset, on average. The symmetry test shows that this is due to the estimates for a number of single destination countries; for the majority of countries, symmetry holds. This result speaks against a possible bias in the SMC series. As discussed in Chapter 4.3.2, such a bias should manifest against the finding of PTM through the marginal cost coefficient. Similarly, this does not speak in favor of an endogeneity bias as discussed in Chapter 4.3.1. Although such a bias tends in the direction of the 
finding of PTM through the marginal cost coefficient, if anything, it should be more pronounced in the non-destination-specific version of (4.10) than for single destinations which can be assumed to have no influence on the overall marginal cost.

When the two erroneous signs are ignored, Table 4.3 shows that in seven out of sixteen cases one or both competitor variables $(\psi$ and $\varphi)$ have a significant influence on Fonterra's price. Again, the coefficient of the marginal cost $(\psi)$ is more often significant than the coefficient of the exchange rate $(\varphi)$ - although this is not as pronounced as in the case of the exporter's variables.

Table 4.3: Estimation results of equation (4.10) for whole milk powder

\begin{tabular}{|c|c|c|c|c|c|c|c|c|c|c|c|}
\hline Destination & 柋 & $\sum \zeta-1$ & $\sum \tau$ & $\begin{array}{c}\text { test for } \\
\text { symmetry }\end{array}$ & $\sum \psi$ & $\sum \varphi$ & $\begin{array}{c}\text { test for } \\
\text { symmetry }\end{array}$ & $\sum \boldsymbol{\sigma}$ & $\mathbf{R}^{2}$ & $\begin{array}{l}\beta^{\mathrm{NZ}} \\
\beta^{\mathrm{EU}}\end{array}$ & $\begin{array}{l}\delta^{\mathrm{NZ}} \\
\delta^{\mathrm{EU}}\end{array}$ \\
\hline China & 1 & $\begin{array}{c}-0.65 * * * \\
(-5.73) \\
\end{array}$ & $\begin{array}{c}-0.63 * * * \\
(-2.74)\end{array}$ & $\begin{array}{c}0.01 \\
{[0.93]}\end{array}$ & $\begin{array}{c}0.43 * * * \\
(3.17)\end{array}$ & $\begin{array}{c}0.15 \\
(0.46) \\
\end{array}$ & $\begin{array}{c}1.94 \\
{[0.17]}\end{array}$ & $\begin{array}{c}0.71 \\
(1.26) \\
\end{array}$ & 0.67 & & 1.11 \\
\hline Venezuela & 1 & $\begin{array}{l}-0.35 * * \\
(-2.52)\end{array}$ & $\begin{array}{l}-0.47 * \\
(-1.76)\end{array}$ & $\begin{array}{c}0.21 \\
{[0.65]}\end{array}$ & $\begin{array}{c}0.06 \\
(0.45)\end{array}$ & $\begin{array}{l}0.46^{*} \\
(1.82)\end{array}$ & $\begin{array}{l}4.27 * * \\
{[0.04]}\end{array}$ & $\begin{array}{c}0.49 \\
(1.17)\end{array}$ & 0.57 & -0.39 & 0.20 \\
\hline Malaysia & 2 & $\begin{array}{c}-0.57 * * * \\
(-4.17)\end{array}$ & $\begin{array}{c}-0.53 * * \\
(-2.33)\end{array}$ & $\begin{array}{c}0.04 \\
{[0.85]}\end{array}$ & $\begin{array}{c}0.24 * * \\
(2.09)\end{array}$ & $\begin{array}{c}0.05 \\
(0.22) \\
\end{array}$ & $\begin{array}{c}0.43 \\
{[0.51]}\end{array}$ & $\begin{array}{c}0.19 \\
(0.42) \\
\end{array}$ & 0.65 & -0.69 & 0.53 \\
\hline Sri Lanka & 1 & $\begin{array}{c}-0.40 * * * \\
(-4.28)\end{array}$ & $\begin{array}{c}-0.78 * * * \\
(-3.54)\end{array}$ & $\begin{array}{l}3.57 * \\
{[0.06]}\end{array}$ & $\begin{array}{c}0.18 \\
(1.60)\end{array}$ & $\begin{array}{c}0.20 \\
(1.04)\end{array}$ & $\begin{array}{c}0.76 \\
{[0.39]}\end{array}$ & $\begin{array}{c}0.94 \\
(0.65)\end{array}$ & 0.58 & -0.50 & 0.34 \\
\hline Mexico & 0 & $\begin{array}{c}-0.45 * * * \\
(-3.80)\end{array}$ & $\begin{array}{c}-0.36 \\
(-1.34) \\
\end{array}$ & $\begin{array}{c}0.10 \\
{[0.76]}\end{array}$ & $\begin{array}{c}0.35 * * * \\
(2.71)\end{array}$ & $\begin{array}{c}0.26 \\
(0.90) \\
\end{array}$ & $\begin{array}{c}0.04 \\
{[0.84]}\end{array}$ & $\begin{array}{c}0.17 \\
(0.63) \\
\end{array}$ & 0.47 & -0.63 & 0.59 \\
\hline $\begin{array}{l}\text { Saudi } \\
\text { Arabia }\end{array}$ & 2 & $\begin{array}{c}-0.39 * * * \\
(-3.00)\end{array}$ & $\begin{array}{c}-0.19 \\
(-1.01) \\
\end{array}$ & $\begin{array}{c}1.34 \\
{[0.25]}\end{array}$ & $\begin{array}{c}0.41 \text { *** } \\
(2.81)\end{array}$ & $\begin{array}{l}0.32^{*} \\
(1.74) \\
\end{array}$ & $\begin{array}{c}0.01 \\
{[0.94]}\end{array}$ & $\begin{array}{c}-0.38 \\
(-0.61) \\
\end{array}$ & 0.81 & -0.63 & 0.63 \\
\hline Thailand & 1 & $\begin{array}{c}-0.34 * * * \\
(-4.19)\end{array}$ & $\begin{array}{c}-0.03 \\
(-0.16) \\
\end{array}$ & $\begin{array}{l}4.73 * * \\
{[0.03]}\end{array}$ & $\begin{array}{c}0.02 \\
(0.20) \\
\end{array}$ & $\begin{array}{l}-0.29 * \\
(-1.89) \\
\end{array}$ & $\begin{array}{c}0.20 \\
{[0.65]}\end{array}$ & $\begin{array}{c}-0.18 \\
(-0.56) \\
\end{array}$ & 0.70 & $\begin{array}{l}-0.30 \\
-0.46 \\
\end{array}$ & $\begin{array}{l}0.00 \\
0.34 \\
\end{array}$ \\
\hline Indonesia & 0 & $\begin{array}{c}-0.47 * * \\
(-2.42)\end{array}$ & $\begin{array}{c}-0.26 \\
(-0.78) \\
\end{array}$ & $\begin{array}{c}0.83 \\
{[0.37]}\end{array}$ & $\begin{array}{l}0.38 * \\
(1.82) \\
\end{array}$ & $\begin{array}{c}0.23 \\
(0.63) \\
\end{array}$ & $\begin{array}{c}0.02 \\
{[0.88]}\end{array}$ & $\begin{array}{c}0.32 \\
(0.63) \\
\end{array}$ & 0.44 & $\begin{array}{l}-0.63 \\
-0.63 \\
\end{array}$ & $\begin{array}{l}0.63 \\
0.53 \\
\end{array}$ \\
\hline Philippines & 2 & $\begin{array}{c}0.08 \\
(0.41)\end{array}$ & $\begin{array}{c}0.37 \\
(1.09)\end{array}$ & $\begin{array}{c}0.93 \\
{[0.34]}\end{array}$ & $\begin{array}{l}-0.40^{*} \\
(-1.89)\end{array}$ & $\begin{array}{c}-0.52 \\
(-1.59)\end{array}$ & $\begin{array}{c}0.11 \\
{[0.74]}\end{array}$ & $\begin{array}{l}2.77^{*} \\
(1.89)\end{array}$ & 0.60 & & \\
\hline Taiwan & 2 & $\begin{array}{c}-0.71 * * * \\
(-4.71) \\
\end{array}$ & $\begin{array}{c}-0.27 \\
(-1.10) \\
\end{array}$ & $\begin{array}{l}4.24 * * \\
{[0.04]} \\
\end{array}$ & $\begin{array}{l}0.31 * \\
(1.68) \\
\end{array}$ & $\begin{array}{c}0.26 \\
(0.71) \\
\end{array}$ & $\begin{array}{c}0.31 \\
{[0.58]}\end{array}$ & & 0.45 & -1.00 & 1.00 \\
\hline $\begin{array}{l}\text { Arab } \\
\text { Emirates }\end{array}$ & 2 & $\begin{array}{l}-0.32 * \\
(-1.88)\end{array}$ & $\begin{array}{c}-0.62 * * \\
(-2.48)\end{array}$ & $\begin{array}{l}3.26^{*} \\
{[0.07]}\end{array}$ & $\begin{array}{c}0.12 \\
(0.60)\end{array}$ & $\begin{array}{c}0.39 \\
(1.17)\end{array}$ & $\begin{array}{c}0.06 \\
{[0.81]}\end{array}$ & & 0.69 & $\begin{array}{l}-0.40 \\
-0.57\end{array}$ & $\begin{array}{l}0.32 \\
0.31\end{array}$ \\
\hline Singapore & 1 & $\begin{array}{c}-0.35 \\
(-1.51)\end{array}$ & $\begin{array}{c}-0.11 \\
(-0.23) \\
\end{array}$ & $\begin{array}{c}0.25 \\
{[0.62]}\end{array}$ & $\begin{array}{c}0.15 \\
(0.56)\end{array}$ & $\begin{array}{c}-0.17 \\
(-0.32)\end{array}$ & $\begin{array}{c}0.06 \\
{[0.80]}\end{array}$ & $\begin{array}{c}-0.76 \\
(-0.56) \\
\end{array}$ & 0.37 & $\begin{array}{l}-0.42 \\
-0.68 \\
\end{array}$ & $\begin{array}{l}0.28 \\
0.48 \\
\end{array}$ \\
\hline Peru & 1 & $\begin{array}{l}-0.42^{* *} \\
(-2.47)\end{array}$ & $\begin{array}{c}-0.46 * * \\
(-2.58)\end{array}$ & $\begin{array}{c}0.05 \\
{[0.82]}\end{array}$ & $\begin{array}{c}0.28 \\
(1.51)\end{array}$ & $\begin{array}{l}0.37 * * \\
(2.18)\end{array}$ & $\begin{array}{c}0.10 \\
{[0.76]}\end{array}$ & $\begin{array}{c}0.06 \\
(0.10) \\
\end{array}$ & 0.58 & -0.57 & 0.51 \\
\hline El Salvador & 2 & $\begin{array}{c}-0.58 * * * \\
(-3.68)\end{array}$ & $\begin{array}{c}-0.25 \\
(-1.08) \\
\end{array}$ & $\begin{array}{c}2.42 \\
{[0.12]}\end{array}$ & $\begin{array}{c}0.25 \\
(1.57)\end{array}$ & $\begin{array}{c}0.02 \\
(0.04)\end{array}$ & $\begin{array}{c}0.00 \\
{[0.96]}\end{array}$ & $\begin{array}{c}-0.57 \\
(-0.58) \\
\end{array}$ & 0.58 & -0.67 & 0.49 \\
\hline Mauritius & 0 & $\begin{array}{c}-0.33 * * * \\
(-3.86) \\
\end{array}$ & $\begin{array}{c}-0.41 * * \\
(-2.19) \\
\end{array}$ & $\begin{array}{c}0.14 \\
{[0.71]}\end{array}$ & $\begin{array}{c}0.10 \\
(1.04) \\
\end{array}$ & $\begin{array}{c}-0.17 \\
(-0.75) \\
\end{array}$ & $\begin{array}{c}1.43 \\
{[0.24]} \\
\end{array}$ & $\begin{array}{c}-2.04 \\
(-1.24) \\
\end{array}$ & 0.61 & -0.35 & 0.11 \\
\hline Fiji & 2 & $\begin{array}{c}-0.55 * * * \\
(-3.08)\end{array}$ & $\begin{array}{c}-0.09 \\
(-0.24)\end{array}$ & $\begin{array}{c}1.80 \\
{[0.18]}\end{array}$ & $\begin{array}{c}0.37 * * \\
(2.25)\end{array}$ & $\begin{array}{c}0.38 \\
(1.57)\end{array}$ & $\begin{array}{c}0.11 \\
{[0.74]}\end{array}$ & $\begin{array}{c}0.13 \\
(0.13) \\
\end{array}$ & 0.58 & -0.90 & 0.88 \\
\hline Average & & -0.46 & -0.37 & & 0.24 & 0.26 & $\leftarrow$ & \multicolumn{4}{|c|}{ values with erroneous signs excluded } \\
\hline
\end{tabular}

Note: The numbers in parenthesis are heteroskedastic and autocorrelation robust t-statistics. Values and t-statistics of the coefficients refer to the sum of contemporaneous and lagged coefficients. The robust p-values appear in square brackets.

F-test for symmetry: The null hypothesis is that the effects are symmetric.

Source: Own calculations 
The theoretical coefficients $\beta$ and $\delta$ in Table 4.3 are calculated in two ways. When a complete unit value series is available for the EU and the specific destination country, $\beta$ and $\delta$ are calculated with the aid of the estimates for the EU; this is the case for only four destination countries. The results show that the coefficients are fairly similar across New Zealand and the EU, although the absolute value of the EU's coefficients is mostly larger. For the destination countries where no complete EU export unit value series is available, the equal coefficient assumption is applied. With the exception of China, $\delta$ is always smaller than the absolute value of $\beta$. When both coefficients sum up to zero, PTM takes place solely due to the presence of the EU as a competitor. This is the case for Saudi Arabia and to a lesser extent for Fiji, Indonesia and Mexico. The smaller $\delta$ is compared to $|\beta|$, the larger the proportion of PTM that is caused by the convexity of the market demand curve - or by the presence of other (foreign) competitors that are not considered in the model. In the case of Thailand where $\delta$ equals zero, PTM takes place solely due to the convexity of the market demand curve. In general, the importance of the EU as a competitor implies an interesting property of the exchange rate induced PTM. When PTM is completely caused by the market presence of the EU, it only takes place when New Zealand's currency changes its worth, but not when the destination country's currency does so. This is because in the latter case, the marginal cost of both New Zealand and the EU in the destination country's currency is affected while in the former case, only New Zealand's marginal cost is affected.

Generally, the results fit (at least partly) well to the European market presence in the destination country. In the observation period, the EU had medium and large import market shares in Saudi Arabia, Malaysia, Mexico and Indonesia that exhibit significant influence from the competitor variables and a rather large value of $\delta$. On the other hand, the results for China, Peru und Fiji are puzzling. In these countries the EU was only responsible for a small share of the WMP exports.

With regard to market power, the results are not as easy to interpret. Basically, they face the same limitations that are described by GoldBERG \& HELLERSTEIN (2008: 424) with respect to the model proposed by KNETTER (1989; 1993). The most important disadvantage is that the approach may prove the existence of a markup but does not provide information about its extent. However, unlike the Knetter model, the competitor coefficient $\delta$ is available, although its interpretation with respect to market power is ambivalent. On one hand, a large value of $\delta$ means that the price of the EU has a high influence on the price Fonterra charges, which implies that the product is perceived as rather ho- 
mogeneous. On the other hand, the fact that Fonterra can react to a high degree with their price implies that there is a sufficiently high buffer in terms of a high destinationspecific markup. However, when the product is very homogeneous, it follows that the relation of the export countries' marginal cost should be stable over the long term. This implies that the buffer needed is not as high as it supposedly could be and the interpretation for $\delta$ as a product differentiation indicator remains valid. It could therefore be argued that the best indication for market power is a large difference in the absolute values of $\beta$ and $\delta$. The large $|\beta|$ could prove that Fonterra indeed has a high markup as a buffer and the small $\delta$ implies that the product is differentiated enough to ensure that competition remains moderate. Of course, this argumentation is only valid as long as $\delta$ is not small because relevant competitors are not considered in the estimation.

Table 4.4: Estimation results for the UV surcharge as dependent variable

\begin{tabular}{|c|c|c|c|c|}
\hline \multicolumn{3}{|c|}{ coefficients (t-values) } & $\begin{array}{c}\text { F-test for } \\
\text { sum of coef. }=\text { zero }\end{array}$ & \multirow{2}{*}{$\mathbf{R}^{\mathbf{2}}$} \\
\hline constant & abs. value of beta & delta & $9.51[0.01]$ & 0.46 \\
\hline$-0.05(-0.90)$ & $0.52 * *(2.69)$ & $-0.31 * *(-2.22)$ & \\
\hline
\end{tabular}

Source: Own calculations

In order to test whether the argumentation above is consistent with the data, we regress $^{15}$ the destination-specific UV surcharges on the estimated values of $|\beta|$ and $\delta$ in Table 4.3. The UV surcharge is surely not equal to the markup since it also consists of quality premiums but it is the next best alternative. The results in Table 4.4 support our argumentation. The table shows that the influence of $|\beta|$ and $\delta$ is significant and has the expected signs. A rise in the absolute value of $\beta$ increases the UV surcharge whereas a rise in the value of $\delta$ decreases it. Nevertheless, the absolute value of the coefficients is not equal (F-test in Table 4.4). This implies that PTM always needs some markup in order to take place, even when it is caused solely by the existence of a competitor.

\subsection{Conclusion}

The approach presented here extends the known pricing-to-market approach to an oligopolistic model of PTM that explicitly takes the competitor influence on the behavior of the firm into account. This allows us to untangle whether PTM is caused by the characteristics of the market demand curve or by the market structure. Furthermore, for the marginal cost is no longer controlled via the fixed effects of a panel model as in the

\footnotetext{
${ }^{15}$ Since the quality premiums as a part of the error term are always positive a suitable econometric model should have a composed error term like equation (11). However, we tried to estimate such a model but the results neglected its superiority.
} 
model proposed by KNETTER $(1989 ; 1993)$. Instead, the marginal cost is directly represented in the model as the stochastic marginal cost series which is estimated in the first step with a stochastic frontier model. Therefore, PTM can no longer be detected just through the influence of bilateral exchange rates on the price; it can also be detected through the influence of the firm's overall marginal cost on the price.

The results of estimating the oligopolistic PTM model - in a non-destination-specific as well as in a destination-specific version - for New Zealand's (Fonterra's) most important dairy exports generally support the validity of the approach presented here. The majority of the estimated coefficients has the sign and lies in the range that was predicted by theory. Furthermore, the calculation of the theoretical coefficients yields values that are mostly consistent with theory. The estimated numbers show that when one or more competitor variables are significant, PTM is primarily caused by the existence of the EU as a competitor and only to a small degree by the characteristics of the market demand curve or by other competitors that are not considered in the model. Unfortunately, the estimated exchange rate coefficients are often not significant - especially in the destination-specific version. This is at least in part due to a high correlation of the two exchange rate series in the model.

In essence, the coefficients of the marginal cost more often exhibit significant values that indicate PTM. In most of the cases, the estimated values support the symmetry conditions - that is, whether detected through changes in bilateral exchange rates or through changes in the overall marginal cost of the firm, the estimated degree of PTM is the same. Only in the destination-specific version are there some cases that the estimated degree of PTM via changes in the overall marginal cost is larger. However, this implies that the stochastic marginal cost series is unlikely to exhibit a systematic bias. If such a bias would exist, it can be expected to tend in the opposite direction. An advantage of the stochastic marginal cost is that - besides the usage in a PTM model - it can also be used in other models of imperfect competition - for instance in the residual demand approach from GoldBERG \& KNETTER (1999). SILVENTE (2005) already uses the time effect series of the model proposed by KNETTER (1989) as instrument for the endogenous quantity. For this purpose, the stochastic marginal cost can be used too; furthermore, it can also be used to depict the competitor's cost in the model. 


\section{References}

Armentano, L.E., Dobson, W.D., Jesse, E. V \& Olson, N.F. (2004): The dairy sectors of New Zealand and Australia: A regional study. Babcock Institute Discussion Paper, 2004(3), pp. 1-64.

Bugamelli, M. \& Tedeschi, R. (2008): Pricing-to-Market and Market Structure. Oxford Bulletin of Economics and Statistics, 70(2), pp. 155-180.

Dobson, W.D. \& WiLcox, A. (2002): How leading international dairy companies adjusted to changes in world markets. Babcock Institute Discussion Paper, 2002(4), pp. $1-30$.

FEENSTRA, R.C. (1989): Symmetric pass-through of tariffs and exchange rates under imperfect competition: an empirical test. Journal of International Economics, 27(1-2), pp. 25-45.

FeEnstra, R.C., Gagnon, J.E. \& KNETTER, M.M. (1996): Market share and exchange rate pass-through in world automobile trade. Journal of International Economics, 40(1-2), pp. 187-207.

GAGNON, J.E. \& KNETTER, M.M. (1995): Markup adjustment and exchange rate fluctuations: evidence from panel data on automobile exports. Journal of International Money and Finance, 14(2), pp. 289-310.

GIL-PAREJA, S. (2003): Pricing to market behaviour in European car markets. European Economic Review, 47(6), pp. 945-962.

GoldberG, P.K. \& Hellerstein, R. (2008): A structural approach to explaining incomplete exchange-rate pass-through and pricing-to-market. The American Economic Review, 98(2), pp. 423-429.

GoldberG, P.K. \& KNETTER, M.M. (1997): Goods prices and exchange rates: What have we learned? Journal of Economic Literature, 35(3), pp. 1243-1272.

Goldberg, P.K. \& KNETTER, M.M. (1999): Measuring the intensity of competition in export markets. Journal of International Economics, 47(1), pp. 27-60.

GTA (2013): Global Trade Atlas. Global Trade Information Services (GTIS).

KNETTER, M.M. (1993): International comparisons of pricing-to-market behavior. The American Economic Review, 83(3), pp. 473-486. 
KnetTer, M.M. (1989): Price Discrimination by U.S. and German Exporters. The American Economic Review, 79(1), pp. 198-210.

KNETTER, M.M. (1995): Pricing to Market in Response to Unobservable and Observable Shocks. International Economic Journal, 9(2), pp. 1-25.

KNETTER, M.M. (1997): Why are retail prices in Japan so high? Evidence from German export prices. International Journal of Industrial Organization, 15(5), pp. 549-572.

KRUgman, P. (1986): Pricing to market when the exchange rate changes. National Bureau of Economic Research (NBER) Working Paper, No. 1926, pp. 1-43.

Kumbhakar, S.C. \& Lovell, C.A.K. (2003): Stochastic frontier analysis, Cambridge: Cambridge University Press.

Lavoie, N. \& LiU, Q. (2007): Pricing-to-Market: Price Discrimination or Product Differentiation? American Journal of Agricultural Economics, 89(3), pp. 571-581.

MARSTON, R.C. (1990): Pricing to market in Japanese manufacturing. Journal of International Economics, 29(3-4), pp. 217-236.

SaghaiAn, S.H. \& REED, M.R. (2004): Integrating Marginal Cost into Pricing-to-market Models for US Agricultural Products. Current Agriculture, Food and Resource Issues, (5), pp. 187-203.

SILVENTE, F.R. (2005): Price discrimination and market power in export markets: the case of the ceramic tile industry. Journal of Applied Economics, VIII(2), pp. 347370. 


\section{Appendix 4.1: Derivation of the theoretical model}

Optimization condition for the export firm:

$$
p_{i}=\frac{\partial C\left(q=\sum q_{i}\left(E R_{i} p_{i}, E R_{i}^{C} p_{i}^{C}, Y_{i}\right), W\right)}{\partial q}\left(\frac{-\eta_{i}\left(E R_{i} p_{i}, E R_{i}^{C} p_{i}^{C}, Y_{i}\right)}{-\eta_{i}\left(E R_{i} p_{i}, E R_{i}^{C} p_{i}^{C}, Y_{i}\right)+1}\right)
$$

Taking the logarithm yields:

$$
\ln \left(p_{i}\right)=\ln \left(\frac{\partial C(q, W)}{\partial q}\right)+\ln \left(\frac{-\eta_{i}\left(E R_{i} p_{i}, E R_{i}^{C} p_{i}^{C}, Y_{i}\right)}{-\eta_{i}\left(E R_{i} p_{i}, E R_{i}^{C} p_{i}^{C}, Y_{i}\right)+1}\right)
$$

Totally differentiating with respect to input price $(W)$, export prices $(p)$, exchange rates $(E R)$ and income $(Y)$ yields:

$$
\begin{aligned}
d \ln \left(p_{i}\right)= & \frac{\partial \ln \left(p_{i}\right)}{\partial W} d W+\frac{\partial \ln \left(p_{i}\right)}{\partial p_{i}} d p_{i}+\frac{\partial \ln \left(p_{i}\right)}{\partial E R_{i}} d E R_{i}+\frac{\partial \ln \left(p_{i}\right)}{\partial p_{i}^{C}} d p_{i}^{C}+\frac{\partial \ln \left(p_{i}\right)}{\partial E R_{i}^{C}} d E R_{i}^{C} \\
& +\frac{\partial \ln \left(p_{i}\right)}{\partial Y_{i}} d Y_{i}
\end{aligned}
$$

Partial differentials:

- input price

$$
\frac{\partial \ln \left(p_{i}\right)}{\partial W} d W=\frac{\partial^{2} C(\cdot)}{\partial q \partial W} * \frac{1}{\frac{\partial C(\cdot)}{\partial q}} * d W
$$

- export price of the firm

$$
\begin{aligned}
& \frac{\partial \ln \left(p_{i}\right)}{\partial p_{i}} d p_{i}=\left(\frac{\partial^{2} C(\cdot)}{\partial q^{2}} \frac{\partial q}{\partial \ddot{p}_{i}} E R_{i} * \frac{1}{\frac{\partial C(\cdot)}{\partial q}}+\frac{-\frac{\partial \eta_{i}(\cdot)}{\partial \ddot{p}_{i}} E R_{i}}{\left(-\eta_{i}(\cdot)+1\right)^{2}} * \frac{1}{\frac{-\eta_{i}(\cdot)}{-\eta_{i}(\cdot)+1}}\right) d p_{i} \\
& \frac{\partial \ln \left(p_{i}\right)}{\partial p_{i}} d p_{i}=\left(\frac{\partial^{2} C(\cdot)}{\partial q^{2}} \frac{\partial q}{\partial \ddot{p}_{i}} E R_{i} * \frac{1}{\frac{\partial C(\cdot)}{\partial q}}+\frac{-\frac{\partial \eta_{i}(\cdot)}{\partial \ddot{p}_{i}} E R_{i}}{-\eta_{i}(\cdot)\left(-\eta_{i}(\cdot)+1\right)}\right) d p_{i} \\
& \frac{\partial \ln \left(p_{i}\right)}{\partial p_{i}} d p_{i}=\frac{\partial^{2} C(\cdot)}{\partial q^{2}} \frac{\partial q}{\partial \ddot{p}_{i}} E R_{i} d p_{i} * \frac{1}{\frac{\partial C(\cdot)}{\partial q}}+\frac{\frac{\partial \eta_{i}(\cdot)}{\partial \ddot{p}_{i}} \frac{E R_{i} p_{i}}{\eta_{i}(\cdot)}}{\left(-\eta_{i}(\cdot)+1\right)} * \frac{d p_{i}}{p_{i}}
\end{aligned}
$$

where $\ddot{p}_{i}=E R_{i} p_{i}$

- exchange rate between the export and the destination country

$$
\frac{\partial \ln \left(p_{i}\right)}{\partial E R_{i}} d E R_{i}=\left(\frac{\partial^{2} C(\cdot)}{\partial q^{2}} \frac{\partial q}{\partial \ddot{p}_{i}} p_{i} * \frac{1}{\frac{\partial C(\cdot)}{\partial q}}+\frac{-\frac{\partial \eta_{i}(\cdot)}{\partial \ddot{p}_{i}} p_{i}}{\left(-\eta_{i}(\cdot)+1\right)^{2}} * \frac{1}{\frac{-\eta_{i}(\cdot)}{-\eta_{i}(\cdot)+1}}\right) d E R_{i}
$$




$$
\begin{aligned}
& \frac{\partial \ln \left(p_{i}\right)}{\partial E R_{i}} d E R_{i}=\left(\frac{\partial^{2} C(\cdot)}{\partial q^{2}} \frac{\partial q}{\partial \ddot{p}_{i}} p_{i} * \frac{1}{\frac{\partial C(\cdot)}{\partial q}}+\frac{-\frac{\partial \eta_{i}(\cdot)}{\partial \ddot{p}_{i}} p_{i}}{-\eta_{i}(\cdot)\left(-\eta_{i}(\cdot)+1\right)}\right) d E R_{i} \\
& \frac{\partial \ln \left(p_{i}\right)}{\partial E R_{i}} d E R_{i}=\frac{\partial^{2} C(\cdot)}{\partial q^{2}} \frac{\partial q}{\partial \ddot{p}_{i}} p_{i} d E R_{i} * \frac{1}{\frac{\partial C(\cdot)}{\partial q}}+\frac{\frac{\partial \eta_{i}(\cdot)}{\partial \ddot{p}_{i}} \frac{E R_{i} p_{i}}{\eta_{i}(\cdot)}}{\left(-\eta_{i}(\cdot)+1\right)} * \frac{d E R_{i}}{E R_{i}}
\end{aligned}
$$

- export price of the competitor

$$
\begin{aligned}
& \frac{\partial \ln \left(p_{i}\right)}{\partial p_{i}^{C}} d p_{i}^{C}=\left(\frac{\partial^{2} C(\cdot)}{\partial q^{2}} \frac{\partial q}{\partial \ddot{p}_{i}^{C}} E R_{i}^{C} * \frac{1}{\frac{\partial C(\cdot)}{\partial q}}+\frac{-\frac{\partial \eta_{i}(\cdot)}{\partial \ddot{p}_{i}^{C}} E R_{i}^{C}}{\left(-\eta_{i}(\cdot)+1\right)^{2}} * \frac{1}{\frac{-\eta_{i}(\cdot)}{-\eta_{i}(\cdot)+1}}\right) d p_{i}^{C} \\
& \frac{\partial \ln \left(p_{i}\right)}{\partial p_{i}^{C}} d p_{i}^{C}=\left(\frac{\partial^{2} C(\cdot)}{\partial q^{2}} \frac{\partial q}{\partial \ddot{p}_{i}^{C}} E R_{i}^{C} * \frac{1}{\frac{\partial C(\cdot)}{\partial q}}+\frac{-\frac{\partial \eta_{i}(\cdot)}{\partial \ddot{p}_{i}^{C}} E R_{i}^{C}}{-\eta_{i}(\cdot)\left(-\eta_{i}(\cdot)+1\right)}\right) d p_{i}^{C} \\
& \frac{\partial \ln \left(p_{i}\right)}{\partial p_{i}^{C}} d p_{i}^{C}=\frac{\partial^{2} C(\cdot)}{\partial q^{2}} \frac{\partial q}{\partial \ddot{p}_{i}^{C}} E R_{i}^{C} d p_{i}^{C} * \frac{1}{\frac{\partial C(\cdot)}{\partial q}}+\frac{\frac{\partial \eta_{i}(\cdot)}{\partial \ddot{p}_{i}^{C}} \frac{E R_{i}^{C} p_{i}^{C}}{\eta_{i}(\cdot)}}{\left(-\eta_{i}(\cdot)+1\right)} * \frac{d p_{i}^{C}}{p_{i}^{C}}
\end{aligned}
$$

where $\ddot{p}_{i}^{C}=E R_{i}^{C} p_{i}^{C}$

- exchange rate between the competitor's and the destination country

$$
\begin{aligned}
& \frac{\partial \ln \left(p_{i}\right)}{\partial E R_{i}^{C}} d E R_{i}^{C}=\left(\frac{\partial^{2} C(\cdot)}{\partial q^{2}} \frac{\partial q}{\partial \ddot{p}_{i}^{C}} p_{i}^{C} * \frac{1}{\frac{\partial C(\cdot)}{\partial q}}+\frac{-\frac{\partial \eta_{i}(\cdot)}{\partial \ddot{p}_{i}^{C}} p_{i}^{C}}{\left(-\eta_{i}(\cdot)+1\right)^{2}} * \frac{1}{\frac{-\eta_{i}(\cdot)}{-\eta_{i}(\cdot)+1}}\right) d E R_{i}^{C} \\
& \frac{\partial \ln \left(p_{i}\right)}{\partial E R_{i}^{C}} d E R_{i}^{C}=\left(\frac{\partial^{2} C(\cdot)}{\partial q^{2}} \frac{\partial q}{\partial \ddot{p}_{i}^{C}} p_{i}^{C} * \frac{1}{\frac{\partial C(\cdot)}{\partial q}}+\frac{-\frac{\partial \eta_{i}(\cdot)}{\partial \ddot{p}_{i}^{C}} p_{i}^{C}}{-\eta_{i}(\cdot)\left(-\eta_{i}(\cdot)+1\right)}\right) d E R_{i}^{C} \\
& \frac{\partial \ln \left(p_{i}\right)}{\partial E R_{i}^{C}} d E R_{i}^{C}=\frac{\partial^{2} C(\cdot)}{\partial q^{2}} \frac{\partial q}{\partial \ddot{p}_{i}^{C}} p_{i}^{C} d E R_{i}^{C} * \frac{1}{\frac{\partial C(\cdot)}{\partial q}}+\frac{\frac{\partial \eta_{i}(\cdot)}{\partial \ddot{p}_{i}^{C}} \frac{E R_{i}^{C} p_{i}^{C}}{\left(-\eta_{i}(\cdot)+1\right)}}{(\cdot)+1)} * \frac{d E R_{i}^{C}}{E R_{i}^{C}}
\end{aligned}
$$

- income in the destination country

$$
\begin{aligned}
& \frac{\partial \ln \left(p_{i}\right)}{\partial Y_{i}} d Y_{i}=\left(\frac{\partial^{2} C(\cdot)}{\partial q^{2}} \frac{\partial q}{\partial Y_{i}} * \frac{1}{\frac{\partial C(\cdot)}{\partial q}}+\frac{-\frac{\partial \eta_{i}(\cdot)}{\partial Y_{i}}}{\left(-\eta_{i}(\cdot)+1\right)^{2}} * \frac{1}{\frac{-\eta_{i}(\cdot)}{-\eta_{i}(\cdot)+1}}\right) d Y_{i} \\
& \frac{\partial \ln \left(p_{i}\right)}{\partial Y_{i}} d Y_{i}=\left(\frac{\partial^{2} C(\cdot)}{\partial q^{2}} \frac{\partial q}{\partial Y_{i}} * \frac{1}{\frac{\partial C(\cdot)}{\partial q}}+\frac{-\frac{\partial \eta_{i}(\cdot)}{\partial Y_{i}}}{-\eta_{i}(\cdot)\left(-\eta_{i}(\cdot)+1\right)}\right) d Y_{i} \\
& \frac{\partial \ln \left(p_{i}\right)}{\partial Y_{i}} d Y_{i}=\frac{\partial^{2} C(\cdot)}{\partial q^{2}} \frac{\partial q}{\partial Y_{i}} d Y_{i} * \frac{1}{\frac{\partial C(\cdot)}{\partial q}}+\frac{\frac{\partial \eta_{i}(\cdot)}{\partial Y_{i}} \frac{Y_{i}}{\eta_{i}(\cdot)}}{\left(-\eta_{i}(\cdot)+1\right)} * \frac{d Y_{i}}{Y_{i}}
\end{aligned}
$$


Substituting into the total differential yields:

$$
\begin{aligned}
\frac{d p_{i}}{p_{i}}= & \frac{\frac{\partial^{2} C(\cdot)}{\partial q^{2}}\left(\sum \frac{\partial q_{i}}{\partial \ddot{p}_{i}}\left(E R_{i} d p_{i}+p_{i} d E R_{i}\right)+\frac{\partial q_{i}}{\partial \ddot{p}_{i}^{C}}\left(E R_{i}^{C} d p_{i}^{C}+p_{i}^{C} d E R_{i}^{C}\right)+\frac{\partial q_{i}}{\partial Y_{i}} d Y_{i}\right)+\frac{\partial^{2} C(\cdot)}{\partial q \partial W} d W}{\frac{\partial C(\cdot)}{\partial q}} \\
& +\frac{\frac{\partial \ln \eta_{i}(\cdot)}{\partial \ln \ddot{p}_{i}}}{\left(-\eta_{i}(\cdot)+1\right)} *\left(\frac{d p_{i}}{p_{i}}+\frac{d E R_{i}}{E R_{i}}\right)+\frac{\frac{\partial \ln \eta_{i}(\cdot)}{\partial \ln \ddot{p}_{i}^{C}}}{\left(-\eta_{i}(\cdot)+1\right)} *\left(\frac{d p_{i}^{C}}{p_{i}^{C}}+\frac{d E R_{i}^{C}}{E R_{i}^{C}}\right)+\frac{\frac{\partial \ln \eta_{i}(\cdot)}{\partial \ln Y_{i}}}{\left(-\eta_{i}(\cdot)+1\right)} * \frac{d Y_{i}}{Y_{i}}
\end{aligned}
$$

Because

$$
\frac{d \frac{\partial C(\cdot)}{\partial q}}{\frac{\partial C(\cdot)}{\partial q}}=\frac{\frac{\partial^{2} C(\cdot)}{\partial q^{2}}\left(\sum \frac{\partial q}{\partial \ddot{p}_{i}}\left(E R_{i} d p_{i}+p_{i} d E R_{i}\right)+\frac{\partial q}{\partial \ddot{p}_{i}^{C}}\left(E R_{i}^{C} d p_{i}^{C}+p_{i}^{C} d E R_{i}^{C}\right)+\frac{\partial q}{\partial Y_{i}} d Y_{i}\right)+\frac{\partial^{2} C(\cdot)}{\partial q \partial W} d W}{\frac{\partial C(\cdot)}{\partial q}}
$$

the equation can be simplified to:

$$
\begin{gathered}
\frac{d p_{i}}{p_{i}}=\frac{d \frac{\partial C(\cdot)}{\partial q}}{\frac{\partial C(\cdot)}{\partial q}}+\frac{\frac{\partial \ln \eta_{i}(\cdot)}{\partial \ln \ddot{p}_{i}}}{\left(-\eta_{i}(\cdot)+1\right)} *\left(\frac{d p_{i}}{p_{i}}+\frac{d E R_{i}}{E R_{i}}\right)+\frac{\frac{\partial \ln \eta_{i}(\cdot)}{\partial \ln \ddot{p}_{i}^{C}}}{\left(-\eta_{i}(\cdot)+1\right)} *\left(\frac{d p_{i}^{C}}{p_{i}^{C}}+\frac{d E R_{i}^{C}}{E R_{i}^{C}}\right) \\
+\frac{\frac{\partial \ln \eta_{i}(\cdot)}{\partial \ln Y_{i}}}{\left(-\eta_{i}(\cdot)+1\right)} * \frac{d Y_{i}}{Y_{i}}
\end{gathered}
$$

Solving for the relative price change yields:

$$
\frac{d p_{i}}{p_{i}}=\left(1+\beta_{i}\right) \frac{d M C}{M C}+\beta_{i} \frac{d E R_{i}}{E R_{i}}+\delta_{i}\left(\frac{d p_{i}^{C}}{p_{i}^{C}}+\frac{d E R_{i}^{C}}{E R_{i}^{C}}\right)+\omega_{i} \frac{d Y_{i}}{Y_{i}}
$$

where

$$
\begin{aligned}
& \frac{d M C}{M C}=\frac{d \frac{\partial C(\cdot)}{\partial q}}{\frac{\partial C(\cdot)}{\partial q}} \\
& \beta_{i}=\frac{\frac{\partial \ln \eta_{i}(\cdot)}{\partial \ln \ddot{p}_{i}}}{\left(-\eta_{i}(\cdot)+1\right)-\frac{\partial \ln \eta_{i}(\cdot)}{\partial \ln \ddot{p}_{i}}} \\
& \delta_{i}=\frac{\frac{\partial \ln \eta_{i}(\cdot)}{\partial \ln \ddot{p}_{i}^{C}}}{\left(-\eta_{i}(\cdot)+1\right)-\frac{\partial \ln \eta_{i}(\cdot)}{\partial \ln \ddot{p}_{i}}} \\
& \omega_{i}=\frac{\frac{\partial \ln \eta_{i}(\cdot)}{\partial \ln y_{i}}}{\left(-\eta_{i}(\cdot)+1\right)-\frac{\partial \ln \eta_{i}(\cdot)}{\partial \ln \ddot{p}_{i}}}
\end{aligned}
$$


Substituting into the competitor's function yields:

$$
\begin{aligned}
\frac{d p_{i}}{p_{i}} & =\left(1+\beta_{i}\right) \frac{d M C}{M C}+\beta_{i} \frac{d E R_{i}}{E R_{i}}+\delta_{i}\left(\left(1+\beta_{i}^{C}\right) \frac{d M C^{C}}{M C^{C}}+\beta_{i}^{C} \frac{d E R_{i}^{C}}{E R_{i}^{C}}+\delta_{i}^{C}\left(\frac{d p_{i}}{p_{i}}+\frac{d E R_{i}}{E R_{i}}\right)+\omega_{i}^{C} \frac{d Y_{i}}{Y_{i}}+\frac{d E R_{i}^{C}}{E R_{i}^{C}}\right) \\
& +\omega_{i} \frac{d Y_{i}}{Y_{i}} \\
\frac{d p_{i}}{p_{i}} & =\left(1+\beta_{i}\right) \frac{d M C}{M C}+\left(\beta_{i}+\delta_{i} \delta_{i}^{C}\right) \frac{d E R_{i}}{E R_{i}}+\delta_{i}\left(1+\beta_{i}^{C}\right)\left(\frac{d M C^{C}}{M C^{C}}+\frac{d E R_{i}^{C}}{E R_{i}^{C}}\right)+\delta_{i} \delta_{i}^{C} \frac{d p_{i}}{p_{i}} \\
& +\left(\omega_{i}+\delta_{i} \omega_{i}^{C}\right) \frac{d Y_{i}}{Y_{i}} \\
\frac{d p_{i}}{p_{i}} & =\left(1+\frac{\left(\beta_{i}+\delta_{i} \delta_{i}^{C}\right)}{\left(1-\delta_{i} \delta_{i}^{C}\right)}\right) \frac{d M C}{M C}+\frac{\left(\beta_{i}+\delta_{i} \delta_{i}^{C}\right)}{\left(1-\delta_{i} \delta_{i}^{C}\right)} \frac{d E R_{i}}{E R_{i}}+\frac{\delta_{i}\left(1+\beta_{i}^{C}\right)}{\left(1-\delta_{i} \delta_{i}^{C}\right)}\left(\frac{d M C^{C}}{M C^{C}}+\frac{d E R_{i}^{C}}{E R_{i}^{C}}\right) \\
& +\frac{\left(\omega_{i}+\delta_{i} \omega_{i}^{C}\right)}{\left(1-\delta_{i} \delta_{i}^{C}\right)} \frac{d Y_{i}}{Y_{i}}
\end{aligned}
$$

Introducing symbols for the coefficients:

$$
\frac{d p_{i}}{p_{i}}=\left(1+\tau_{i}\right) \frac{d M C}{M C}+\tau_{i} \frac{d E R_{i}}{E R_{i}}+\varphi_{i}\left(\frac{d M C^{C}}{M C^{C}}+\frac{d E R_{i}^{C}}{E R_{i}^{C}}\right)+\varpi_{i} \frac{d Y_{i}}{Y_{i}}
$$




\section{Appendix 4.2: SMC series for New Zealand (in 1000 NZ\$)}

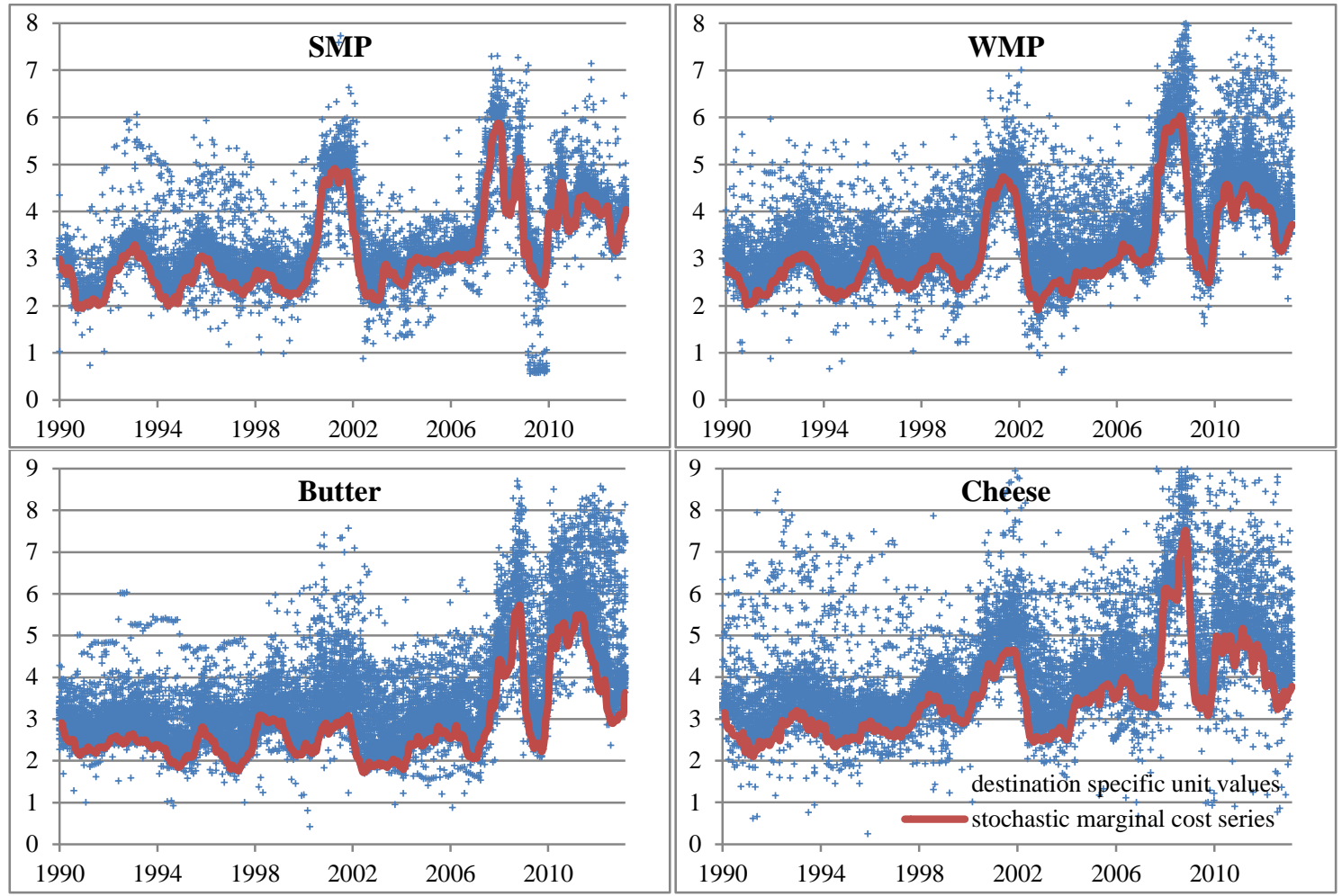

Source: Own compilation, GTA (2013)

\section{Appendix 4.3: SMC series for the EU (in $1000 €$ )}

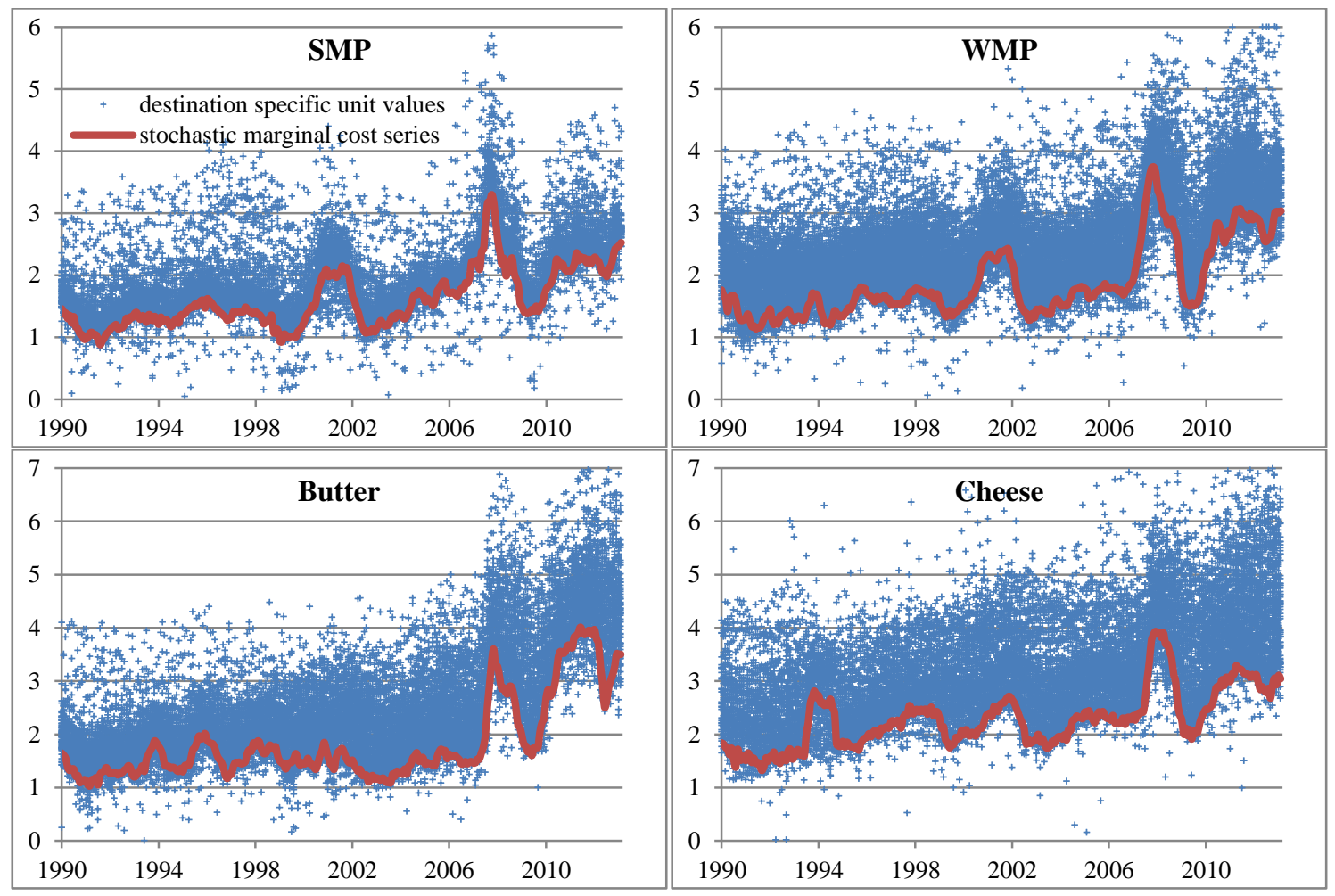

Source: Own compilation, GTA (2013) 


\title{
5 Measuring Market Power on the World Dairy Markets: A Resid- ual Demand Analysis
}

\begin{abstract}
The international dairy markets are highly concentrated. In particular, the New Zealand dairy co-operative Fonterra controls - directly or indirectly - huge proportions of the important markets for milk powders and butter. Under these conditions, Fonterra can be expected to have a significant degree of market power. However, to our knowledge this question has not been addressed in the literature until now. The conceptual innovation of this paper is to therefore close this gap by using the residual demand approach to estimate the ability to raise the price above the marginal cost. Usually in the residual demand model, cost shifting variables are used to reflect changes in the marginal cost. Since this entails several disadvantages, we instead use an alternative measure of the marginal cost, the stochastic lower price frontier; this is the methodological innovation of the paper. The rather conservative results of estimating the residual demand for New Zealand dairy exports show a significant degree of market power with an average optimal markup of around $9 \%$ of the price in more than fifty percent of the destination countries. The most important competitors that limit the market power of Fonterra are Australia and the EU.
\end{abstract}

Keywords: residual demand, market power, price discrimination, international dairy markets 


\subsection{Introduction}

The international dairy markets are highly concentrated. On the supply side, only four large exporting countries - New Zealand, the EU, Australia and the US - make up 80\% to $90 \%$ of all dairy exports. On the opposite side, demand is much less concentrated. However, even when the focus is shifted from countries to companies, the international supply side concentration remains strong. The most remarkably company is the New Zealand dairy cooperative Fonterra that developed in part from the New Zealand Dairy Board, and is still responsible for $95 \%$ of New Zealand's dairy exports (ARMENTANO et al. 2004: 41). This alone equals roughly a third of the international dairy exports, whereas in some markets the share is much higher. Furthermore, through foreign subsidiaries, partnerships, joint ventures and agreements, Fonterra can directly or indirectly influence the exports of other countries (BLAYNEY et al. 2006: 13-15). Taking this into account, Fonterra controls more than half of the market, especially in the case of the important markets for milk powder and butter. This raises the suspicion that the company has a noticeable degree of market power, particularly in destination countries where competition is weaker. This is additionally supported by the fact that DAIRY AUSTRALIA (2008: 18) observe differences in dairy products with respect to quality, safety and functionality according to the country of origin. To our knowledge there are no studies that analyze New Zealand's (or Fonterra's) market power on the international dairy markets.

In this paper, we close this gap in the literature by applying the residual demand approach to New Zealand's exports of the most important dairy products. The approach rests on the estimation of the residual demand curve faced by a single firm or a group of firms; in other words, the demand curve obtained when the reaction of the competitors is already considered. In the case of perfect competition, the residual demand curve is flat - that is, the firm (or the group of firms) is not able to raise the price by reducing its quantity. Conversely, for a monopolist the residual demand curve equals the market demand curve since no competitors are in place. By estimating the residual demand, it is possible to distinguish between the case of perfect competition and the alternative of some degree of market power. Under some conditions, it is even possible to quantify the markup in terms of the Lerner index. The residual demand approach is developed by BAKER \& BRESNAHAN (1988) for single firms while GOLDBERG \& KNETTER (1999) use the approach to analyze market power on international markets and thus on the country level - that is, groups of firms are usually considered. In general, the approach is used for a wide variety of products and markets - for domestic markets and single firms as 
well as in the international framework at the country level. Examples of studies at the country level in the area of agricultural and food products are CARTER et al. (1999), Glauben \& Loy (2003), NARdis \& Pensa (2004), ReEd \& Saghaian (2004), PoOSIRIPINYO \& REED (2005), TASDOGAN et al. (2005) as well as FELT et al. (2011).

Nevertheless, the residual demand approach also entails some econometrical estimation challenges. In order to estimate the influence of the endogenous export quantity on the export price, suitable instruments are necessary. For this purpose, cost shifting variables of the export country are usually used. When these cost shifters depict only a small fraction of the marginal cost, the estimated coefficients and its standard errors can be expected to be biased. A similar result can occur when the considered cost shifters are not able to explain the export quantity at all - that is, they prove to be weak instruments. These kinds of problems seem to be common when international markets are analyzed (GOLDBERG \& KNETTER 1997: 1266-1268). Therefore, instead of using usual cost shifting variables we rely on using a measure of the marginal cost that is always available, when a certain number of destination-specific unit values are available: the stochastic lower price frontier. This represents the methodological contribution of this paper. The concept is introduced in Chapter 4 and builds on the basic idea from KNETTER (1989; 1993) to use prices - measured by unit values - in order to control for changes in the marginal cost. Indeed, SILVENTE (2005) already uses a series obtained from an application of the model proposed by KNETTER (1989) as a measure of the marginal cost in a residual demand model.

The paper is structured as follows: In Chapter 5.2 the concept of the residual demand curve is developed as derived by GOLDBERG \& KNETTER (1999), and the connection between the residual demand curve and the relative markup is established. This is followed by the presentation of the empirical specification of the model in Chapter 5.3 along with typical estimation problems and the introduction of the stochastic lower price frontier as a measure of the marginal cost. In Chapter 5.4, the data that is used for the estimation of the New Zealand export market is discussed. Chapter 5.5 contains the estimation results for the most important dairy products and Chapter 5.6 finalizes the paper with some conclusions. 


\subsection{The residual demand and its connection to market power}

GOLDBERG \& KNETTER (1999) consider a group of $m$ firms located in a certain export country and exporting a homogenous good to a particular destination country. In the destination country, the group of export firms faces competition from firms of $n$ different export countries. This could be groups of firms (as in the export country) or only a single firm per country. While the good exported is always homogeneous (or a perfect substitute) for firms located in the same country - which implies that the firms always charge the same price -, it may be a perfect substitute or an imperfect substitute for the goods produced in other countries. This assumption of product differentiation according to the country of origin is also known as the Armington assumption (ARMINGTON 1969).

Under these conditions, the common inverse demand function that the group of export firms faces and the inverse demand function that the k-th competing country faces are:

$$
\begin{aligned}
& p^{e x}=P^{e x}\left(Q^{e x}, p^{k=1, \ldots, n}, \boldsymbol{Z}\right) \\
& p^{k}=P^{k}\left(Q^{k}, p^{l=1, \ldots, n \mid l \neq k}, p^{e x}, \boldsymbol{Z}\right)
\end{aligned}
$$

where $p^{e x}$ is the export price (in the destination country's currency) charged by the group of export firms and $Q^{e x}$ is the total quantity exported to the particular destination country by these firms; $p^{k}$ is the export price (in the destination country's currency) charged by the export firm or group of export firms of the k-th competing country and $Q^{k}$ is the corresponding export quantity; $\boldsymbol{Z}$ is a vector of demand shifters in the particular destination country. The profit that the i-th export firm makes with exports to the destination country is:

$$
\Pi_{i}^{e x}\left(q_{i}^{e x}\right) \equiv p^{e x} q_{i}^{e x}-E R * C_{i}^{e x}\left(q_{i}^{e x}, \boldsymbol{W}_{i}^{e x}\right)
$$

where $q_{i}^{e x}$ is the export quantity of the $\mathrm{i}$-th firm, $E R$ is the bilateral exchange rate between the export and the destination country (units of destination country's currency per unit of export country's currency), $\mathrm{C}_{\mathrm{i}}^{\mathrm{ex}}$ is the cost of the firm (in the export country's currency) and $\boldsymbol{W}_{\boldsymbol{i}}^{\boldsymbol{e x}}$ is a vector of cost shifters. When the destination-specific profit defined in equation (5.3) is maximized with respect to the quantity exported, we obtain the first order condition: marginal cost equals perceived marginal revenue. It is the perceived marginal revenue instead of the actual revenue that appears in the first order condition because the marginal revenue depends on the conduct of the competitors at home and abroad; the firm is not aware of this conduct and can only make conjectures 
about it. This can be seen in the following equation where the first order condition is solved for export price:

$$
p^{e x}=E R * M C_{i}^{e x}-q_{i}^{e x} \frac{\partial P^{e x}}{\partial Q^{e x}}\left(1+\sum_{j \neq i}^{m} \frac{\partial q_{j}^{e x}}{\partial q_{i}^{e x}}\right)\left(1+\sum_{k=1}^{n} \frac{\partial P^{e x}}{\partial p^{k}} \frac{\partial P^{k}}{\partial p^{e x}}\right)
$$

Equation (5.4) states that the perceived optimal price for the group of export firms consists of the marginal cost in the destination country's currency $E R * M C_{i}^{e x}$ (the arguments of the marginal cost are suppressed) plus the perceived optimal markup as the second term on the right hand side. The two bracketed terms in the perceived optimal markup depict the conjectured conduct of the competitors. The first bracketed term shows the reaction of the domestic competitors and is hereafter labeled $\theta_{i}$. Under perfect competition, each quantity change by the firm will be offset by its competitors and $\theta_{i}$ is therefore equal to zero. On the other side, a value of one reflects the situation in a perfect cartel (or a monopoly). The second bracketed term captures the reaction of the foreign competitors and is hereafter labeled $\phi$. Again, a value of zero indicates perfect competition whereas a value of one implies a perfect cartel. When the bracketed terms are replaced by the symbols introduced above, equation (5.4) simplifies to:

$$
p^{e x}=E R * M C_{i}^{e x}-q_{i}^{e x} * \frac{\partial P^{e x}}{\partial Q^{e x}} * \theta_{i} * \phi
$$

Equation (5.5) is still based on firm-level data that is often not available for the purpose of an econometric estimation - especially in the framework of international trade. GOLDBERG \& KNETTER (1999) therefore prefer to use market share weighted industry averages. The set of first order conditions for the group of $m$ firms is multiplied with their respective market share $s_{i}$ and summed up for all firms in the group. Therefore, the result based on market-level data becomes:

$$
p^{e x}=E R * M C^{e x}-Q^{e x} * \frac{\partial P^{e x}}{\partial Q^{e x}} * \theta * \phi
$$

where $M C^{e x}=\sum s_{i} M C_{i}^{e x}, Q^{e x}=\sum q_{i}^{e x}$ and $\theta=\sum s_{i}{ }^{2} \theta_{i}$. Similar to equation (5.6), the first order conditions can be derived in the same way for the competing countries. For the $\mathrm{k}$-th competitor, this is:

$$
p^{k}=E R^{k} * M C^{k}-Q^{k} * \frac{\partial P^{k}}{\partial Q^{k}} * \vartheta^{k}
$$

Up to this point, the approach is very general and not specific for the residual demand. The demand equations (5.1) and (5.2) as well as the supply equations (5.6) and (5.7) could be estimated in a system after defining suitable functional forms. However, the 
specificity of the residual demand approach is that these equations are manipulated in a way that only one equation remains: the residual demand. For this purpose, GoLDBERG \& KNETTER (1999) start by solving a system of $2 n$ competitor demand and competitor supply equations that are defined in equations (5.2) and (5.7). When the competitor demand function (5.2) is substituted into the competitor supply function (5.7), we obtain:

$$
p^{k}=E R^{k} * M C^{k}\left(Q^{k}, \boldsymbol{W}^{k}\right)-Q^{k} * \frac{\partial P^{k}}{\partial Q^{k}}\left(Q^{k}, p^{l=1, \ldots, n \mid l \neq k}, p^{e x}, \boldsymbol{Z}\right) * \vartheta^{k}
$$

Solving the system of competitor equations yields for the k-th competitor:

$$
p^{k}=p^{k *}\left(Q^{e x}, \boldsymbol{W}^{N}, \boldsymbol{Z}, \boldsymbol{\vartheta}^{N}\right)
$$

where $\boldsymbol{W}^{\boldsymbol{N}}$ is a vector of the cost shifters of the $n$ competing countries and $\boldsymbol{\vartheta}^{\boldsymbol{N}}$ is the vector of the conduct parameters. The function depicted in (5.9) explains the perceived optimal competitor prices depending on cost shifters of the competitors, demand shifters in the destination country and quantity supplied by the export country. Because $Q^{e x}$ is the only endogenous right hand side variable, equation (5.9) represents a function of partial-reduced form. When the equation is substituted into equation (5.1) for all $k \in\{1, \ldots, n\}$ and common variables are grouped together, we obtain the inverse residual demand function of the export country in the particular destination country:

$$
\begin{aligned}
p^{e x} & =P^{e x}\left(Q^{e x}, \mathrm{p}^{1 *}(\cdot), \ldots, \mathrm{p}^{\mathrm{n} *}(\cdot), \boldsymbol{Z}\right) \\
& =P^{r e s, e x}\left(Q^{e x}, \boldsymbol{W}^{N}, \boldsymbol{Z}, \boldsymbol{\vartheta}^{N}\right)
\end{aligned}
$$

This is again a function of partial-reduced form with quantity exported, supply shifters of the competitors and demand shifters as observable arguments. Note that the cost shifters of the export country are not represented in the function. Moreover, their exclusion ensures that the inverse residual demand function is econometrically identified. However, the cost shifters of the export country are the perfect candidates as instruments for the only endogenous right hand side variable $Q^{e x}$.

The key variable in equation (5.10) is $Q^{e x}$ since it reveals whether the group of export country's firms has market power in the particular destination country. When the price of the export country can be fully explained by the competitors' costs and demand conditions, and the firms' export quantity has no influence at all, the group of the export country's firms has no market power. Conversely, the more elastic the price is with respect to the firms' export quantity - i.e. the higher the inverse residual demand elasticity (RDE) is -, the more pronounced the market power of the group of export country's 
firms is. The composition of the $\operatorname{RDE}\left(\eta_{e x}^{r e s}\right)$ can be illustrated, when the logarithm of equation (5.10) is taken and the result is differentiated with respect to $Q^{e x}$. This yields:

$$
\begin{aligned}
\eta_{e x}^{r e s} \equiv \frac{\partial \ln P^{r e s, e x}}{\partial \ln Q^{e x}} & =\frac{\partial \ln P^{e x}}{\partial \ln Q^{e x}}+\sum_{k=1}^{n} \frac{\partial \ln P^{e x}}{\partial \ln p^{k *}} * \frac{\partial \ln p^{k *}}{\partial \ln Q^{e x}} \\
& =\eta_{e x}+\sum_{k=1}^{n} \eta_{e x, k} * \varepsilon_{k, e x}
\end{aligned}
$$

The equation reveals that $\eta_{e x}^{r e s}$ is composed of two elements: Firstly, the (inverse) own price elasticity of demand $\eta_{e x}$ for the variety of the good produced in the export country. Secondly, the elasticity of the competitor interactions - this is the sum of the (inverse) elasticities with respect to competitor prices $\eta_{e x, k}$ multiplied by the elasticities of the competitors' prices with respect to changes in the export quantity of the group of export country's firms $\varepsilon_{k, e x}$. BAKER \& BRESNAHAN (1988) show that the RDE can be even more precise in indicating market power than suggested above. When the marginal cost is brought to the right hand side in equation (5.6), both sides are divided through $p^{e x}$ and equation (5.11) is applied, the following equality appears:

$$
\frac{p^{e x}-M C^{e x}}{p^{e x}}=-\eta_{e x}^{r e s}
$$

where $M C^{e x}$ is now the marginal cost in the destination country's currency. This means that the RDE is equal to the relative markup, also known as the Lerner index (LERNER 1934). However, in this strict sense this is only true under certain conditions. In fact, while the firms choose their profit maximizing price according to the conjectured conduct of the competitors, the estimation of the residual demand is instead based on the actual conduct of the competitors. Therefore, the equality displayed in (5.12) only holds when the actual and the conjectured residual demand coincide. This is generally the case in a Consistent Conjectures Equilibrium that is described by BRESNAHAN (1981). BAKER \& BRESNAHAN (1988: 289-290) report four cases in which it can be safely assumed that the equality with the Lerner index holds. These cases are a) perfect competition as non-cooperative case, b) a firm that is a Stackelberg leader, c) a dominant firm with a price-taking fringe and d) a significant degree of product differentiation. However, even when the equality with the Lerner index does not hold perfectly, GOLDBERG \& KNETTER (1999: 39) argue that a higher absolute value of the RDE still indicates a higher degree of market power. 


\subsection{Empirical specification and estimation problems}

\subsubsection{The residual demand specification}

Equation (5.10) reveals the variables that determine the residual demand. With regard to the functional form of the residual demand, GoldBERG \& KNETTER (1999: 40) propose a double-log specification that allows interpreting the coefficients as elasticities. The general form of the resulting time series model for a particular destination country is:

$$
\ln p_{t}^{e x}=\alpha+\eta \ln Q_{t}^{e x}+\boldsymbol{\beta}^{\prime} \ln \boldsymbol{Z}_{t}+\boldsymbol{\gamma}^{\prime} \ln \boldsymbol{W}_{t}^{N}+u_{t}
$$

where $p_{t}^{e x}$ is the export price (in the destination country's currency), $Q_{t}^{e x}$ is the endogenous quantity exported by the group of export country's firms, $\boldsymbol{Z}_{t}$ is a vector of demand shifters in the destination country (and in its currency), $\boldsymbol{W}_{t}^{N}$ is a vector of the competing countries' cost shifters and $u_{t}$ is an error term for which the usual assumptions apply.

The most important parameter in equation (5.13) is $\eta$ since it represents the estimate for the inverse residual demand elasticity (RDE). According to its relation to the Lerner index, we can expect it to lie between zero and minus one; zero indicates perfect competition and significant absolute values smaller than zero indicate market power. In contrast, the parameters $\boldsymbol{\beta}^{\prime}$ and $\boldsymbol{\gamma}^{\prime}$ do not have a clear interpretation. They both depict direct effects on the demand the group of export country's firms face as well as indirect effects based on the adjustment of the competitors (BAKER \& BRESNAHAN 1988: 297).

Variables that should usually be among the demand shifters are the real gross domestic product (GDP), the consumer price index (CPI) and a time trend. Furthermore, dummy variables can account for changes in barriers to trade such as the change of tariff rates or the occurrence of free trade agreements. Typical cost shifting variables are the factor prices for important inputs such as wages, interest rates as well as prices for raw materials, intermediate goods and energy. However, these variables often do not reveal a high variation and follow similar patterns across exporting countries. This is problematic because the econometric identification of the residual demand requires specific cost variables for the considered country groups of firms at least for the group of export country's firms that is analyzed (BAKER \& BRESNAHAN 1988: 289). This is where the advantage of international markets as a research object comes into play. GOLDBERG \& KNETTER (1999: 41) argue that the bilateral exchange rates (ER) between the export or competitor country and the destination country are ideal cost shifters. They move the costs of the export country and its competitors independently of each other and usually exhibit a substantial amount of variation. 
The cost shifting variables of the group of export country's firms - including its ER are not represented in equation (5.13) since this allows the econometric identification. However, these variables are the natural instruments for the endogenous export quantity of the group of export country's firms $\left(Q_{t}^{e x}\right)$. They do not appear in equation (5.13), are exogenous and are therefore not correlated with the error term but correlated with the export quantity.

\subsubsection{Instrumentation problems and cost shifting variables}

FROEB \& WERDEN (1991: 42-46) discuss some typical problems that may arise when the residual demand has to be estimated. Although the authors have primary national markets and single firms in mind, we will argue that on international markets these problems can be even more serious. The problems concern the need for cost shifting variables - firstly as suitable instruments for the endogenous quantity, and secondly to depict the competitors' marginal costs in equation (5.13). Even if cost shifting variables are available in empirical applications, they are not necessarily good candidates. At best, such variables should reflect a high proportion of the variance of the marginal cost.

When cost shifters do not reflect a high proportion of the marginal cost, the instrumental variables (IV) estimator reveals an increasing variance and may even be biased ${ }^{16}$. The latter is true when the observed and unobserved proportions of the marginal cost are correlated. Suppose that $W^{e x}$ is the observed and $V^{e x}$ the unobserved proportion of the group of export country's firms' marginal cost, while $W^{N}$ is the observed and $V^{N}$ the unobserved proportion of the marginal cost of a competing country. When $W^{N}$ and $V^{N}$ are correlated, both the IV and the OLS estimator are biased since $V^{N}$ is part of the error term. The case is similar when $W^{e x}$ is correlated with $V^{N}$. This again results in a bias of the IV estimator because $W^{e x}$ serves as instrument (FROEB \& WERDEN 1991: 44-45). Therefore, the instrument is not valid. As described in Chapter 5.3.1, the most important cost shifters that are used on an international markets framework are ERs since they shift the marginal cost in the destination country's currency. However, ERs are also correlated with determinants of the marginal cost in the country of origin (GOLDBERG \& KNETTER 1997: 1251). They influence a) the prices of imported goods in the country of origin and b) the exported quantity of the good and therefore the marginal cost. Moreover, in residual demand studies on international markets, cost shifting variables other than the ERs are hardly used.

\footnotetext{
${ }^{16}$ The same holds for the two step least squares (2SLS) estimator.
} 
However, even if the observed and unobserved parts of the marginal cost are not correlated with each other, the IV estimator suffers an increased variance when the respective parts are correlated among the exporting countries - that is, $W^{e x}$ is correlated with $W^{N}$ and $V^{e x}$ is correlated with $V^{N}$. In fact, the larger this correlation is and the smaller the proportion of the marginal cost that is observed, the larger the variance of the IV estimator is (FROEB \& WERDEN 1991: 45-46). Indeed, a lot of cost shifters - for instance factor prices - show very similar trends and patterns across exporting countries. This also applies for ERs as cost shifters and is especially important when the variation of the ERs is primary caused by a changing worth of the destination country's currency.

In the case of inappropriately chosen cost shifters which do not explain the quantity exported well, the additional problem of weak instruments arises. Weak instruments imply that the endogenous right-hand side variable is poorly explained in the first step of 2SLS. This causes two serious problems with the estimator. Firstly, the estimator is biased in the direction of the OLS estimator. This is due to a finite-sample bias that can be - even in large samples - quite serious, and may in the worst case be more pronounced than for OLS. Secondly, the estimated standard error of the replaced endogenous right-hand variable is biased downwards so that the null hypothesis of a coefficient of zero is too often rejected (MURRAY 2006: 120-128). Furthermore, when the endogenous right-hand variable is only explained by the other exogenous variables of equation (5.13), this introduces quite a high amount of multicollinearity in the model and again influences the standard errors (FROEB \& WERDEN 1991: 42).

For international markets, the danger of weak instruments for the export quantity seems very pronounced in general. GOLDBERG \& KNETTER (1997: 1266-1268) discuss that bilateral export quantities reveal a high degree of volatility that is probably too high in order to be explained by changes in fundamental factors such as demand. The authors refer to their own work as well as to Aw (1993). They suspect an improper data collection as a reason for this observation. GLAUBEN \& LOY (2003) report explicitly that they were not able to explain export quantity in the first step of 2SLS with the bilateral exchange rate for the markets they analyze. Unfortunately, in all other residual demand studies that we know of, the issue of weak instruments is neither explicitly mentioned nor are tests reported. It is therefore unclear whether this problem applies in general with international markets. 
In order to avoid the problem of weak instruments, FROEB \& WERDEN (1991: 42-44) propose to use either price or quantity as the left-hand side variable depending on which one reveals the lower correlation with the cost shifters. In the case of an elastic residual demand, that is price; for an inelastic residual demand, that is quantity. However, if quantity is on the left-hand side, $\eta$ in equation (5.13) actually measures the residual demand elasticity, not the inverse one. That introduces a disadvantage with regard to the testing procedure for market power. When the inverse residual demand elasticity is tested against zero, this is a test for market power at the same time. In contrast, the residual demand elasticity cannot be tested against infinity, only against particular values.

An alternative way to get rid of the problem of weak instruments is to stick to OLS. BAKER \& BRESNAHAN (1988: 298) state that the OLS estimates are most likely biased in the direction of rejection of market power. Therefore, they can simply be seen as a conservative estimate for the RDE. This is also supported by the results of GOLDBERG \& KNETTER (1999) who compare SUR estimates with IV and 3SLS estimates. In general, FROEB \& WERDEN (1991: 43-44) show that the severity of the bias depends on the relation between the variance of the error term and the variance of the group of export country's firms' marginal cost as the natural instrument. The smaller the variance of the error term is in comparison to the variance of the marginal cost, the less serious the endogeneity bias of OLS is. This implies that when a larger part of the competitors' marginal costs is represented via $\boldsymbol{W}_{t}^{N}$ in equation (5.13), the price of the group of export country's firms can probably be explained to a higher degree; therefore, the variance of the error term decreases and the endogeneity bias decreases too. Since 2SLS has a bias in the same direction as OLS in finite samples, this applies for 2SLS as well.

\subsubsection{A measure of the marginal cost as an alternative}

As discussed in Chapter 5.3.2, the reliance on cost shifting variables instead of the marginal cost can lead to serious problems. Unfortunately, the marginal cost is not directly observable and therefore cannot be introduced in equation (5.13). However, in the pricing-to-market (PTM) literature, the model proposed by KNETTER $(1989 ; 1993)$ provides a measure of the marginal cost that is estimated through the use of fixed time effects in a panel approach. In fact, SILVENTE (2005) uses the series thus obtained as a measure of the marginal cost in a residual demand equation. The fixed effects of the Knetter model basically depict the average price by means of unit values in the sample while simultaneously correcting them for PTM. The resulting series is surely connected to the mar- 
ginal cost, but may be noisy and even biased when the markup contained therein varies due to imperfect cost pass-through; in any case, it is not necessarily the best approximation available for the marginal cost.

Based on the key idea of KNETTER (1989; 1993), we use an alternative measure of the marginal cost that we explain in detail in Chapter 4.3.2. In addition to the marginal cost, the observed unit values contain several further elements such as markups, quality premiums, measurement errors and expectation effects - for the case that contracts are used. While the marginal cost is equal for all destinations at the point of export, the other elements are not. Finding a good approximation for the marginal cost requires decomposing unit values into these elements. In a statistical sense, a complete decomposition is even not necessary when something is known about the basic characteristics of these elements. We can then estimate distributions for these elements and distinguish them from the marginal cost. In doing so, we can separate the elements into two groups: Measurement errors and expectation effects (first group) can be expected to be independently normally distributed with a mean of zero; thus their sum is normally distributed with zero mean as well. Markups and quality premiums (second group) on the other side are positive deviations from the marginal cost. Since larger markups are more difficult to defend, a truncated normal distribution is a natural candidate for a suitable distribution. This implies that the i-th export unit value (in the export country's currency) at time $\mathrm{t}$ is composed as follows:

$$
p_{i t}=\theta_{t}+v_{i t}+u_{i t}
$$

where for the composed error term $\left(v_{i t}+u_{i t}\right)$ it is assumed:

$$
\begin{aligned}
& v_{i t} \sim \operatorname{iid} \mathrm{N}\left(0, \sigma_{v_{t}}^{2}\right) \\
& u_{i t} \sim \operatorname{iid} \mathrm{N}^{+}\left(\mu_{t}, \sigma_{u_{t}}^{2}\right)
\end{aligned}
$$

Additionally, the error components are assumed to be independently distributed (KUMBHAKAR \& LOVELL 2003: 169). The first error component $v_{i t}$ contains measurement errors and expectation effects whereas the second error component $u_{i t}$ contains markups and quality premiums.

Equation (5.14) is a stochastic frontier model that is usually estimated via maximum likelihood and provides the stochastic lower price frontier (SLPF) as fitted values - that is $\theta_{t}$. When the distribution assumptions hold ${ }^{17}$, the SLPF is an unbiased estimate of the

\footnotetext{
${ }^{17}$ See Chapter 4.3.2 for a discussion of consequences when the distribution assumptions are violated.
} 
marginal cost; this estimate is hereafter called the "stochastic" marginal cost (SMC). Since, for example, the level of the markups can vary over time, the distribution parameters depend on time too. Therefore, equation (5.14) cannot be estimated for the whole time span but separately for each point in time. However, in order to increase the number of observations and therefore the estimation efficiency, we prefer to estimate the model in a rolling window procedure for three consecutive points in time. As long as the distribution parameters are similar for adjacent periods and only change significantly over longer time periods, the increase of efficiency can be expected to outweigh the loss of temporal flexibility in the estimation.

In general, the SMC is estimated in the respective export country's currency. This means that the ERs remain in equation (5.13), while all other cost shifters are replaced by the SMC of the respective country. Nevertheless, in combination with the SMC, the ERs do not exhibit the problems discussed in Chapter 5.3.2, but depict the full range of variations of the marginal cost in the destination country's currency. In summary, the usage of the SMC in a residual demand model has the following advantages:

- There is no need to search for cost shifters whose appropriateness with respect to the good analyzed may not be clear. Conversely, the SLPF can always be estimated when a certain number of destination-specific unit values are available.

- Instead of relying on cost shifters, the SMC depicts the complete range of changes in the marginal cost. Therefore, the danger of a higher variance and a bias of the 2SLS estimation are averted.

- The marginal cost can be expected to be a stronger instrument than single cost shifters.

- The usage of the SMC for the competing countries can be expected to explain a larger fraction of the price and therefore reduce the endogeneity bias in OLS and also in 2SLS that is biased toward the same direction in finite samples.

A possible disadvantage of the SMC is that it carries the risk of some degree of endogeneity. However, as we argue in Chapter 4.3.2 this risk can probably be neglected when the SMC is used in equations for single destination countries. 


\subsection{Data}

The international dairy markets cover a wide range of products traded. For the estimation of the residual demand, we chose the four most important products. They are skimmed milk powder (SMP, HS 040210), whole milk powder (WMP, HS 040221), butter (HS 040510) and cheddar cheese (HS 0406900011) ${ }^{18}$. Together, these products account for the majority of New Zealand's dairy exports. Furthermore, all of them are commodities and therefore quite homogeneous. The destination countries selected for the analysis have to fulfill certain conditions. That is, the quantity traded should be sufficiently high in order ensure that the trade data is of reliable quality with (almost) no periods where trade is not observed.

As competitors of New Zealand, we consider the respective domestic competitors in the destination country as well as the EU and Australia (for SMP the US is also considered). On average, New Zealand and its competitors account for around $90 \%$ of the imports of the destination countries and products considered. The remaining foreign competitors are very small and are only of regional importance. This means that the most important sources of competition should be represented in the model.

The data for prices and quantities required for the estimation of the residual demand is gathered at the port of export. As measure of the prices, we use unit values (i.e. trade volume divided by quantity). Furthermore, we also use them to estimate the $\mathrm{SMC}^{19}$. The data is obtained from the Global Trade Atlas (GTA 2013) for a time period of 1995 to 2012. For New Zealand and the EU, the data would be available from 1990 onwards but the availability for Australia restricts the start year to 1995. For the estimation of equation (5.13), we use quarterly data ${ }^{20}$. Quarterly or even annual data is often used in residual demand studies. Unlike monthly data, this holds the advantage that the number of missing values in the trade data is reduced and thus more destination countries can be analyzed. Furthermore, a lower frequency increases the accuracy of the trade data since, for example, the unit values are based on larger quantities traded. Finally, FroEB \& WERDEN (1991: 40-42) also suggest the usage of lower frequencies since this reduces problems that stem from the dynamic properties of the data. When the observations do

\footnotetext{
${ }^{18}$ Because Cheddar cheese is of less importance for the EU, we instead use as competing product a composition consisting of Gouda, Edam and cheddar cheese (HS 04069021, HS 04069023, HS 04069078).

${ }^{19}$ The sample characteristics of the unit values and the estimation results for the SMC series are listed in Appendix 5.1 and discussed in general in Chapter 4.5.1. Furthermore, both destination-specific unit values and the SMC series are depicted in Appendix 4.2, 4.3 and 5.2.

${ }^{20}$ In contrast, for the estimation of the SMC series we use monthly data and transform the obtained series afterwards into a quarterly frequency.
} 
not represent static equilibriums, the estimated RDEs may just represent short term reactions. However, lower frequencies also entail a number of problems. If the dynamic process itself is the object of interest, aggregation clearly makes no sense; but even if not, aggregation may cause a bias and reduces the number of degrees of freedom. Therefore, quarterly data seems to be a good compromise.

Since we use the unit value data to estimate the SMC in the currency of the country to which it belongs, we need the nominal ERs as additional cost shifters. They are obtained from the International Financial Statistics (IFS). In order to depict the competitors from the destination country in the model, we use the milk price in the respective destination country as a cost shifter which is obtained from FAOSTAT. Furthermore, as demand shifters, the real Gross Domestic Product (GDP) and the Consumer Price Index (CPI) are again obtained from the IFS.

\subsection{Estimation results}

In residual demand studies, equation (5.13) is usually estimated in levels without checking for the time series properties of the variables - that is whether the variables exhibit a unit root or not, and if so whether they are co-integrated. An exception is GLAUBEN \& LOY (2003); they explicitly tested for this and mostly rejected the existence of a longrun relationship. We experience a similar result. Some - but not all - variables exhibit a unit root whereas in almost all cases the Engle-Granger test cannot reject the null hypothesis of no Cointegration. This implies that the estimation in levels and in an error correction representation is not valid, and equation (5.13) has to be estimated in first differences. This at least has the advantage that it is not necessary to control for changes in the trade policy, such as changing import tariffs. Import tariffs changed in the observation period, for example, due to a number of free trade agreements between New Zealand and some of the destination countries. Indeed, we would not have detailed information about all of those changes that supposedly took place in the observation period.

As discussed in Chapter 5.3, the right hand side variable quantity is endogenous and has to be instrumented. Therefore we started estimating the first difference version of equation (5.13) with 2SLS. Unfortunately, the preferred instruments - that is, the SMC of New Zealand and its ER to the destination country - turned out to be very weak instruments. Indeed, they are mostly not even significant at the ten percent level in the first stage. This means that the usage of the SMC does not solve the weak instrument problem - at least not in our dataset. Additionally, we tried to use the milk price and the 
milk production in New Zealand as well as the lagged change in quantity as instruments, but this does not change the result ${ }^{21}$. If the model is still estimated with 2SLS, the estimated RDE shows very unusual values. We therefore decided to estimate the model in the next step with OLS. Since the Breusch-Pagan test rejects the null hypothesis of no contemporaneous correlation of the residuals across the equations, we finally estimated the equations for each product as a system with seemingly unrelated regressions (SUR). For contemporaneously correlated errors, SUR increases the estimation efficiency. However, since OLS and SUR yield conservative estimates of the RDE, the true absolute values can be expected to lie above the estimated coefficients.

In general, all equations are tested for heteroscedasticity (Breusch-Pagan test), autocorrelation (Breusch-Godfrey test) and parameter stability (CUSUM test). In almost all equations, the coefficients are constant whereas in the majority of the cases the errors are homoscedastic and are not serially correlated. In order to address a lagged adjustment of the price, we include several lags of the right hand side variables into the model. The lag numbers used are chosen according to the minimum of the information criteria $\mathrm{AIC}, \mathrm{BIC}$ and HQK. When lags are included, we depict the sum of the contemporaneous and lagged coefficients in the tables; the t-statistics belong to this sum too.

In Table 5.1, the estimation results for $\mathrm{SMP}^{22}$ as well as the average surcharge of the unit values on SMC (UV surcharge ${ }^{23}$ ) and the import market shares of New Zealand are shown. In addition to the variables displayed in the table, we include a constant, the GDP, the CPI, a time trend (that equals a quadratic trend in the model in levels) and quarterly dummies. However, changes in GDP and CPI do not exhibit a high amount of variation and are only significant in three cases. The same is true for the time trend that is only significant in one case. On the contrary, at least one quarterly dummy is significant in twelve out of sixteen equations. According to the information criteria, for half of the equations no lags are optimal, while for the other half mostly one lag is optimal. This means that competition is significantly lagged for half of the destination countries. A possible reason for this could be the usage of medium- and long-term contracts. Nonetheless, the model explains a high share of the changes in the prices. The coeffi-

\footnotetext{
${ }^{21}$ Even if the model is estimated in levels the instruments turn out to be weak.

${ }^{22}$ The order of the destinations in the table represents their importance with respect to New Zealand's total export quantity in the observation period.

${ }^{23}$ The UV surcharges are calculated similar to the Lerner index with unit values serving as prices. That is, they depict the difference of unit value and SMC in relation to the unit value as average for the whole observation period. The UV surcharges can consist of a markup as well as quality premiums and are therefore not a measure of market power by themself. Nonetheless, since a quality premium cannot be negative, they represent the upper limit of the actual markup for the respective destination country.
} 
cient of determination has an average value of 0.60 , which is quite high for time series models in first differences. Single equations exhibit even higher R-squared values, but there are also equations with rather low values.

Table 5.1: SUR estimation results for SMP

\begin{tabular}{|c|c|c|c|c|c|c|c|c|c|c|c|c|}
\hline \multirow{3}{*}{ Destination } & \multirow{3}{*}{ 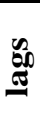 } & \multirow{3}{*}{$\eta$} & \multicolumn{6}{|c|}{ competing countries } & \multirow{3}{*}{$\begin{array}{l}\text { dest. } \\
\text { milk } \\
\text { price }\end{array}$} & \multirow{3}{*}{$\mathbf{R}^{2}$} & \multirow{3}{*}{$\begin{array}{l}\text { UV sur- } \\
\text { charge }\end{array}$} & \multirow{3}{*}{$\begin{array}{c}\text { market } \\
\text { share }\end{array}$} \\
\hline & & & \multicolumn{2}{|c|}{$\mathbf{E U}$} & \multicolumn{2}{|c|}{ Australia } & \multicolumn{2}{|c|}{ USA } & & & & \\
\hline & & & SMC & ER & SMC & ER & SMC & ER & & & & \\
\hline Philip & 1 & $\begin{array}{c}-0.07 * * \\
(-2.41)\end{array}$ & $\begin{array}{c}0.78 * * * \\
(4.15)\end{array}$ & $\begin{array}{c}0.45 \\
(1.32)\end{array}$ & $\begin{array}{c}0.04 \\
(0.19)\end{array}$ & $\begin{array}{c}0.20 \\
(0.58)\end{array}$ & $\begin{array}{c}0.25 * * * \\
(2.94)\end{array}$ & $\begin{array}{c}0.02 \\
(0.06)\end{array}$ & $\begin{array}{c}-0.04 \\
(-0.06)\end{array}$ & 0.72 & $9.0 \%$ & $36.3 \%$ \\
\hline Malay & 1 & $\begin{array}{c}-0.13 * * * \\
(-4.40)\end{array}$ & $\begin{array}{c}0.53 * * * \\
(3.28)\end{array}$ & $\begin{array}{c}0.11 \\
(0.32)\end{array}$ & $\begin{array}{c}0.45^{* *} \\
(2.61)\end{array}$ & $\begin{array}{c}1.06^{* * *} \\
(3.02)\end{array}$ & $\begin{array}{c}0.03 \\
(0.38)\end{array}$ & $\begin{array}{c}0.54 \\
(1.48)\end{array}$ & $\begin{array}{c}-0.38 \\
(-1.02)\end{array}$ & 0.78 & $10.2 \%$ & $38.1 \%$ \\
\hline China & 0 & $\begin{array}{c}0.01 \\
(1.29)\end{array}$ & $\begin{array}{c}0.07 \\
(0.57)\end{array}$ & $\begin{array}{c}0.23 \\
(0.83)\end{array}$ & $\begin{array}{c}0.59 * * * \\
(5.43)\end{array}$ & $\begin{array}{c}0.61 * * \\
(2.67)\end{array}$ & $\begin{array}{c}0.18 * * * \\
(3.33)\end{array}$ & $\begin{array}{c}-0.21 \\
(-0.18)\end{array}$ & $\begin{array}{c}0.01 \\
(0.08)\end{array}$ & 0.68 & $5.7 \%$ & $54.3 \%$ \\
\hline Indo & 2 & $\begin{array}{l}-0.06^{*} \\
(-1.71)\end{array}$ & $\begin{array}{c}0.75 * * * \\
(4.65)\end{array}$ & $\begin{array}{l}0.83 * * \\
(2.61)\end{array}$ & $\begin{array}{c}-0.02 \\
(-0.09)\end{array}$ & $\begin{array}{c}-0.15 \\
(-0.46)\end{array}$ & $\begin{array}{l}0.19^{*} \\
(2.00)\end{array}$ & $\begin{array}{c}-0.01 \\
(-0.03)\end{array}$ & $\begin{array}{c}0.04 \\
(0.21)\end{array}$ & 0.91 & $10.6 \%$ & $27.0 \%$ \\
\hline The & 1 & $\begin{array}{c}-0.02 \\
(-1.09)\end{array}$ & $\begin{array}{c}0.74 * * * \\
(3.45)\end{array}$ & $\begin{array}{c}0.26 \\
(0.62)\end{array}$ & $\begin{array}{c}0.19 \\
(0.82)\end{array}$ & $\begin{array}{c}0.58 \\
(1.40)\end{array}$ & $\begin{array}{c}0.07 \\
(0.59)\end{array}$ & $\begin{array}{c}0.38 \\
(0.98)\end{array}$ & $\begin{array}{l}1.49 * * \\
(2.06)\end{array}$ & 0.78 & $7.6 \%$ & $34.1 \%$ \\
\hline Sauci & 2 & $\begin{array}{c}0.01 \\
(0.21)\end{array}$ & $\begin{array}{c}1.13 * * * \\
(3.69)\end{array}$ & $\begin{array}{c}0.86 \\
(1.64)\end{array}$ & $\begin{array}{c}-0.06 \\
(-0.19)\end{array}$ & $\begin{array}{c}1.41 * * * \\
(3.02)\end{array}$ & $\begin{array}{c}0.10 \\
(0.53)\end{array}$ & & $\begin{array}{c}0.81 \\
(0.90)\end{array}$ & 0.69 & $7.1 \%$ & $50.3 \%$ \\
\hline Japa & 0 & $\begin{array}{c}0.04^{* *} \\
(2.18)\end{array}$ & $\begin{array}{c}-0.11 \\
(-0.60)\end{array}$ & $\begin{array}{c}0.57 \\
(1.40)\end{array}$ & $\begin{array}{c}0.82 * * * \\
(4.50)\end{array}$ & $\begin{array}{c}0.38 \\
(1.02)\end{array}$ & $\begin{array}{c}0.23 * * * \\
(2.80)\end{array}$ & $\begin{array}{c}0.37 \\
(0.98)\end{array}$ & $\begin{array}{c}-4.60 * * \\
(-2.18)\end{array}$ & 0.63 & $1.6 \%$ & $29.1 \%$ \\
\hline Taiu & 0 & $\begin{array}{c}-0.07 * * * \\
(-3.73)\end{array}$ & $\begin{array}{c}0.38 * * * \\
(3.15)\end{array}$ & $\begin{array}{c}0.25 \\
(0.92)\end{array}$ & $\begin{array}{c}0.25^{* *} \\
(2.11)\end{array}$ & $\begin{array}{c}0.32 \\
(1.34)\end{array}$ & $\begin{array}{c}0.04 \\
(0.77)\end{array}$ & $\begin{array}{c}0.29 \\
(0.96)\end{array}$ & & 0.57 & $13.9 \%$ & $48.1 \%$ \\
\hline Sing & 1 & $\begin{array}{c}-0.10 * * * \\
(-3.76)\end{array}$ & $\begin{array}{c}0.74 * * \\
(2.59)\end{array}$ & $\begin{array}{c}0.18 \\
(0.30)\end{array}$ & $\begin{array}{c}0.15 \\
(0.52)\end{array}$ & $\begin{array}{l}1.17 * * \\
(2.14)\end{array}$ & $\begin{array}{c}0.13 \\
(1.03)\end{array}$ & $\begin{array}{c}0.38 \\
(0.57)\end{array}$ & & 0.68 & $5.5 \%$ & $34.5 \%$ \\
\hline $\mathbf{N}$ & 0 & $\begin{array}{c}0.01 \\
(1.48)\end{array}$ & $\begin{array}{c}0.17 \\
(0.75)\end{array}$ & $\begin{array}{c}-0.09 \\
(-0.14)\end{array}$ & $\begin{array}{c}0.69 * * * \\
(2.91)\end{array}$ & $\begin{array}{c}0.87 \\
(1.59)\end{array}$ & $\begin{array}{c}-0.03 \\
(-0.31)\end{array}$ & $\begin{array}{c}-0.09 \\
(-0.18)\end{array}$ & $\begin{array}{c}0.68 \\
(0.74)\end{array}$ & 0.33 & $16.3 \%$ & $8.2 \%$ \\
\hline Peru & 0 & $\begin{array}{c}0.00 \\
(-0.81)\end{array}$ & $\begin{array}{c}0.42 * * \\
(2.62)\end{array}$ & $\begin{array}{c}0.49 \\
(1.28)\end{array}$ & $\begin{array}{c}0.54 * * * \\
(3.48)\end{array}$ & $\begin{array}{c}0.78 * * \\
(2.31)\end{array}$ & $\begin{array}{c}-0.01 \\
(-0.13)\end{array}$ & $\begin{array}{c}-0.12 \\
(-0.25)\end{array}$ & $\begin{array}{c}0.41 \\
(0.74)\end{array}$ & 0.57 & $8.4 \%$ & $34.1 \%$ \\
\hline A & 0 & $\begin{array}{c}-0.09 * * * \\
(-2.75)\end{array}$ & $\begin{array}{c}0.72 * * \\
(2.41)\end{array}$ & $\begin{array}{c}-0.20 \\
(-0.22)\end{array}$ & & & $\begin{array}{c}-0.10 \\
(-0.56)\end{array}$ & $\begin{array}{l}1.16^{*} \\
(1.70)\end{array}$ & $\begin{array}{c}-0.65 \\
(-0.85)\end{array}$ & 0.26 & $0.0 \%$ & $91.7 \%$ \\
\hline ong & 1 & $\begin{array}{c}0.00 \\
(0.15)\end{array}$ & $\begin{array}{c}0.88 * * * \\
(3.27)\end{array}$ & $\begin{array}{c}0.55 \\
(1.06)\end{array}$ & $\begin{array}{c}0.19 \\
(0.70)\end{array}$ & $\begin{array}{c}0.68 \\
(1.43)\end{array}$ & $\begin{array}{c}0.07 \\
(0.56)\end{array}$ & & & 0.58 & $12.4 \%$ & $51.2 \%$ \\
\hline Sri I & 0 & $\begin{array}{c}-0.05 * * * \\
(-3.54)\end{array}$ & $\begin{array}{c}0.18 \\
(1.11)\end{array}$ & $\begin{array}{c}-0.03 \\
(-0.09)\end{array}$ & $\begin{array}{c}0.77 * * * \\
(4.74)\end{array}$ & $\begin{array}{c}0.78 * * \\
(2.43)\end{array}$ & $\begin{array}{c}0.05 \\
(0.63)\end{array}$ & $\begin{array}{c}0.21 \\
(0.43)\end{array}$ & $\begin{array}{l}-1.03^{*} \\
(-1.84)\end{array}$ & 0.62 & $11.2 \%$ & $53.5 \%$ \\
\hline $\begin{array}{l}\text { Arab } \\
\text { Emirates }\end{array}$ & 1 & $\begin{array}{c}-0.02 \\
(-0.87)\end{array}$ & $\begin{array}{c}0.50 * * \\
(2.35)\end{array}$ & $\begin{array}{c}0.37 \\
(0.90)\end{array}$ & $\begin{array}{l}0.41^{*} \\
(1.81)\end{array}$ & $\begin{array}{c}0.23 \\
(0.67)\end{array}$ & $\begin{array}{c}0.13 \\
(1.27)\end{array}$ & & & 0.67 & $4.5 \%$ & $18.9 \%$ \\
\hline $\begin{array}{l}\text { South } \\
\text { Korea }\end{array}$ & 0 & $\begin{array}{c}-0.13 * * * \\
(-2.93)\end{array}$ & $\begin{array}{c}-0.52 \\
(-0.61) \\
\end{array}$ & $\begin{array}{l}-3.76^{*} \\
(-1.79)\end{array}$ & $\begin{array}{l}1.68^{*} \\
(1.99)\end{array}$ & $\begin{array}{c}4.42 * * \\
(2.24)\end{array}$ & $\begin{array}{c}0.21 \\
(0.52)\end{array}$ & $\begin{array}{c}1.12 \\
(0.73)\end{array}$ & $\begin{array}{c}0.08 \\
(0.09)\end{array}$ & 0.26 & $16.1 \%$ & $10.8 \%$ \\
\hline Average & & -0.08 & 0.69 & 0.83 & 0.69 & 1.46 & 0.21 & 1.16 & & 0.60 & $8.8 \%$ & $38.8 \%$ \\
\hline
\end{tabular}

Note: The numbers in parenthesis are t-statistics; the asterisks denote the $10 \%(*), 5 \%(* *)$ and $1 \%(* * *)$ significance level. For coefficients the average applies to the significant ones that have the correct sign. The import market share is calculated by dividing New Zealand's exports in the period 2000 to 2012 through the total exports to this destination.

Source: Own calculations, GTA (2013)

The key coefficients in Table 5.1 are the estimates of the inverse residual demand elasticity (RDE, $\eta$ in the table). In eight out of sixteen equations, the table shows a significantly negative RDE. The mean of these values is -0.085 . This implies that the optimal markup would be $8.5 \%$ of the price. In comparison, the average UV surcharge for the same destinations is $9.5 \%$. Therefore, the majority of the deviations from the marginal 
cost seem to be markups and not quality premiums. However, even for the destination countries with non-significant RDE estimates, the UV surcharges are $8.8 \%$ on average. In general, the RDE estimates and UV surcharges in Table 5.1 are only weakly correlated; a fact that also applies for the results for WMP, butter and cheese (Tables 5.2, 5.3, 5.4). This can be explained as follows: Firstly, the endogeneity bias can be more serious in some equations than in others. Secondly, the UV surcharge can be highly affected by different qualities. Thirdly, the RDE estimates indicate the actual optimal markup that can deviate from the one that is perceived by Fonterra. In the case of Malaysia, Singapore and Australia, the markups implied by the RDEs are even higher than the UV surcharges. Thus, Fonterra could charge a higher markup than it is obviously doing.

The equation for Australia is especially notable for a number of idiosyncratic aspects. Firstly, Australia is an important export country that produces under world market conditions, but imports SMP itself. Since these imports are almost exclusively from New Zealand, the competitor variables only explain a small fraction of the price changes (the R-squared is only 0.26). Secondly, the estimated RDE implies that Fonterra can charge a markup of $7 \%$ of the price. However, the average unit value Fonterra is actually charging in the observation period just equals the SMC. This low UV surcharge also speaks against some kind of special quality. The answer could be that Fonterra delivers SMP at cost price to the Australian dairy company Bonlac in which it has an ownership stake of 50\% (ARMENTANO et al. 2004: 49). Nevertheless, two further equations also exhibit low R-squares, those of South Korea and Mexico. In both countries Fonterra has a very low market share of about $10 \%$ and the UV surcharge is about $16 \%$. Therefore, Fonterra could supply some niche or premium qualities. While this fits to the relatively high estimate of the RDE in South Korea, it does not fit in the case of Mexico.

In the case of Mexico, the lack of influence of the US is particularly surprising. Mexico is the most important destination country for the US, reaching an import market share of around $70 \%$. However, as Table 5.1 shows, the US only has influence in a few destination countries, and when it does have influence, it is rather small ${ }^{24}$. The reason for this could be an agreement of Dairy America - an association of seven US dairy companies - with Fonterra. This agreement concerns the selling of US-SMP on the global markets and makes Fonterra the most important exporter of US-SMP (ARMENTANO et al. 2004: 46-47). The agreement could enable Fonterra to protect itself from US-competition.

\footnotetext{
${ }^{24}$ Note that the expected values for the SMC and the ER lie between zero and one; zero, when there is no influence at all and one, when the price is completely determined by the marginal cost of the competitor.
} 
Moreover, as a competitor for Fonterra even the domestic dairy industry in the destination countries is rarely important. This is indicated by the estimated coefficients for the milk prices in the destination countries. Only in the case of Thailand is there a significant positive coefficient. As a result, only the EU and Australia remain as important competitors. For both countries, there are just four destinations in which they do not have any influence, but there is no destination that is not influenced by at least one of the competitors. Furthermore, almost all of their variables' coefficients have the expected sign, but the SMC has more often a significant influence than the ER - especially in the case of the EU. This could be because the ERs included are correlated to a rather high degree or that the official ERs may - in some cases - not be the actual ones.

In addition to the different significance of the ERs in the case of the EU and Australia, there are further differences. Although the average t-value of the EU's SMC is larger than for Australia, a highly significant influence of the Australian variables seems to be more often associated with a non-significant RDE. This would mean that Australia more effectively restricts the market power of Fonterra. This could be a sign of different kinds of competition with the EU in comparison to Australia. In the case of the EU, SMP is subject to the intervention scheme and its export was subsidized until 2007. This resulted in very volatile EU exports of SMP and probably periods with larger overall price gaps between the competitors as well as a high competition pressure - even without products necessarily perceived as being highly homogenous across origins. Conversely, changes in the bilateral ERs could be offset to some degree by the export subsidy policy that allowed (in part) country specific payments. For Australia, the situation is different. Exports stayed on a similar level and a high degree of competition could be due to similar distribution channels or products being perceived as more similar.

These considerations are supported by an interesting detail with regard to the lag number of the equations. When the lag numbers are increased, the influence of the EU's SMC and ER increases (the value of the coefficients and the value of the t-statistics), whereas Australia's importance as a competitor decreases. If there is no difference with respect to the contract practice, this could be a sign that the switch to Australian SMP is easier and faster than to SMP from the EU. Furthermore, the significant quarterly dummies could be a sign for different degrees of competition throughout the year. In the quarters in which competition is rather weak, Fonterra could increase its price relative to its competitors. This kind of seasonality is probably caused by a strong seasonality in the milk production as is the case for New Zealand and Australia. 
Table 5.2: SUR estimation results for WMP

\begin{tabular}{|c|c|c|c|c|c|c|c|c|c|c|c|c|}
\hline \multirow{3}{*}{ Destination } & \multirow{3}{*}{ 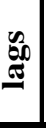 } & \multirow{3}{*}{$\eta$} & \multicolumn{4}{|c|}{ competing countries } & \multirow{3}{*}{$\begin{array}{l}\text { dest. } \\
\text { milk } \\
\text { price }\end{array}$} & \multicolumn{2}{|c|}{ demand shifter } & \multirow{3}{*}{$\mathbf{R}^{2}$} & \multirow{3}{*}{$\begin{array}{l}\text { UV sur- } \\
\text { charge }\end{array}$} & \multirow{3}{*}{$\begin{array}{c}\text { market } \\
\text { share }\end{array}$} \\
\hline & & & \multicolumn{2}{|c|}{$\mathbf{E U}$} & \multicolumn{2}{|c|}{ Australia } & & GDP & CPI & & & \\
\hline & & & SMC & ER & SMC & ER & & GDT & CFI & & & \\
\hline China & 0 & $\begin{array}{c}0.00 \\
(0.13)\end{array}$ & $\begin{array}{l}0.24 * \\
(1.85)\end{array}$ & $\begin{array}{l}0.49^{*} \\
(1.86)\end{array}$ & $\begin{array}{c}0.61 * * * \\
(5.22)\end{array}$ & $\begin{array}{c}0.35 \\
(1.57)\end{array}$ & $\begin{array}{c}0.08 \\
(0.71)\end{array}$ & $\begin{array}{c}0.63 \\
(0.81) \\
\end{array}$ & & 0.64 & $6.3 \%$ & $86.1 \%$ \\
\hline Venezuela & 0 & $\begin{array}{c}0.01 \\
(0.95)\end{array}$ & $\begin{array}{c}0.18 \\
(1.02)\end{array}$ & $\begin{array}{c}0.58 * * \\
(2.03)\end{array}$ & $\begin{array}{c}0.52 * * * \\
(3.41)\end{array}$ & $\begin{array}{c}0.29 \\
(1.03) \\
\end{array}$ & $\begin{array}{c}0.23 \\
(0.74) \\
\end{array}$ & $\begin{array}{c}0.91 \\
(1.52)\end{array}$ & & 0.65 & $10.2 \%$ & $45.0 \%$ \\
\hline Malaysia & 1 & $\begin{array}{c}-0.15 * * * \\
(-3.17)\end{array}$ & $\begin{array}{c}0.10 \\
(0.64) \\
\end{array}$ & $\begin{array}{c}0.33 \\
(0.97) \\
\end{array}$ & $\begin{array}{c}0.58 * * * \\
(3.89)\end{array}$ & $\begin{array}{c}0.39 \\
(1.13) \\
\end{array}$ & \begin{tabular}{|c|}
-0.16 \\
$(-0.42)$ \\
\end{tabular} & $\begin{array}{c}1.16 \\
(1.23) \\
\end{array}$ & $\begin{array}{c}2.99 * * \\
(2.12)\end{array}$ & 0.64 & $12.0 \%$ & $73.4 \%$ \\
\hline Sri Lanka & 0 & $\begin{array}{c}-0.16^{* * * *} \\
(-4.00)\end{array}$ & $\begin{array}{c}0.17 \\
(1.00) \\
\end{array}$ & $\begin{array}{c}0.48 \\
(1.52) \\
\end{array}$ & $\begin{array}{c}0.42 * * * \\
(2.85)\end{array}$ & $\begin{array}{c}-0.02 \\
(-0.08) \\
\end{array}$ & $\begin{array}{c}0.38 \\
(0.76) \\
\end{array}$ & $\begin{array}{c}2.15 \\
(1.63) \\
\end{array}$ & $\begin{array}{c}0.25 \\
(0.56) \\
\end{array}$ & 0.41 & $11.1 \%$ & $76.8 \%$ \\
\hline Mex & 0 & $\begin{array}{l}0.01 * \\
(1.89) \\
\end{array}$ & $\begin{array}{c}0.70 * * * \\
(3.37) \\
\end{array}$ & $\begin{array}{c}1.08 * * * \\
(3.07) \\
\end{array}$ & $\begin{array}{l}0.35^{*} \\
(1.91) \\
\end{array}$ & $\begin{array}{c}-0.10 \\
(-0.25) \\
\end{array}$ & $\begin{array}{c}-0.19 \\
(-0.25) \\
\end{array}$ & $\begin{array}{c}0.55 \\
(1.08) \\
\end{array}$ & $\begin{array}{c}1.41 \\
(1.05) \\
\end{array}$ & 0.49 & $8.5 \%$ & $67.1 \%$ \\
\hline $\begin{array}{l}\text { Saudi } \\
\text { Arabia } \\
\end{array}$ & 1 & \begin{tabular}{|c|}
$-0.05 * *$ \\
$(-2.04)$ \\
\end{tabular} & $\begin{array}{c}0.49 * * * \\
(3.83) \\
\end{array}$ & $\begin{array}{c}0.39 \\
(1.66) \\
\end{array}$ & \begin{tabular}{|c|}
$0.38 * * *$ \\
$(3.29)$ \\
\end{tabular} & \begin{tabular}{|c|}
$0.60 * * *$ \\
$(3.01)$ \\
\end{tabular} & \begin{tabular}{c|}
-0.29 \\
$(-0.74)$ \\
\end{tabular} & \begin{tabular}{|l|}
$1.82 *$ \\
$(1.83)$ \\
\end{tabular} & $\begin{array}{c}0.66 \\
(0.72) \\
\end{array}$ & 0.82 & $7.1 \%$ & $42.8 \%$ \\
\hline Thailand & 1 & $\begin{array}{c}-0.02 \\
(-0.52)\end{array}$ & $\begin{array}{c}0.12 \\
(0.86)\end{array}$ & $\begin{array}{l}0.44 * \\
(1.82)\end{array}$ & $\begin{array}{c}0.52 * * * \\
(4.16)\end{array}$ & $\begin{array}{l}0.39 * \\
(1.68)\end{array}$ & \begin{tabular}{c|}
-0.10 \\
$(-0.23)$ \\
\end{tabular} & $\begin{array}{c}0.41 \\
(0.72) \\
\end{array}$ & $\begin{array}{c}0.03 \\
(0.04)\end{array}$ & 0.71 & $11.3 \%$ & $64.2 \%$ \\
\hline Indonesia & 0 & $\begin{array}{c}-0.05 * * * \\
(-3.17)\end{array}$ & $\begin{array}{c}0.49 * * * \\
(3.02)\end{array}$ & $\begin{array}{c}0.31 \\
(1.09)\end{array}$ & $\begin{array}{c}0.44 * * * \\
(3.04)\end{array}$ & $\begin{array}{l}0.55^{*} \\
(1.96)\end{array}$ & $\begin{array}{c}0.05 \\
(0.21) \\
\end{array}$ & $\begin{array}{c}-0.56 \\
(-0.34)\end{array}$ & $\begin{array}{c}-0.14 \\
(-0.30)\end{array}$ & 0.77 & $7.8 \%$ & $66.5 \%$ \\
\hline Philippines & 0 & $\begin{array}{c}-0.04 * * \\
(-2.17)\end{array}$ & $\begin{array}{c}0.21 \\
(1.28)\end{array}$ & $\begin{array}{c}0.22 \\
(0.77)\end{array}$ & $\begin{array}{c}0.38 * * * \\
(2.69)\end{array}$ & $\begin{array}{c}0.26 \\
(0.94)\end{array}$ & $\begin{array}{c}1.42 * * \\
(2.56)\end{array}$ & $\begin{array}{c}3.00 \\
(1.48)\end{array}$ & $\begin{array}{c}-0.92 \\
(-0.97)\end{array}$ & 0.50 & $15.5 \%$ & $70.8 \%$ \\
\hline Taiwan & 0 & $\begin{array}{l}-0.07 * \\
(-1.78) \\
\end{array}$ & $\begin{array}{c}0.47 * * * \\
(2.69) \\
\end{array}$ & $\begin{array}{l}0.62 * \\
(1.88) \\
\end{array}$ & $\begin{array}{c}0.22 \\
(1.41) \\
\end{array}$ & $\begin{array}{c}0.27 \\
(0.93) \\
\end{array}$ & & & & 0.47 & $20.1 \%$ & $55.4 \%$ \\
\hline $\begin{array}{l}\text { rab } \\
\text { mirates }\end{array}$ & 1 & $\begin{array}{c}-0.07 * * * \\
(-3.06)\end{array}$ & $\begin{array}{c}-0.02 \\
(-0.12) \\
\end{array}$ & $\begin{array}{c}0.73 * * * \\
(2.76)\end{array}$ & $\begin{array}{c}0.71 * * * \\
(5.19)\end{array}$ & \begin{tabular}{|c|}
-0.04 \\
$(-0.17)$ \\
\end{tabular} & & & & 0.70 & $9.3 \%$ & $53.9 \%$ \\
\hline Singa & 0 & $\begin{array}{c}-0.11 * * * \\
(-4.33)\end{array}$ & $\begin{array}{c}0.58 * * \\
(2.21) \\
\end{array}$ & $\begin{array}{c}0.44 \\
(0.74) \\
\end{array}$ & $\begin{array}{c}0.29 \\
(1.27)\end{array}$ & $\begin{array}{c}0.25 \\
(0.53) \\
\end{array}$ & & $\begin{array}{c}0.21 \\
(0.13) \\
\end{array}$ & $\begin{array}{c}0.10 \\
(0.04) \\
\end{array}$ & 0.49 & $1.2 \%$ & $43.0 \%$ \\
\hline Peru & 1 & $\begin{array}{c}-0.04 * * \\
(-2.32)\end{array}$ & $\begin{array}{l}0.43^{*} \\
(1.97) \\
\end{array}$ & $\begin{array}{c}0.30 \\
(0.73) \\
\end{array}$ & $\begin{array}{c}0.44 * * \\
(2.30) \\
\end{array}$ & $\begin{array}{c}1.18 * * * \\
(3.25) \\
\end{array}$ & $\begin{array}{c}0.26 \\
(0.48) \\
\end{array}$ & $\begin{array}{c}-1.08 \\
(-0.84) \\
\end{array}$ & $\begin{array}{c}-0.61 \\
(-0.52)\end{array}$ & 0.62 & $11.2 \%$ & $48.9 \%$ \\
\hline El Salvador & 1 & $\begin{array}{c}0.03 \\
(1.25) \\
\end{array}$ & $\begin{array}{c}0.85 * * * \\
(4.30)\end{array}$ & $\begin{array}{c}0.52 \\
(1.53) \\
\end{array}$ & $\begin{array}{c}0.08 \\
(0.45) \\
\end{array}$ & $\begin{array}{c}0.35 \\
(1.43) \\
\end{array}$ & $\begin{array}{c}0.37 \\
(1.13) \\
\end{array}$ & $\begin{array}{c}-1.59 \\
(-0.82) \\
\end{array}$ & $\begin{array}{c}0.09 \\
(0.08) \\
\end{array}$ & 0.68 & $11.2 \%$ & $44.9 \%$ \\
\hline Mauritius & 0 & $\begin{array}{c}-0.02 \\
(-0.83) \\
\end{array}$ & $\begin{array}{c}0.46^{* * * *} \\
(3.01)\end{array}$ & $\begin{array}{c}0.41 \\
(1.31) \\
\end{array}$ & $\begin{array}{c}0.38 * * * \\
(2.99) \\
\end{array}$ & $\begin{array}{c}0.24 \\
(0.98) \\
\end{array}$ & $\begin{array}{c}0.65^{* *} \\
(2.10)\end{array}$ & $\begin{array}{c}-1.88 \\
(-1.26) \\
\end{array}$ & $\begin{array}{c}-0.60 \\
(-0.65)\end{array}$ & 0.51 & $16.5 \%$ & $49.4 \%$ \\
\hline Fiji & 0 & $\begin{array}{c}0.02 \\
(1.63) \\
\end{array}$ & $\begin{array}{c}0.58 * * * \\
(4.42) \\
\end{array}$ & $\begin{array}{c}0.34 \\
(1.41) \\
\end{array}$ & $\begin{array}{c}0.25 * * \\
(2.18) \\
\end{array}$ & \begin{tabular}{|c|}
$1.06 * * *$ \\
$(4.68)$
\end{tabular} & & $\begin{array}{c}2.00 \\
(1.60)\end{array}$ & $\begin{array}{c}-0.22 \\
(-0.34) \\
\end{array}$ & 0.67 & $15.6 \%$ & $61.8 \%$ \\
\hline Average & & -0.08 & 0.53 & 0.66 & 0.46 & 0.76 & & & & 0.61 & $10.9 \%$ & $59.4 \%$ \\
\hline
\end{tabular}

Source: Own calculations, GTA (2013)

In Table 5.2, the results for WMP are displayed. In general, they are very similar to those for SMP. This applies, for instance, to the average R-squared value, the nonsignificance of demand shifters and competition from the destination country as well as to the estimates of the RDE itself. There are nine out of sixteen equations with significant negative RDE coefficients and an average value of -0.082 . This proximity to the RDE estimates for SMP is surprising since Fonterra has a markedly higher market share for WMP. Even when the same destination countries are considered, the estimates are almost always very similar. A further similarity is that the RDE estimates are hardly 
correlated with the UV surcharges or with the market share of New Zealand and its competitors - this is a general result for all products analyzed. The market share alone seems to have no influence on the degree of market power indicated by the RDE.

Some differences between the results for SMP and WMP exist with respect to the competitor influence. Again, only the EU and Australia remain as main competitors but the EU's variables are less often significant than the Australian variables when compared to SMP. Furthermore, the average t-values of the SMC coefficients are smaller for the EU and larger for Australia compared to SMP - although the average SMC coefficient of the significant variables is larger for the EU than for Australia. This could be due to a different supply behavior of the EU. WMP is not subject to the intervention scheme and - in contrast to SMP - WMP exports are hardly volatile in the observation period and exhibit a downward trend. This implies that there is not a similar competition pressure from highly fluctuating EU exports as is the case for SMP. Furthermore, in the case of WMP, the competition is often less lagged and the t-statistics of the EU's SMC and ER generally do not increase anymore when the lag number is increased.

An interesting case with regard to the RDE estimates is Singapore. The country has huge RDE estimates for all products (including butter and cheese), but for SMP and WMP it has very low UV surcharges (5.5\% and $1.2 \%)$. The country is a net importer but exports noticeable amounts of dairy products. When these exports are actually reexports, this could explain the RDE estimates which imply a markedly larger markup than the UV surcharges would allow - at least for milk powder. In this case, a low price would facilitate re-exports and therefore also increase the exports to Singapore, while for a higher price only the domestic consumption will probably remain.

The estimation results for butter in Table 5.3 show some differences to those for the milk powders, SMP and WMP. Although the mean of the significant RDE estimates of -0.078 is again similar, the coefficients are significant in more cases - that is, in twelve out of eighteen cases. This goes along with a) lower coefficients of determination (i.e. changes in competitor prices explain a lower fraction of changes in Fonterra's prices), b) smaller average coefficients for competitors' SMC (competitor ER's are significant only in a few cases) and c) markedly higher UV surpluses. On the contrary, the market share lies between those of the milk powders. All this suggests that butter is more heterogeneous (or differentiated) across origins than the milk powders. However, for the average degree of markup implied by the RDE coefficients this hardly matters. 
Table 5.3: SUR estimation results for butter

\begin{tabular}{|c|c|c|c|c|c|c|c|c|c|c|c|c|}
\hline \multirow{3}{*}{ Destination } & \multirow{3}{*}{$\begin{array}{l}\mathscr{y} \\
\underline{60} \\
\mathbb{E}\end{array}$} & \multirow{3}{*}{$\eta$} & \multicolumn{4}{|c|}{ competing countries } & \multirow{3}{*}{$\begin{array}{l}\text { dest. } \\
\text { milk } \\
\text { price }\end{array}$} & \multicolumn{2}{|c|}{ demand shifter } & \multirow{3}{*}{$\mathbf{R}^{2}$} & \multirow{3}{*}{$\begin{array}{l}\text { UV sur- } \\
\text { charge }\end{array}$} & \multirow{3}{*}{$\begin{array}{c}\text { market } \\
\text { share }\end{array}$} \\
\hline & & & \multicolumn{2}{|c|}{ EU } & \multicolumn{2}{|c|}{ Australia } & & GDP & CPI & & & \\
\hline & & & SMC & ER & SMC & ER & & & & & & \\
\hline Russia & 1 & \begin{tabular}{|c|}
$-0.08 * * *$ \\
$(-4.75)$
\end{tabular} & $\begin{array}{l}0.28^{*} \\
(1.68)\end{array}$ & \begin{tabular}{|c|}
$0.99 * *$ \\
$(2.47)$ \\
\end{tabular} & $\begin{array}{c}0.32 * * \\
(2.64)\end{array}$ & \begin{tabular}{|c|}
-0.20 \\
$(-0.50)$ \\
\end{tabular} & $\begin{array}{c}0.30 \\
(0.79) \\
\end{array}$ & & & 0.61 & $5.7 \%$ & $31.7 \%$ \\
\hline Australia & 1 & $\mid \begin{array}{c}-0.13 * * * \\
(-3.16)\end{array}$ & $\begin{array}{c}0.62 * * * \\
(5.39)\end{array}$ & $\begin{array}{c}-0.14 \\
(-0.48)\end{array}$ & & & $\begin{array}{c}0.03 \\
(0.10)\end{array}$ & $\begin{array}{c}2.99 \\
(1.27)\end{array}$ & \begin{tabular}{c|}
3.00 \\
$(1.38)$
\end{tabular} & 0.39 & $14.0 \%$ & $95.4 \%$ \\
\hline Taiwan & 0 & $\begin{array}{c}-0.01 \\
(-0.96) \\
\end{array}$ & $\begin{array}{c}0.32 * * * \\
(3.70)\end{array}$ & $\begin{array}{c}0.54 * * \\
(2.42) \\
\end{array}$ & $\begin{array}{c}0.31 * * * \\
(4.63)\end{array}$ & $\begin{array}{c}0.19 \\
(0.88) \\
\end{array}$ & & & & 0.57 & $13.5 \%$ & $65.2 \%$ \\
\hline $\begin{array}{l}\text { Saudi } \\
\text { Arabia }\end{array}$ & 0 & $\begin{array}{c}-0.03 * * \\
(-2.15)\end{array}$ & $\begin{array}{c}0.18 \\
(1.28)\end{array}$ & $\begin{array}{c}0.67 \\
(1.66)\end{array}$ & $\begin{array}{c}0.30 * * * \\
(2.68)\end{array}$ & $\begin{array}{c}0.02 \\
(0.07)\end{array}$ & \begin{tabular}{c|}
0.88 \\
$(1.20)$
\end{tabular} & $\begin{array}{c}2.01 \\
(1.19)\end{array}$ & $\begin{array}{c}-1.36 \\
(-0.88) \\
\end{array}$ & 0.26 & $13.2 \%$ & $25.7 \%$ \\
\hline China & 0 & $\begin{array}{c}-0.08 * * * \\
(-7.50) \\
\end{array}$ & $\begin{array}{l}0.30 * \\
(1.90) \\
\end{array}$ & $\begin{array}{c}0.59 \\
(1.29) \\
\end{array}$ & $\begin{array}{l}0.23^{*} \\
(1.89) \\
\end{array}$ & $\begin{array}{l}0.76^{*} \\
(1.94) \\
\end{array}$ & $\begin{array}{c}-0.07 \\
(-0.38) \\
\end{array}$ & $\begin{array}{c}3.08 * * \\
(2.58) \\
\end{array}$ & & 0.50 & $14.0 \%$ & $72.0 \%$ \\
\hline USA & 1 & \begin{tabular}{|c|}
$-0.06 * * *$ \\
$(-4.12)$
\end{tabular} & $\begin{array}{c}0.63 * * * \\
(3.37)\end{array}$ & $\begin{array}{c}0.04 \\
(0.08) \\
\end{array}$ & $\begin{array}{c}0.22 \\
(1.41)\end{array}$ & \begin{tabular}{c|}
0.62 \\
$(1.36)$
\end{tabular} & \begin{tabular}{c|}
0.36 \\
$(1.11)$
\end{tabular} & $\begin{array}{c}-0.44 \\
(-0.16) \\
\end{array}$ & \begin{tabular}{c|}
2.27 \\
$(0.70)$
\end{tabular} & 0.70 & $11.4 \%$ & $46.2 \%$ \\
\hline Hong & 1 & $\begin{array}{c}-0.11 * * * \\
(-3.31)\end{array}$ & $\begin{array}{c}0.21 \\
(1.60)\end{array}$ & $\begin{array}{c}-0.02 \\
(-0.06)\end{array}$ & $\begin{array}{c}0.28 * * * \\
(2.72)\end{array}$ & $\begin{array}{c}1.06 * * * \\
(3.14)\end{array}$ & & $\begin{array}{c}-0.54 \\
(-0.61) \\
\end{array}$ & $\begin{array}{c}-0.58 \\
(-0.73) \\
\end{array}$ & 0.59 & $19.7 \%$ & $48.6 \%$ \\
\hline Mexico & 1 & $\begin{array}{c}-0.01 \\
(-0.31) \\
\end{array}$ & $\begin{array}{c}0.28 \\
(1.38) \\
\end{array}$ & $\begin{array}{c}0.41 \\
(0.84) \\
\end{array}$ & $\begin{array}{c}0.44 * * * \\
(2.81)\end{array}$ & $\begin{array}{c}0.05 \\
(0.10) \\
\end{array}$ & $\begin{array}{c}-0.89 \\
(-1.10) \\
\end{array}$ & $\begin{array}{c}-2.25^{* *} \\
(-2.36) \\
\end{array}$ & $\begin{array}{c}1.54 \\
(1.03) \\
\end{array}$ & 0.48 & $17.7 \%$ & $26.8 \%$ \\
\hline Sing: & 0 & $\begin{array}{c}-0.11 * * * \\
(-5.89)\end{array}$ & $\begin{array}{c}0.26 \\
(1.43) \\
\end{array}$ & $\begin{array}{c}0.24 \\
(0.40) \\
\end{array}$ & $\begin{array}{c}0.35 * * \\
(2.51)\end{array}$ & $\begin{array}{c}-0.10 \\
(-0.20) \\
\end{array}$ & & $\begin{array}{c}1.16 \\
(0.77) \\
\end{array}$ & $\begin{array}{c}-0.27 \\
(-0.10) \\
\end{array}$ & 0.42 & $13.0 \%$ & $21.0 \%$ \\
\hline $\begin{array}{l}\text { Arab } \\
\text { Emirates } \\
\end{array}$ & 2 & $\begin{array}{c}-0.09 * * * \\
(-2.75) \\
\end{array}$ & $\begin{array}{c}0.65^{* * *} * \\
(3.63) \\
\end{array}$ & $\begin{array}{c}0.55 \\
(1.35) \\
\end{array}$ & $\begin{array}{c}0.03 \\
(0.19) \\
\end{array}$ & $\begin{array}{c}-0.19 \\
(-0.53) \\
\end{array}$ & & & & 0.61 & $15.5 \%$ & $37.7 \%$ \\
\hline Mal & 2 & $\begin{array}{c}-0.05 \\
(-1.13) \\
\end{array}$ & $\begin{array}{l}0.34^{*} \\
(1.69)\end{array}$ & \begin{tabular}{|c|}
-0.30 \\
$(-0.60)$ \\
\end{tabular} & $\begin{array}{c}0.30 \\
(1.64) \\
\end{array}$ & \begin{tabular}{c|}
0.74 \\
$(1.34)$ \\
\end{tabular} & $\begin{array}{c}-0.42 \\
(-0.68) \\
\end{array}$ & $\begin{array}{c}-0.88 \\
(-0.68) \\
\end{array}$ & \begin{tabular}{c|}
3.92 \\
$(1.41)$ \\
\end{tabular} & 0.56 & $21.3 \%$ & $53.8 \%$ \\
\hline Indonesia & 0 & $\begin{array}{l}0.05^{*} \\
(1.84)\end{array}$ & $\begin{array}{c}-0.05 \\
(-0.27)\end{array}$ & $\begin{array}{c}0.22 \\
(0.43)\end{array}$ & $\begin{array}{c}0.82 * * * \\
(4.92)\end{array}$ & $\begin{array}{c}0.61 \\
(1.18)\end{array}$ & \begin{tabular}{c|}
0.10 \\
$(0.27)$
\end{tabular} & $\begin{array}{c}-3.13 \\
(-1.17)\end{array}$ & $\begin{array}{c}-1.15 \\
(-1.55)\end{array}$ & 0.52 & $19.2 \%$ & $49.6 \%$ \\
\hline Philippines & 0 & $\begin{array}{c}-0.05 * * * \\
(-3.30)\end{array}$ & $\begin{array}{c}0.42^{* *} \\
(2.48) \\
\end{array}$ & $\begin{array}{c}0.54 \\
(1.17) \\
\end{array}$ & $\begin{array}{c}0.31 * * \\
(2.22)\end{array}$ & $\begin{array}{c}0.46 \\
(1.03) \\
\end{array}$ & \begin{tabular}{c|}
0.77 \\
$(0.94)$ \\
\end{tabular} & $\begin{array}{c}3.57 \\
(1.30) \\
\end{array}$ & $\begin{array}{c}-1.42 \\
(-1.07) \\
\end{array}$ & 0.40 & $25.9 \%$ & $64.7 \%$ \\
\hline Fiji & 0 & $\begin{array}{c}-0.08 * * * \\
(-6.88)\end{array}$ & $\begin{array}{c}0.34 * * * \\
(2.85)\end{array}$ & $\begin{array}{c}0.39 \\
(1.23) \\
\end{array}$ & $\begin{array}{c}0.26^{* *} \\
(2.64)\end{array}$ & $\begin{array}{c}0.63 * * \\
(2.07) \\
\end{array}$ & & $\begin{array}{c}0.76 \\
(0.50) \\
\end{array}$ & $\begin{array}{c}0.22 \\
(0.28) \\
\end{array}$ & 0.49 & $13.3 \%$ & $75.9 \%$ \\
\hline Japan & 1 & $\begin{array}{c}0.02 \\
(0.48) \\
\end{array}$ & $\begin{array}{c}0.76 \\
(1.60) \\
\end{array}$ & $\begin{array}{c}-1.27 \\
(-1.01) \\
\end{array}$ & $\begin{array}{c}0.24 \\
(0.63) \\
\end{array}$ & $\begin{array}{l}2.21 * \\
(1.79) \\
\end{array}$ & $\begin{array}{c}-0.70 \\
(-0.12) \\
\end{array}$ & $\begin{array}{c}-6.34 \\
(-1.57) \\
\end{array}$ & $\begin{array}{c}-9.43 \\
(-0.85) \\
\end{array}$ & 0.31 & $17.7 \%$ & $16.3 \%$ \\
\hline $\begin{array}{l}\text { South } \\
\text { Korea }\end{array}$ & 0 & $\begin{array}{c}-0.05 * * * \\
(-3.62)\end{array}$ & $\begin{array}{c}0.29 * * \\
(2.60) \\
\end{array}$ & \begin{tabular}{|c|}
$0.86 * * *$ \\
$(2.92)$ \\
\end{tabular} & $\begin{array}{c}0.36 \text { *** } \\
(4.03)\end{array}$ & $\begin{array}{c}0.05 \\
(0.16) \\
\end{array}$ & $\begin{array}{c}0.02 \\
(0.19) \\
\end{array}$ & $\begin{array}{c}0.31 \\
(0.35) \\
\end{array}$ & \begin{tabular}{c|}
-0.29 \\
$(-0.18)$ \\
\end{tabular} & 0.65 & $15.9 \%$ & $31.4 \%$ \\
\hline Thailand & 1 & $\begin{array}{c}0.03 \\
(1.13) \\
\end{array}$ & $\begin{array}{c}0.56 * * * \\
(3.08)\end{array}$ & $\begin{array}{c}1.35 * * * \\
(2.82)\end{array}$ & $\begin{array}{c}-0.09 \\
(-0.59) \\
\end{array}$ & $\begin{array}{c}0.14 \\
(0.32) \\
\end{array}$ & $\begin{array}{c}-0.32 \\
(-0.35) \\
\end{array}$ & $\begin{array}{c}2.61 * * \\
(2.26) \\
\end{array}$ & \begin{tabular}{c|}
2.30 \\
$(1.34)$ \\
\end{tabular} & 0.52 & $19.4 \%$ & $52.6 \%$ \\
\hline Bahrain & 0 & $\begin{array}{c}-0.07 * * * \\
(-5.33)\end{array}$ & $\begin{array}{c}0.49 * * \\
(2.51)\end{array}$ & $\begin{array}{c}0.25 \\
(0.44) \\
\end{array}$ & $\begin{array}{c}0.14 \\
(0.89) \\
\end{array}$ & $\begin{array}{c}-0.01 \\
(-0.02)\end{array}$ & & & & 0.36 & $12.2 \%$ & $54.2 \%$ \\
\hline Average & & -0.08 & 0.44 & 0.94 & 0.36 & 1.17 & & & & 0.50 & $15.7 \%$ & $48.3 \%$ \\
\hline
\end{tabular}

Source: Own calculations, GTA (2013)

The most important competitors in the butter market are again the EU and Australia. As for WMP and cheese, the US is almost absent from these markets and domestic competitors again do not have any influence. Essentially, the degree of competition seems to be similar, whether it comes from the EU or Australia. The number of significant coefficients is almost equal, although the EU's SMC has on average a moderately higher influence. The situation with regard to the competitors is somewhat similar to that in the 
SMP market. In the EU, butter is the subject of the intervention scheme and its export is rather unsteady in the observation period, although not as pronounced as for SMP. Therefore, while the EU's SMC often has a significant influence on the price Fonterra charges, this seldom goes along with small or non-significant RDE coefficients.

Table 5.4: SUR estimation results for cheese

\begin{tabular}{|c|c|c|c|c|c|c|c|c|c|c|c|c|}
\hline \multirow{3}{*}{ Destination } & \multirow{3}{*}{ 量 } & \multirow{3}{*}{$\eta$} & \multicolumn{4}{|c|}{ competing countries } & \multirow{3}{*}{$\begin{array}{l}\text { dest. } \\
\text { milk } \\
\text { price }\end{array}$} & \multicolumn{2}{|c|}{ demand shifter } & \multirow{3}{*}{$\mathbf{R}^{2}$} & \multirow{3}{*}{$\begin{array}{l}\text { UV sur- } \\
\text { charge }\end{array}$} & \multirow{3}{*}{$\begin{array}{c}\text { market } \\
\text { share }\end{array}$} \\
\hline & & & \multicolumn{2}{|c|}{ EU } & \multicolumn{2}{|c|}{ Australia } & & IDP & CPI & & & \\
\hline & & & SMC & ER & SMC & ER & & GDP & CPI & & & \\
\hline Japan & 0 & $\begin{array}{c}-0.03 \\
(-1.04)\end{array}$ & $\begin{array}{c}0.14 \\
(1.04)\end{array}$ & $\begin{array}{c}0.37 \\
(1.55) \\
\end{array}$ & $\begin{array}{c}0.45 * * * \\
(4.87)\end{array}$ & $\begin{array}{c}0.27 \\
(1.16) \\
\end{array}$ & $\begin{array}{c}-0.61 \\
(-0.53)\end{array}$ & $\begin{array}{c}0.16 \\
(0.25) \\
\end{array}$ & \begin{tabular}{|c|}
-1.28 \\
$(-0.91)$ \\
\end{tabular} & 0.51 & $17.1 \%$ & $31.8 \%$ \\
\hline Aust & 1 & $\begin{array}{c}-0.11 * * * \\
(-2.88)\end{array}$ & $\begin{array}{c}0.60 * * * \\
(4.92)\end{array}$ & $\begin{array}{c}-0.12 \\
(-0.54) \\
\end{array}$ & & & $\begin{array}{c}-0.23 \\
(-1.07)\end{array}$ & $\begin{array}{c}0.62 \\
(0.35) \\
\end{array}$ & $\begin{array}{c}1.97 \\
(1.25)\end{array}$ & 0.58 & $14.6 \%$ & $76.0 \%$ \\
\hline USA & 0 & $\begin{array}{c}-0.06 * * * \\
(-3.05)\end{array}$ & $\begin{array}{c}-0.11 \\
(-0.36)\end{array}$ & $\begin{array}{c}0.16 \\
(0.28)\end{array}$ & $\begin{array}{c}0.31 \\
(1.42)\end{array}$ & $\begin{array}{c}0.21 \\
(0.40)\end{array}$ & $\begin{array}{c}-0.03 \\
(-0.08)\end{array}$ & $\begin{array}{c}-2.36 \\
(-0.77)\end{array}$ & $\begin{array}{c}3.69 \\
(1.06)\end{array}$ & 0.23 & $12.6 \%$ & $15.2 \%$ \\
\hline $\begin{array}{l}\text { United } \\
\text { Kingdom }\end{array}$ & 0 & $\begin{array}{c}0.06 * * * \\
(3.63)\end{array}$ & $\begin{array}{c}0.23 \\
(1.09)\end{array}$ & $\begin{array}{c}-0.04 \\
(-0.09)\end{array}$ & $\begin{array}{c}0.51 * * * \\
(3.31)\end{array}$ & $\begin{array}{c}0.86 * * \\
(2.16)\end{array}$ & $\begin{array}{c}1.00 \\
(1.47)\end{array}$ & $\begin{array}{c}-1.85 \\
(-0.92)\end{array}$ & $\begin{array}{l}-6.34^{*} \\
(-1.80)\end{array}$ & 0.44 & $22.9 \%$ & $56.3 \%$ \\
\hline Belgi & 0 & $\begin{array}{c}-0.02 \\
(-1.50) \\
\end{array}$ & $\begin{array}{c}0.61 * * * \\
(3.19)\end{array}$ & & $\begin{array}{c}0.14 \\
(1.03) \\
\end{array}$ & $\begin{array}{l}0.65^{*} \\
(1.99) \\
\end{array}$ & & $\begin{array}{c}1.20 \\
(1.53) \\
\end{array}$ & $\begin{array}{c}0.81 \\
(0.34) \\
\end{array}$ & 0.43 & $8.3 \%$ & $85.6 \%$ \\
\hline $\begin{array}{l}\text { Saudi } \\
\text { Arabia }\end{array}$ & 1 & $\begin{array}{c}-0.06 * * * \\
(-2.84)\end{array}$ & $\begin{array}{c}0.81 * * * \\
(5.02)\end{array}$ & $\begin{array}{c}0.30 \\
(1.10) \\
\end{array}$ & $\begin{array}{c}0.19 \\
(1.43) \\
\end{array}$ & $\begin{array}{c}0.17 \\
(0.69)\end{array}$ & $\begin{array}{c}0.05 \\
(0.11) \\
\end{array}$ & $\begin{array}{c}0.12 \\
(0.11)\end{array}$ & \begin{tabular}{|c|}
-0.99 \\
$(-0.96)$ \\
\end{tabular} & 0.68 & $10.6 \%$ & $27.1 \%$ \\
\hline Egypt & 0 & $\begin{array}{c}0.00 \\
(0.20)\end{array}$ & $\begin{array}{c}0.44 * * * \\
(2.75)\end{array}$ & $\begin{array}{c}0.32 \\
(1.11)\end{array}$ & $\begin{array}{c}0.52 * * * \\
(4.48)\end{array}$ & $\begin{array}{l}0.72 * * \\
(2.53)\end{array}$ & $\begin{array}{c}0.17 \\
(0.33)\end{array}$ & & $\begin{array}{c}-0.04 \\
(-0.08)\end{array}$ & 0.56 & $4.3 \%$ & $42.6 \%$ \\
\hline Jam & 0 & $\begin{array}{c}-0.05^{* * *} * \\
(-3.10) \\
\end{array}$ & $\begin{array}{c}0.44 * * \\
(2.30) \\
\end{array}$ & $\begin{array}{c}0.39 \\
(1.16) \\
\end{array}$ & $\begin{array}{c}0.07 \\
(0.41) \\
\end{array}$ & $\begin{array}{c}-0.01 \\
(-0.02) \\
\end{array}$ & $\begin{array}{c}0.24 \\
(1.36) \\
\end{array}$ & $\begin{array}{c}-0.32 \\
(-0.15) \\
\end{array}$ & $\begin{array}{c}0.49 \\
(0.80) \\
\end{array}$ & 0.27 & $15.3 \%$ & $86.3 \%$ \\
\hline Trinid & 0 & $\begin{array}{c}-0.01 \\
(-0.73) \\
\end{array}$ & $\begin{array}{c}0.38 * * * \\
(3.26)\end{array}$ & $\begin{array}{c}0.12 \\
(0.55) \\
\end{array}$ & $\begin{array}{c}0.55 * * * \\
(6.42)\end{array}$ & $\begin{array}{l}0.34^{*} \\
(1.73)\end{array}$ & $\begin{array}{c}0.21 \\
(0.59) \\
\end{array}$ & & \begin{tabular}{|c|}
-0.62 \\
$(-1.45)$ \\
\end{tabular} & 0.65 & $13.0 \%$ & $68.0 \%$ \\
\hline Par & 0 & $\begin{array}{c}-0.01 \\
(-1.02) \\
\end{array}$ & $\begin{array}{l}0.31 * \\
(1.78)\end{array}$ & $\begin{array}{c}0.30 \\
(0.93) \\
\end{array}$ & $\begin{array}{c}0.76 * * * \\
(6.11)\end{array}$ & $\begin{array}{c}0.96 * * * \\
(3.32)\end{array}$ & $\begin{array}{c}0.13 \\
(1.09) \\
\end{array}$ & $\begin{array}{c}-0.96 \\
(-0.89) \\
\end{array}$ & $\begin{array}{c}0.76 \\
(0.57) \\
\end{array}$ & 0.58 & $9.8 \%$ & $61.4 \%$ \\
\hline Ind & 0 & $\begin{array}{c}-0.04 * * * \\
(-3.38)\end{array}$ & $\begin{array}{c}0.24 \\
(1.02)\end{array}$ & $\begin{array}{c}0.65 \\
(1.55)\end{array}$ & $\begin{array}{c}0.55^{* * * *} \\
(3.24)\end{array}$ & $\begin{array}{c}0.20 \\
(0.48)\end{array}$ & $\begin{array}{c}0.43 \\
(1.27)\end{array}$ & $\begin{array}{c}-0.55 \\
(-0.25)\end{array}$ & $\begin{array}{c}-0.33 \\
(-0.55)\end{array}$ & 0.60 & $21.0 \%$ & $48.1 \%$ \\
\hline Barb & 0 & $\begin{array}{c}-0.06 \\
(-1.35) \\
\end{array}$ & $\begin{array}{c}0.22 \\
(1.02) \\
\end{array}$ & $\begin{array}{c}0.37 \\
(0.90) \\
\end{array}$ & $\begin{array}{c}0.36 * * \\
(2.30) \\
\end{array}$ & $\begin{array}{c}0.08 \\
(0.23) \\
\end{array}$ & $\begin{array}{c}0.29 \\
(0.19)\end{array}$ & & $\begin{array}{c}-0.16 \\
(-0.20)\end{array}$ & 0.22 & $21.2 \%$ & $81.1 \%$ \\
\hline Gus & 0 & $\begin{array}{c}-0.01 \\
(-0.99) \\
\end{array}$ & $\begin{array}{c}0.16 \\
(1.15) \\
\end{array}$ & $\begin{array}{c}0.16 \\
(0.63) \\
\end{array}$ & $\begin{array}{c}0.53 * * * \\
(5.24) \\
\end{array}$ & $\begin{array}{c}0.29 \\
(1.25) \\
\end{array}$ & & & & 0.45 & $16.6 \%$ & $88.9 \%$ \\
\hline Gren & 0 & $\begin{array}{c}0.01 \\
(0.76)\end{array}$ & $\begin{array}{c}-0.01 \\
(-0.09)\end{array}$ & $\begin{array}{c}-0.07 \\
(-0.33)\end{array}$ & $\begin{array}{c}0.44 * * * \\
(5.13)\end{array}$ & $\begin{array}{l}0.51 * * \\
(2.53)\end{array}$ & & & $\begin{array}{c}0.45 \\
(0.82)\end{array}$ & 0.39 & $24.8 \%$ & $94.4 \%$ \\
\hline Ma & 0 & $\begin{array}{c}-0.07 * * * \\
(-6.76)\end{array}$ & $\begin{array}{c}0.13 \\
(0.51)\end{array}$ & $\begin{array}{c}0.44 \\
(0.90)\end{array}$ & $\begin{array}{c}0.56^{* * * *} \\
(3.02)\end{array}$ & $\begin{array}{c}0.29 \\
(0.58)\end{array}$ & $\begin{array}{c}0.05 \\
(0.09)\end{array}$ & $\begin{array}{c}-0.72 \\
(-0.50)\end{array}$ & $\begin{array}{c}0.28 \\
(0.15)\end{array}$ & 0.42 & $15.4 \%$ & $26.0 \%$ \\
\hline $\begin{array}{l}\text { Arab } \\
\text { Emirates }\end{array}$ & 2 & $\begin{array}{c}-0.01 \\
(-0.39) \\
\end{array}$ & $\begin{array}{c}0.28 \\
(0.95) \\
\end{array}$ & $\begin{array}{c}0.03 \\
(0.07) \\
\end{array}$ & $\begin{array}{l}0.45^{*} \\
(1.71)\end{array}$ & $\begin{array}{l}0.70^{*} \\
(1.79)\end{array}$ & & & & 0.46 & $21.4 \%$ & $7.3 \%$ \\
\hline Hong & 1 & $\begin{array}{c}-0.13 * * * \\
(-3.40) \\
\end{array}$ & $\begin{array}{c}-0.41 \\
(-1.19) \\
\end{array}$ & $\begin{array}{c}-0.08 \\
(-0.14) \\
\end{array}$ & $\begin{array}{c}0.77 * * * \\
(2.69) \\
\end{array}$ & $\begin{array}{c}1.64 * * * \\
(2.91)\end{array}$ & & $\begin{array}{c}-0.84 \\
(-0.52) \\
\end{array}$ & $\begin{array}{c}-1.96 \\
(-1.39) \\
\end{array}$ & 0.67 & $23.8 \%$ & $8.9 \%$ \\
\hline Singapore & 0 & $\begin{array}{c}-0.19 * * * \\
(-8.03)\end{array}$ & $\begin{array}{c}-0.10 \\
(-0.24)\end{array}$ & $\begin{array}{c}1.31 \\
(1.49)\end{array}$ & $\begin{array}{c}0.76^{* *} \\
(2.49)\end{array}$ & $\begin{array}{c}0.41 \\
(0.53)\end{array}$ & & $\begin{array}{c}0.10 \\
(0.04)\end{array}$ & $\begin{array}{c}-1.90 \\
(-0.46)\end{array}$ & 0.39 & $26.8 \%$ & $12.5 \%$ \\
\hline Thai & 0 & $\begin{array}{c}-0.10 * * * \\
(-8.87)\end{array}$ & $\begin{array}{l}0.39^{*} \\
(1.69)\end{array}$ & $\begin{array}{c}0.54 \\
(1.30)\end{array}$ & $\begin{array}{c}0.05 \\
(0.34)\end{array}$ & $\begin{array}{l}0.67 * \\
(1.68)\end{array}$ & $\begin{array}{c}-0.40 \\
(-0.51)\end{array}$ & $\begin{array}{c}-0.56 \\
(-0.54)\end{array}$ & $\begin{array}{c}-0.14 \\
(-0.10)\end{array}$ & 0.55 & $24.5 \%$ & $21.9 \%$ \\
\hline Fiji & 1 & $\begin{array}{c}-0.17 * * * \\
(-4.13)\end{array}$ & $\begin{array}{c}0.60 \\
(1.52) \\
\end{array}$ & $\begin{array}{c}-0.60 \\
(-0.94)\end{array}$ & $\begin{array}{c}-0.56 \\
(-1.62)\end{array}$ & $\begin{array}{l}-1.40^{*} \\
(-1.80)\end{array}$ & & $\begin{array}{c}3.40 \\
(1.25) \\
\end{array}$ & $\begin{array}{c}3.50 \\
(1.65) \\
\end{array}$ & 0.55 & $40.9 \%$ & $77.7 \%$ \\
\hline refage & & -0.10 & 0.50 & & 0.55 & 0.78 & & & & 0.48 & $18.5 \%$ & $50.5 \%$ \\
\hline
\end{tabular}

Note: The numbers in parenthesis are t-statistics; the asterisks denote the $10 \%(*), 5 \%(* *)$ and $1 \%(* * *)$ significance level. For coefficients the average applies to the significant ones that have the correct sign. The import market share is calculated by dividing New Zealand's exports in the period 2000 to 2012 through the total exports to this destination.

Source: Own calculations, GTA (2013) 
For cheddar cheese (Table 5.4), the results share some of the same tendencies that the butter results already showed. These tendencies are smaller R-squared values and larger UV surcharges. This could again be a sign of a less homogeneous product, which is plausible in the case of cheese. As already mentioned in Chapter 5.4, cheddar cheese only plays a minor role in the EU's exports, so instead we use the observations of an aggregation of similar cheese varieties. Indeed, the EU variables are often not significant - the SMC is significant in just eight out of twenty cases and the ER never. For Australia this is quite different, the SMC and ER lack significance in only three destination countries. In general, this result does not hinge on a different market presence of the two competing countries; there are no systematic differences. Instead, Australian cheddar cheese seems to be a closer substitute to New Zealand cheddar cheese than is the case for the EU. The weak competition from the EU may also cause a larger average value of the significant RDE coefficient of -0.099 in comparison to the other products. Nonetheless, only half of the RDE coefficients are negative and significant at all.

The equations for destination countries that are themselves important dairy producers and exporters show some particularly interesting results. These include Australia, the US and the UK and Belgium as EU member states. As for SMP and butter, the equation for Australia again shows a high optimal markup indicated by the RDE estimate, in conjunction with a high import market share. In contrast to SMP, the UV surcharge for butter and cheese support the utilization of this market power in Australia. This is surprising since Australia is the most important competitor for Fonterra on foreign markets but on its own domestic market, the conditions seem to be different. The case is somewhat similar for the US where a significant RDE of -0.06 is found for both butter and cheese. However, it can be suspected that this is a result of the usage of a tariff rate quota. For cheese, GAST (2002) already reports that Fonterra takes advantage of the complete inquota quantity and also exports an important additional quantity to the US. Furthermore, the author discovers signs of price discrimination; that is, important unit values differences between in-quota and out-quota imports from New Zealand. This can explain the significant RDE estimates since it implies that a change of the quantity has an influence on the average unit value. Although Fonterra also has licenses for EU tariff rate quotas, a similar effect does not seem to be in place for the EU. The equations for the UK and Belgium do not show significant negative RDE coefficients. 


\subsection{Conclusion}

In this paper, we use the residual demand approach as proposed by GOLDBERG \& KNETTER (1999) to analyze New Zealand's exports of the most important dairy products with respect to market power. This approach usually relies on the usage of cost shifting variables to depict changes in the marginal cost for the exporting country and competing countries. However, this method has several disadvantages, may bias coefficients and standard errors, and the cost shifters cannot be expected to be the ideal instruments in the 2SLS estimation. The methodological innovation of the paper is that we use a measure of the marginal cost that reflects the full range of variations in the marginal cost: the stochastic lower price frontier (SLPF). We call this estimate of the marginal cost the "stochastic" marginal cost (SMC) and first propose the concept in Chapter 4.

The estimation of the residual demand is done with SUR in first differences. This is because the variables are not co-integrated and the usage of the SMC does not solve the problem of weak instruments, but is still used for the competing countries. The results show that in $56 \%$ of the equations, significant negative RDEs are present with an average value of -0.086 . This means that in more than half of the destination-product combinations, Fonterra is able to charge an optimal markup that is, on average, $8.6 \%$ of the price. Since we are forced to use OLS (or SUR) instead of 2SLS (or 3SLS), these estimates could even be considered conservative. The unit value surcharge on SMC is compatible with an even higher markup. Nevertheless, these values are only weakly correlated with the optimal markups implied by the RDE. The same is true for the import market shares of New Zealand as well as of its competitors. None of them has any influence on the optimal markup implied by the RDE. The perceived degree of differentiation and different distribution channels seem to be of more importance.

As a limitation of Fonterra's market power, competition from the US and the respective destination country is mainly unimportant. Instead, the overall most important competitor is Australia, and the second most important is the EU. However, while the influence of Australia is similar across products and seems to be more restrictive on the RDE, the EU's influence is most pronounced for SMP and butter - products that are subject to the intervention scheme and exhibit volatile exports for the EU. Conversely, the EU's influence is less pronounced for WMP and least pronounced for cheese. Again, these results cannot be explained by large differences in the import market shares but seem to be the result of perceived differences between the competitors' products. 


\section{References}

Armentano, L.E., Dobson, W.D., Jesse, E. V \& Olson, N.F. (2004): The dairy sectors of New Zealand and Australia: A regional study. Babcock Institute Discussion Paper, 2004(3), pp. 1-64.

Armington, P.S. (1969): The Geographic Pattern of Trade and the Effects of Price Changes. International Monetary Fund, Staff Papers, 16(2), pp. 179-201.

Aw, B. (1993): Price discrimination and markups in export markets. Journal of Development Economics, 42, pp. 315-336.

BAKER, J.B. \& BRESNAHAN, T.F. (1988): Estimating the residual demand curve facing a single firm. International Journal of Industrial Organization, 6, pp. 283-300.

Blayney, D.P., Gehlhar, M.J., Bolling, C.H., Jones, K., Langley, S., Normile, M.A. \& SomwarU, A. (2006): US dairy at a global crossroads. United States Department of Agriculture, Economic Research Service, ERR No. 28, pp. 1-44.

Bresnahan, T.F. (1981): Duopoly models with consistent conjectures. The American Economic Review, 71(5), pp. 934-945.

Carter, C.A., Maclaren, D. \& Yilmaz, A. (1999): How Competitive is the World Wheat Market? Working Paper No. 99-002, Department of Agricultural and Resource Economics, University of California Davis.

DAIRY AustRAlia (2008): Dairy 2008: Situation and Outlook, Victoria, Australia.

Felt, M.-H., Gervais, J.-P. \& Larue, B. (2011): Market power and import bans: the case of Japanese pork imports. Agribusiness, 27(1), pp. 47-61.

Froeb, L.M. \& WERDEN, G.J. (1991): Residual demand estimation for market delineation: complications and limitations. Review of Industrial Organization, 6, pp. 3348.

GAST, M.W. (2002): Zollkontingente bei US-amerikanischen Käseimporten. Agrarwirtschaft, 51(4), pp. 192-202.

Glauben, T. \& Loy, J.-P. (2003): Pricing-to-market versus residual demand elasticity analysis of imperfect competition in food exports: Evidence from Germany. Journal of Agricultural \& Food Industrial Organization, 1(1), p. 1-19. 
GoldberG, P.K. \& KNETTER, M.M. (1997): Goods prices and exchange rates: What have we learned? Journal of Economic Literature, 35(3), pp. 1243-1272.

GoldberG, P.K. \& KNETTER, M.M. (1999): Measuring the intensity of competition in export markets. Journal of International Economics, 47(1), pp. 27-60.

GTA (2013): Global Trade Atlas. Global Trade Information Services (GTIS).

KNETTER, M.M. (1993): International comparisons of pricing-to-market behavior. The American Economic Review, 83(3), pp. 473-486.

KnetTer, M.M. (1989): Price Discrimination by U.S. and German Exporters. The American Economic Review, 79(1), pp. 198-210.

KumbhaKar, S.C. \& Lovell, C.A.K. (2003): Stochastic frontier analysis, Cambridge: Cambridge University Press.

LERNER, A.P. (1934): The concept of monopoly and the measurement of monopoly power. The Review of Economic Studies, 1(3), pp. 157-175.

MurRAY, M.P. (2006): Avoiding invalid instruments and coping with weak instruments. The Journal of Economic Perspectives, 20(4), pp. 111-132.

NARDIS, S. DE \& PENSA, C. (2004): How intense is competition in international markets of traditional goods? The case of Italian exporters. The Case of Italian Exporters (May 2004), (30), p. 1-36.

PoOsIRIPINYO, R. \& REED, M.R. (2005): Measuring market power in the Japanese chicken meat market. Journal of International Agricultural Trade and Development, 1(2), pp. 135-148.

REED, M.R. \& SAghaIAN, S.H. (2004): Measuring the intensity of competition in the Japanese beef market. Journal of Agricultural and Applied Economics, 36(1), pp. $113-121$.

Silvente, F.R. (2005): Price discrimination and market power in export markets: the case of the ceramic tile industry. Journal of Applied Economics, VIII(2), pp. 347370.

Tasdogan, C., Tsakiridou, E. \& Mattas, K. (2005): Country Market Power in EU Olive Oil Trade. South-Eastern Europe Journal of Economics, 2, pp. 211-219. 
Appendix 5.1: Sample characteristics and SMC estimation results ${ }^{25}$

\begin{tabular}{|c|c|c|c|c|c|c|c|c|c|c|c|}
\hline \multirow{3}{*}{$\begin{array}{l}\text { export } \\
\text { country }\end{array}$} & \multirow{3}{*}{ product } & \multirow{3}{*}{$\begin{array}{c}\text { observa- } \\
\text { tions per } \\
\text { month }\end{array}$} & \multicolumn{3}{|c|}{ outlier correction } & \multirow{2}{*}{\multicolumn{3}{|c|}{$\begin{array}{c}\text { distrubution } \\
\text { parameters }\end{array}$}} & \multicolumn{3}{|c|}{ average values } \\
\hline & & & \multirow{2}{*}{$\begin{array}{c}\text { min. } \\
\text { quant. }\end{array}$} & \multicolumn{2}{|c|}{ observ. used } & & & & \multirow{2}{*}{ SMC } & \multirow{2}{*}{$\begin{array}{c}\text { unit } \\
\text { values }\end{array}$} & \multirow{2}{*}{$\begin{array}{l}\text { UV sur- } \\
\text { charge }\end{array}$} \\
\hline & & & & abs. & $\%$ & $\gamma$ & $\mu$ & $\mathbf{s} \mathbf{V}_{\mathrm{u}}$ & & & \\
\hline \multirow{4}{*}{$\begin{array}{c}\text { New } \\
\text { Zealand }\end{array}$} & SMP & 41.3 & 10 & 33.0 & $80 \%$ & 0.63 & -278 & $53 \%$ & 3096 NZ\$ & $3365 \mathrm{NZ \$}$ & $8 \%$ \\
\hline & WMP & 59.4 & 10 & 49.5 & $83 \%$ & 0.79 & -300 & $68 \%$ & $3121 \mathrm{NZ \$}$ & $3490 \mathrm{NZ \$}$ & $11 \%$ \\
\hline & Butter & 58.8 & 10 & 48.6 & $83 \%$ & 0.88 & -253 & $78 \%$ & $2780 \mathrm{NZ \$}$ & 3307 NZ\$ & $17 \%$ \\
\hline & Cheese & 53.0 & 5 & 38.8 & $73 \%$ & 0.81 & -623 & $68 \%$ & 3453 NZ\$ & 4048 NZ\$ & $16 \%$ \\
\hline \multirow{4}{*}{$\begin{array}{l}\text { Aus- } \\
\text { tralia }\end{array}$} & SMP & 28.6 & 10 & 25.6 & $90 \%$ & 0.45 & -136 & $36 \%$ & 2715 AU\$ & 2948 AU\$ & $7 \%$ \\
\hline & WMP & 33.2 & 10 & 28.4 & $86 \%$ & 0.84 & -558 & $73 \%$ & 2670 AU\$ & 3356 AU\$ & $21 \%$ \\
\hline & Butter & 30.5 & 5 & 26.6 & $87 \%$ & 0.92 & -444 & $85 \%$ & 2313 AU\$ & 2922 AU\$ & $21 \%$ \\
\hline & Cheese & 36.5 & 5 & 27.5 & $75 \%$ & 0.86 & -538 & $75 \%$ & 3214 AU\$ & 3922 AU\$ & $18 \%$ \\
\hline \multirow{4}{*}{$\mathbf{E U}$} & SMP & 74.6 & 10 & 53.2 & $71 \%$ & 0.82 & -375 & $69 \%$ & $1598 €$ & $1859 €$ & $14 \%$ \\
\hline & WMP & 110.3 & 10 & 91.8 & $83 \%$ & 0.86 & -124 & $75 \%$ & $1879 €$ & $2309 €$ & $20 \%$ \\
\hline & Butter & 109.3 & 10 & 65.3 & $60 \%$ & 0.88 & -187 & $77 \%$ & $1843 €$ & $2215 €$ & $17 \%$ \\
\hline & \begin{tabular}{|l} 
Cheese \\
\end{tabular} & 99.6 & 5 & 59.9 & $60 \%$ & 0.89 & -26 & $81 \%$ & $2286 €$ & $2823 €$ & $20 \%$ \\
\hline$\overline{\text { USA }}$ & SMP & 25.6 & 10 & 21.4 & $84 \%$ & 0.31 & -82 & $26 \%$ & 1778 \$ & $2076 \$$ & $16 \%$ \\
\hline
\end{tabular}

Source: Own calculations, GTA (2013)

\section{Appendix 5.2: SMC series for Australia (in 1000 AU\$)}

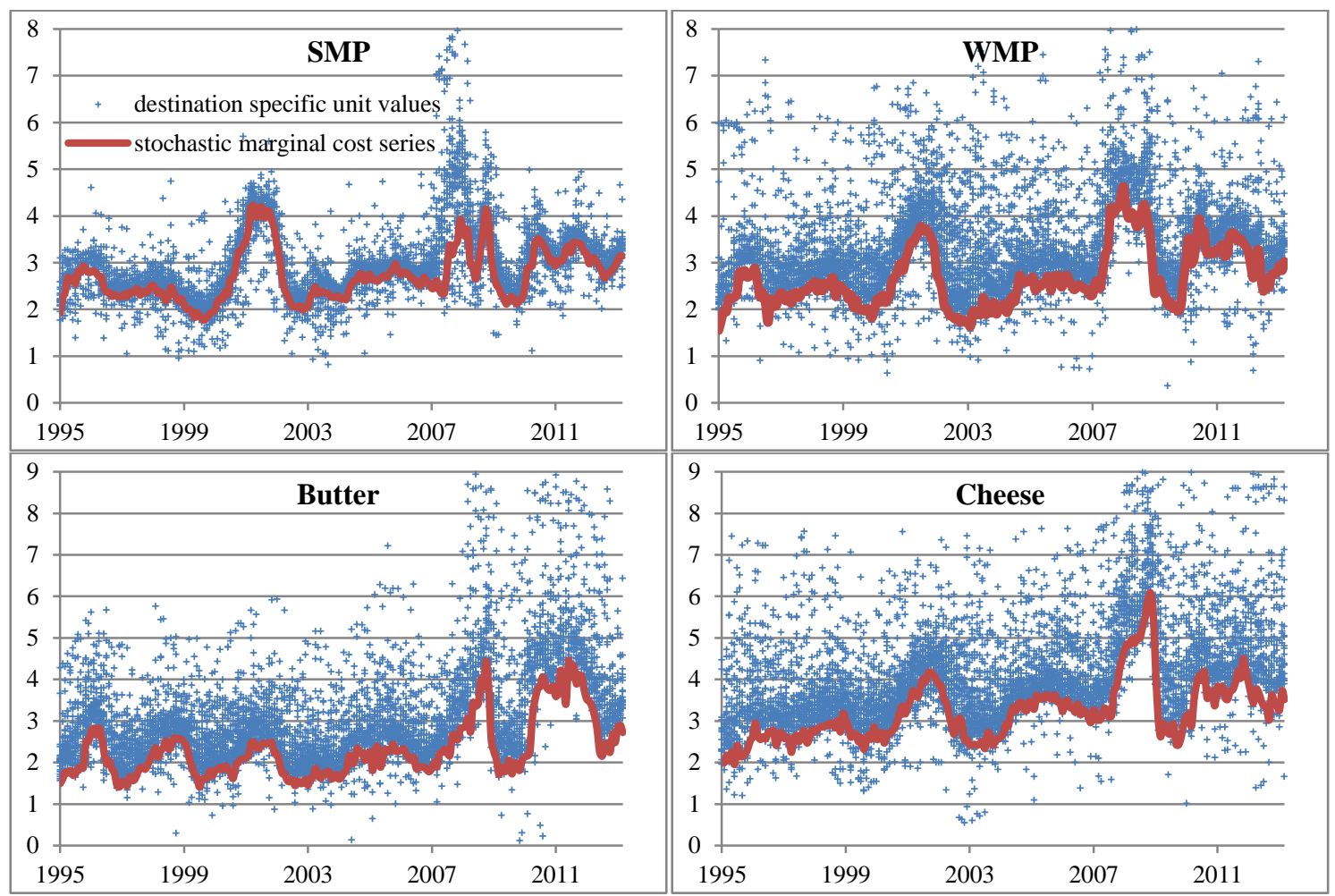

Source: Own compilation, GTA (2013)

${ }^{25}$ For the distribution parameter applies: $\gamma=\frac{\sigma_{u}^{2}}{\sigma_{v}^{2}+\sigma_{u}^{2}}$. Since $\sigma_{u}^{2}$ is the variance parameter of a truncated normal distribution, it does not represent the actual variance of the error component $u_{i t}$. Therefore, $\gamma$ does not represent the share of the variance of $u$ in the total variance. Instead, the share of the variance of $u$ in the total variance is given by $\mathrm{sV}_{\mathrm{u}}$. 


\section{Discussion}

In this chapter some overall issues with respect to the papers that shape the core of this thesis are discussed. These primarily focus on the challenges for the estimation of the stochastic marginal cost, the connection between the approaches in Chapters 4 and 5 as well as a comparison of the respective results. Finally, some implications with respect to the international dairy markets are considered.

\subsection{A note on the stochastic marginal cost}

The main innovation of this thesis is clearly the usage of the stochastic lower price frontier (SLPF) as a measure of the marginal cost - when interpreted in this way, we call the estimate the "stochastic" marginal cost (SMC). In Chapter 3, we argue that it is important to control for the marginal cost when PTM is analyzed. At the same time, we show that the usage of fixed time effects in a panel model to do so leads to PTM coefficients that are biased toward the average PTM coefficient in the sample. Alternative ways to depict the marginal cost in a PTM model may allow a destination-specific influence on the price - which is the key problem of the usage of fixed effects - but can be expected to bias the coefficients too. This is in general the case for cost shifting variables, non-destination-specific unit values or wholesale prices in the country of origin. As we argue in Chapter 5, the case is somewhat similar for the residual demand model. Therefore, the usage of the SMC can represent a significant improvement in both approaches in contrast to the existing procedures.

However, there are some challenges that are inherent in the estimation and the properties of the SMC. With regard to the estimation, one of these challenges is the question of outliers and their influence on the estimation. Of course, the SLPF already accounts for measurement errors in the unit values but some observations can hardly be seen just as measurement errors. There are, for example, single destination-specific unit values that are up to fifty times higher than the average or, in contrast, equal to just a quarter of the average. An explanation for these observations could be that their values have simply been incorrectly typed in at the data collection points. The problem is how to identify and how to deal with these observations. In any event, they cannot be expected to exhibit the same distribution as the actual measurement errors.

As already mentioned in Chapter 4.5.1, we decide to try to exclude outliers from the samples in two ways: Firstly, we exclude all destination-specific unit values that are 
based on less than a certain minimum quantity. The number of observations excluded in this way is quite high but represents only a small proportion of the quantity traded. This procedure assumes that, for a lower quantity and volume, typing errors affect the unit values more strongly. Furthermore, very low quantities could belong to premium varieties of the product and show, in general, a larger variation in the unit values. Alternatively, we tried to let the distribution parameter depend on the level of the quantity but this does not yield significantly different results. Secondly, we exclude all observations that lie outside the range of five standard deviations around the mean. This is a more direct way of excluding outliers and usually concerns only a very limited number of observations. In this procedure, the most critical may be a) the choice of the number of standard deviations where the border is defined and b) the choice of the observations that are used for the calculation of the standard deviation. The number of standard deviations we actually use is large enough to ensure that only extreme outliers are excluded. This is especially important since the observations are not normal distributed - this is the main assumption of the SLPF estimation. Therefore, the standard deviation procedure entails the risk of biasing the SLPF estimation. Furthermore, the value of the standard deviations is calculated by using the observations that are in the outlier corrected sample for the single time period considered. The value is additionally restricted to be at least as high as the average standard deviation of the full observation period.

Nonetheless, we also estimate the SMC with a number of different outlier specifications with regard to the minimum quantity and the number of standard deviations - including a bootstrap procedure. It turns out that the outlier specification does not heavily influence the results. A variation of the minimum quantity does not have a systematic influence whereby a smaller number of standard deviations around the mean usually results in a moderate increase of the average SMC estimated. The latter is because the standard deviation procedure mainly has an effect of restricting the observations with large values; this is due to the fact that the observations are not normally distributed. Therefore, we interpret this as a bias in the level due to a restriction that is too narrow. However, when we estimate the oligopolistic PTM model with differently outlier specified SMCs, the estimated coefficients do not significantly change, but the average standard error changes. The smallest standard errors appear in the case of a cautious outlier specification (i.e. a small minimum quantity and large number of standard deviations around the mean). As a result of the issues discussed, we use such a cautious specification. 
A further challenge for the estimation of the SMC is the choice of the length of the rolling window. As discussed in Chapter 4.3.2, the distribution parameters of the composed error term of the stochastic frontier model can be expected to vary with time. The use of a rolling window procedure is therefore a tribute to limited observation numbers. For the dairy markets that are analyzed in this thesis, the observation numbers may be sufficiently large in the case of New Zealand and the EU, but for Australia the average numbers only lie between 26 and 28 per month - outliers already excluded. In all cases, the usage of a three month rolling window procedure leads to a less noisy SMC series while not significantly changing the single estimates. This means that the estimation efficiency is increased. Strictly speaking, this procedure is only valid if the distribution parameters do not change significantly within three months. Indeed, the parameters always follow an AR(1) process and are therefore - on average - more different when the time gap is larger. Furthermore, in the majority of cases, F-tests cannot reject that adjacent periods have the same distribution parameters. However, since the monthly SMC series is transformed into a quarterly one in order to estimate the approaches in Chapters 4 and 5 , a three month rolling window is not seen as critical - although there may be some adjacent periods with significantly different distribution parameters.

Nevertheless, the length of a rolling window should not be too large and a certain minimum number of monthly destination-specific unit values should be given in order to estimate the SMC. This has some implications such as the fact that it is not possible to analyze each export country, in both the PTM and the residual demand approach. In the latter, the same applies for less important competitor countries or those that are just of regional importance (and therefore do not exhibit enough observations). In the case of the international dairy markets, these are countries like the US (for some products), Argentina, the Ukraine or Uruguay. In general, the observation number restriction can also be expected to limit the markets available for the approach. When certain markets are not of huge importance at all, or specific for a limited number of import countries, it is probably not possible to estimate the SMC for even a single export country. As discussed in Chapter 4.3.2, the SMC estimation further assumes a rather homogenous product - whereby the consequences of a violation of this assumption are not clear. This further restricts the number of appropriate markets. As a result, the SMC can probably mainly be estimated (and used in the PTM or residual demand approach) in the case of heavily traded commodities and important export countries. However, when niche, highly processed or premium products are considered the case may be different. 
Two further challenges remain with regard to the properties of the SMC; this is its relation to the marginal cost and the question of exogeneity. It is already mentioned in Chapter 4.3.2 that the SMC is at best a noisy measure of the marginal cost, and at worst biased through the correlation of a certain minimum markup with price. The most important questions are therefore whether such a bias is likely, and if so, how serious it can be expected to be. In general, the existence of a minimum markup is necessary for such a bias. Although a minimum markup may be very likely in some markets, the results in Chapter 5 speak against a minimum markup or at least against the fact that such a markup is very pronounced. However, even if it exists and is negatively correlated with the price, the resulting bias would be much less than in comparison to the usage of non-destination-specific unit values or the wholesale price. This is an implicit result of the non-destination-specific estimation of the oligopolistic PTM model in Chapter 5.2. In general, the results do not give any hints for the existence of this bias. However, if this bias still exists, it should be quite small, and additionally, it should tend in the direction against finding of PTM - that is, producing a conservative estimate for PTM.

The last challenge - the risk of the endogeneity of the marginal cost and therefore of the SMC - is a serious issue. Such a bias would tend in the direction of finding of PTM through the marginal cost coefficient. The basic problem is that the SMC cannot be instrumented; in this case the advantages of using the SMC vanish. Furthermore, the usage of cost shifters - that are probably the best instruments available - lead to biased coefficients as already described in Chapters 3.1, 4.3.2 and 5.3.2. Therefore, the question is whether a possible endogeneity bias can be expected to be serious. As argued in Chapter 4.3.2, a price change in single destination countries without a huge market share should have a negligible influence on the overall marginal cost of the export firm - especially when it is compared to the influence of the marginal cost on the price. Indeed, the destination-specific estimation results of the PTM model (Chapter 4.5.2) show that the absolute value of the SMC coefficient is mostly not larger than the absolute value of the exchange rate coefficient (Table 4.3) - that is, symmetry is fulfilled. Interestingly, when the average SMC coefficient for WMP is compared between the destination-specific and the non-destination-specific model version (Table 4.2), the latter is even smaller (in absolute terms). This means that endogeneity may not be a problem even in the non-destination-specific case. The results certainly show no hints of a problem. Furthermore, in the estimation of the residual demand model (Chapter 5.5) the export country's SMC turned out to be a valid instrument. 


\subsection{The connection between PTM and the residual demand}

When Knetter's basic PTM model that is depicted in equation (3.3) is compared with the residual demand model in equation (5.13), the approaches seem to be quite different. Much of this difference disappears when the models introduced in Chapter 4 and 5 are compared - that is, the oligopolistic PTM model and the residual demand model with the stochastic marginal cost (SMC) used.

In both models, the left hand side variable is New Zealand's export price, measured by destination-specific export unit values - except that they are measured in different currencies ${ }^{26}$. Furthermore, in both models the SMC and bilateral exchange rate of the competitors appear on the right hand side. Although the residual demand model covers more than the single competitor in the oligopolistic PTM model, the latter can be generalized for a larger number of competitors. Furthermore, the GDP appears in both models. A notable difference is that the destination milk price and the CPI do not appear in the PTM model. This is, however, not of importance since both a) are almost never significant in the residual demand model and b) could theoretically also be included in the oligopolistic PTM model. The same holds true for a time trend and the quarterly dummies $^{27}$. As a result, only one important difference of the models remains: Instead of the export country's SMC and bilateral exchange rate - as in the oligopolistic PTM model the export quantity appears in the residual demand model. However, the export quantity can again be instrumented by the former variables when 2SLS is used.

These considerations may raise the question whether or not the competitor variables as the main similarity - measure the same thing in both models. In fact, this is not the case, at least not exactly. As equation (4.3) reveals, the competitor's price - which in turn depends on the competitor's SMC and its bilateral exchange rates - influences the price charged by the export country in two ways ${ }^{28}$. Firstly, it has an influence on the marginal cost of the export country (marginal cost channel), and secondly, it also influences its optimal markup (markup channel). Since the marginal cost of the export country is directly represented in the PTM model, only the influence on the optimal markup

\footnotetext{
${ }^{26}$ The export price is measured in the export country's currency in the case of the PTM model and in the destination country's currency in the case of the residual demand model.

${ }^{27}$ We also tried to include quarterly dummies in the oligopolistic PTM model. Interestingly, and opposed to the residual demand model, they are almost never significant.

${ }^{28}$ The theoretical derivation that is depicted by this equation is also valid with regard to the residual demand model - except that the exporter's price as dependent variable is measured in the exporter's currency, instead of the destination country's currency. Moreover, the residual demand model could also be based on this equation with clear theoretical interpretations of the coefficients.
} 
remains as a statement of the competitor variables in the PTM model. For the residual demand model the case is different; both channels are at work.

What can be said about these channels? As already described in Chapter 4.2, the magnitude of the markup channel is determined through the perceived degree of product differentiation in the destination country (the coefficient $\delta$ ). Conversely, when measured in the export country's currency, the marginal cost channel should be equally pronounced in each destination country - at least in the case of the SMC coefficient. This is because the competitor's SMC has an influence on the competitor's price in all destination countries, which in turn influences the export quantities and therefore the export country's overall marginal cost. The magnitude of this influence can be expected to be determined by the overall degree of product differentiation in addition to the export share for which the export country faces competition from the competing country. However, since the price in the destination country's currency is used in the residual demand model, the magnitude of the marginal cost channel may actually vary to a certain degree across the destination countries. This happens when the competitor's SMC is correlated with the exchange rates between the export country and the destination countries. Conversely, for the competitor's exchange rate coefficient the marginal cost channel cannot be expected to be equally pronounced across the destinations - this holds true independent of the currency. The reason for this is that an exchange rate change influences the competitor's price (and therefore export quantities and export country's marginal cost) only in the respective destination country. Since exchange rates are correlated (Chapter 3), the prices in other destination countries can also be affected to a certain degree. Nevertheless, the marginal cost channel can always be expected to be more pronounced for the SMC coefficient than for the exchange rate coefficient.

These considerations have some implications for the competitor coefficients in the residual demand model and their linkage to those of the oligopolistic PTM model. Firstly, unlike the PTM model, the effects that are measured by the SMC and the exchange rate coefficient cannot be expected to be symmetric anymore. Secondly, the values of the competitor coefficients can be expected to be larger in the residual demand model. Thirdly, the value of the SMC coefficients in the residual demand model can be expected to lie around a constant value above the one in the oligopolistic PTM model. Finally, the last point implies that even when a competitor plays no role in a certain destination country, it can still exhibit significant coefficients of its SMC and exchange rate in the destination country's equation. 
Furthermore, it is clear that a large competitor coefficient in the residual demand model can be caused by a large magnitude of the marginal cost channel as well as by a large magnitude of the markup channel. The question is whether both channels equally restrict the value of the inverse residual demand elasticity (RDE) - that is, the ability to charge a markup. Usually, a large competitor coefficient (close to one) in the residual demand model implies that the exporter's price is largely explained by the competitors' costs. In such a case, no space is left for the exporter to increase the price by reducing the quantity. However, when a noticeable proportion of the competitor coefficient is caused by the markup channel, it is unlikely that the markup is small or even zero. The oligopolistic PTM estimates for WMP (Chapter 4.5.2) suggested that a large $\delta$ coefficient (markup channel) does not reduce the markup as much as the markup is raised through the necessary $\beta$ coefficient. A pronounced markup channel therefore implies the existence of a certain markup. This means that a large competitor coefficient in the residual demand model does not necessarily go along with the absence of market power. Conversely, the marginal cost channel is consistent with the lack of a markup. Moreover, in the case of perfect competition only the marginal cost channel can operate.

These considerations could explain the results in Chapter 5.5. The coefficients of the EU as a competitor are often large but its pattern is not clearly connected with low absolute values of the RDE. Conversely, for Australia - as a competitor - such a connection seems to be more pronounced. In Chapter 5.5 we speculate that this observation could be due to a different kind of competition. Indeed, the reason could be that the Australian coefficients are stronger driven by the marginal cost channel. New Zealand and Australia compete in mostly the same markets. Conversely, the overlap of markets is much smaller for New Zealand and the EU, and the EU's coefficients could therefore be caused to a higher degree by the markup channel. 


\subsection{Comparison of the estimation results}

As discussed in Chapter 6.2, the competitor coefficients constitute a link between the oligopolistic PTM model and the residual demand model. Since both contain an influence that we call the markup channel, we expect the coefficients to be related. Firstly, the competitor coefficients in the residual demand model should lie above those in the PTM model. Figure 6.1 shows that this condition is mostly fulfilled for the SMC coefficients in the $\mathrm{WMP}^{29}$ market. In thirteen out of sixteen cases, the SMC coefficients are larger (or equal) in the residual demand model than in the PTM model. Secondly, we hypothesized that the difference between the SMC coefficients of the models is almost constant across the destinations. As Figure 6.1 shows, this is not the case. Nonetheless, the coefficients exhibit a correlation coefficient of 0.43 across the models.

\section{Figure 6.1: Comparison of competitor coefficients for WMP}

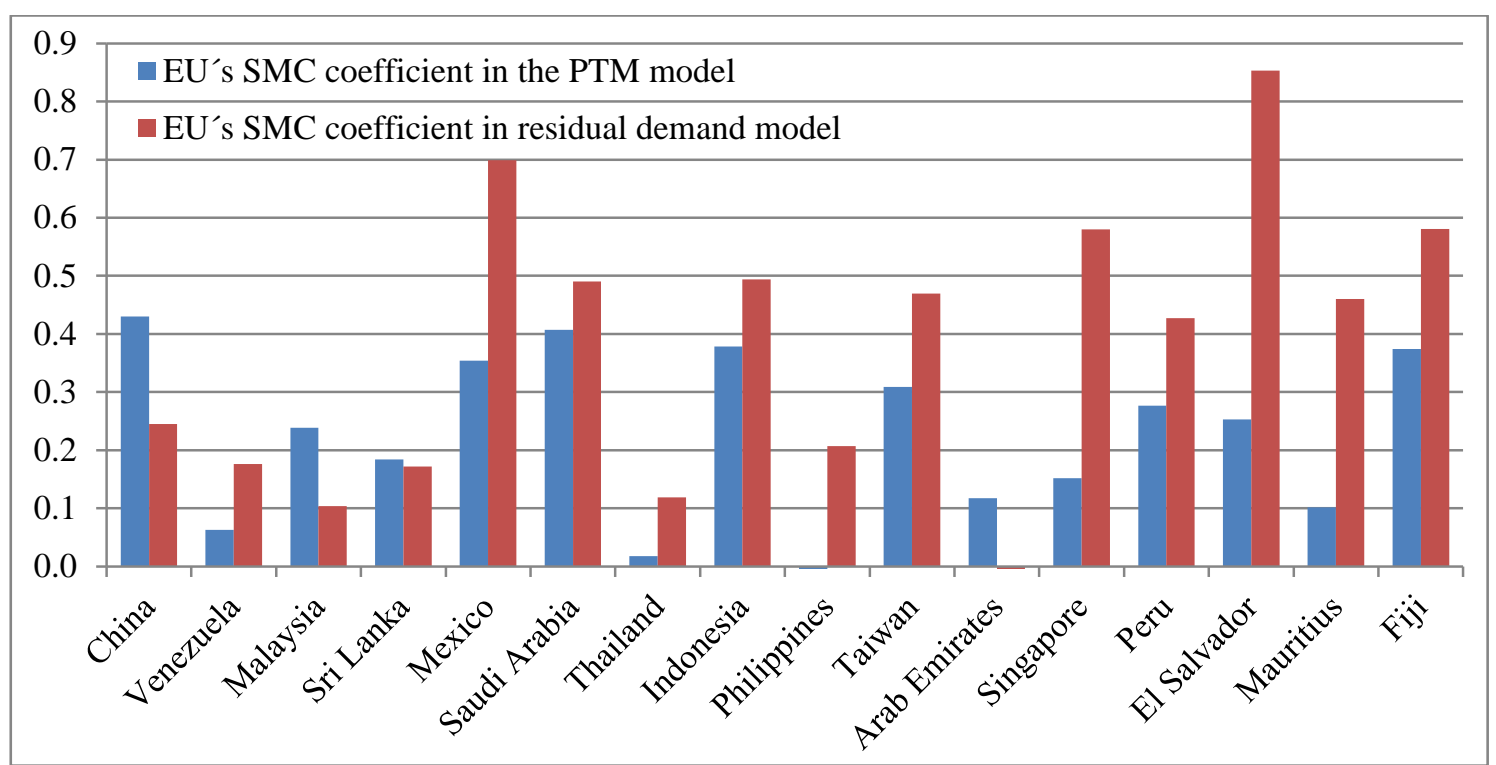

Source: own calculations

There are a lot of possible reasons why the expectation of constant differences is not fulfilled and the SMC coefficients are only loosely linked across the models. One reason is that a constant difference can only be expected when the price (as the dependent variable in the residual demand model) would be measured in the export country's currency. Furthermore, Australia - as an additional foreign competitor - was considered in the residual demand model but not in the oligopolistic PTM model. This means that the EU's coefficients in the oligopolistic PTM model could be influenced by the omission of Australia when the variables are correlated. Finally, for most of the destination coun-

\footnotetext{
${ }^{29}$ Since the destination-specific version of the oligopolistic PTM model is only estimated for WMP, the results for the other products cannot be compared.
} 
tries the number of lags introduced in the oligopolistic PTM model is larger than in the residual demand model. This further complicates any comparison.

However, this raises the question of why the optimal lag numbers are so different across the models. The most likely explanation for this is that New Zealand's SMC and exchange rate - that are not part of the residual demand model - cause the need for more lags. Contrary to this explanation, however, we understand that a larger lag number in the oligopolistic PTM model (Chapter 4.5.2) primarily has an influence on the EU's coefficients. Alternatively, in the residual demand model a significant further lag of a certain variable could be overshadowed by a lack of significance of the lags of the large number of other coefficients. Since most of the variables can be expected to be correlated, we always used the same lag number for all variables included in the model. In addition to the lag number, a further difference in the results is that for the residual demand model quarterly dummies are significant, whereas for the PTM model they are not. This means that when New Zealand`s marginal cost is accounted for, the price does not show any seasonal anomalies. Conversely, when only competitors' marginal costs are considered, seasonality is an issue. This supports our explanation in Chapter 5.5 of seasonal differences in competition, probably due to seasonality in the milk production.

Since a PTM model usually only provides proof of whether market power is existent or not, these results can hardly be compared with the estimate of the RDE. In general, only information on whether market power is supported by the models can be compared, not the extent of the market power. However, the case is different for the oligopolistic PTM model. In Chapter 4.5.2 we hypothesized that a large difference between $|\beta|$ and $\delta$ can be seen as an indication of a large markup. We tested for this hypothesis by regressing the UV surcharges on the coefficients' values. Since this procedure delivered significant results, the fitted values of the regression could be used for a comparison with the optimal markup indicated by the RDE estimates. This is done for WMP in Figure 6.2. In addition to the fitted values and the optimal markup, the UV surcharges are displayed in the figure. As shown in Figure 6.2, the fitted values are very close to the actual UV surcharges, with the exception of Singapore where a large difference is depicted. Interestingly, the RDE estimates support the large fitted value for Singapore. Besides this, the optimal markups indicated by the RDE estimates and the fitted values of the UV surcharges do not show a similar pattern nor are they correlated at all. Moreover, the PTM results indicate the presence of market power for each destination country while the RDE estimates only support the existence of markups for single destinations. This result 
could be expected for two reasons. Firstly, the RDE estimates already showed no linkage to the UV surcharges, and secondly, the value of the EU's SMC coefficient in the residual demand model is not connected to the RDE estimates. Remember that the competitors' coefficients constitute a link between the approaches.

Figure 6.2: Comparison of market power indicators ${ }^{30}$ for WMP

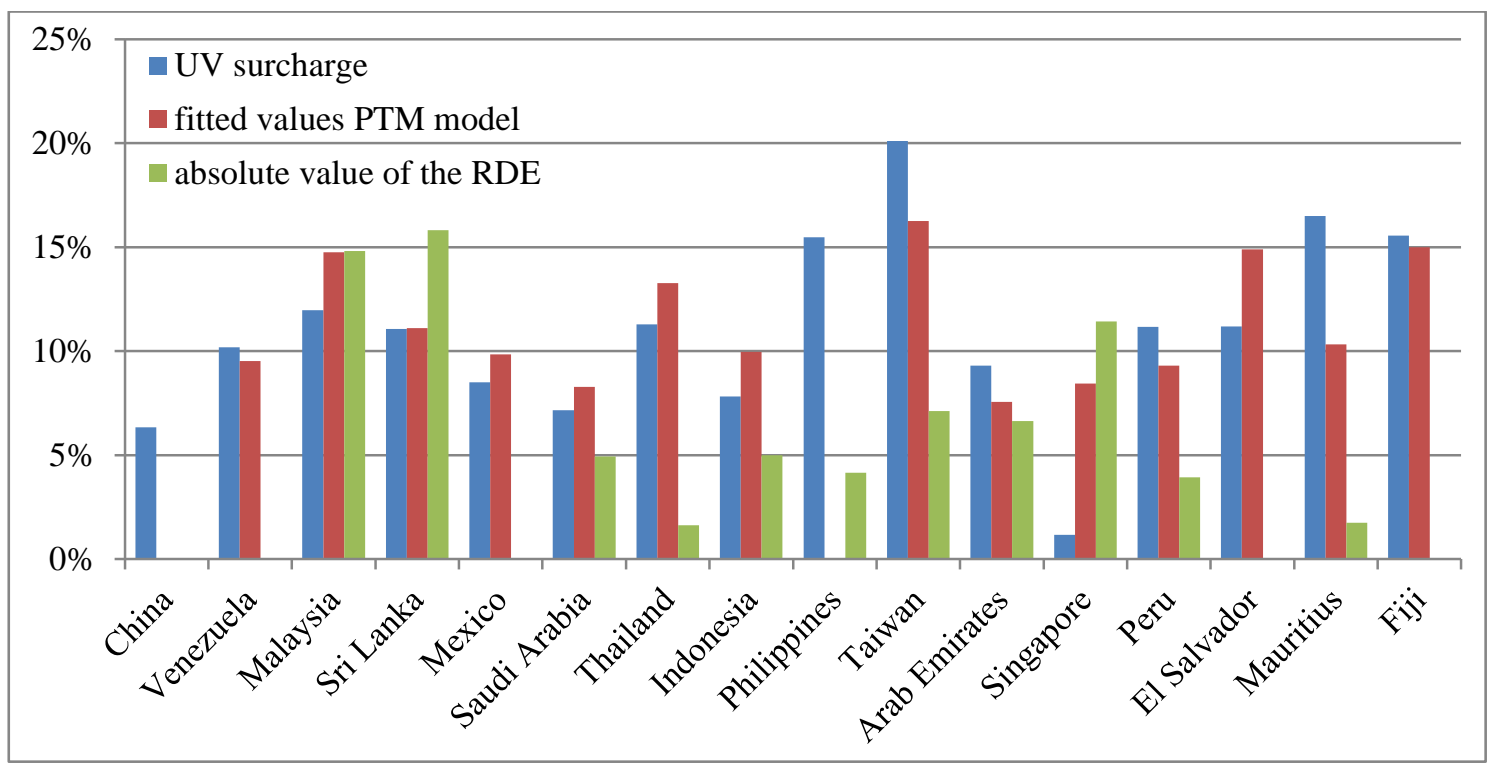

Source: own calculations

A number of reasons can be considered for the lack of agreement between the two destination-specific measures of Fonterra's market power. Both measures may not show the actual markup. For the RDE, it is discussed in Chapter 5.3.2 that the usage of OLS (or SUR) can be expected to bias the RDE estimates in the direction of rejection of market power - we therefore speak of conservative estimates. Such a bias can be differently pronounced across the destination countries. However, even when the RDE estimates would be unbiased, according to the discussion in Chapter 5.2, they show the optimal markup of the firm and not the actual markup which can differ from the former.

In the case of the fitted values (PTM approach), it is not clear at all whether these values can be considered a good approximation of the markup. If quality premiums play an important role on the market, the assumptions of the OLS error term are surely violated since quality premiums are only positive surcharges and not zero on average. If the quality premiums are uncorrelated with the variables of the oligopolistic PTM model, they only bias the constant of the OLS model - i.e. the level of the fitted values. If, however, the quality premiums are correlated with the SMC or the exchange rate, the

\footnotetext{
${ }^{30}$ Since the theoretical coefficients for China and the Philippines in the PTM model are outside the range which is consistent with theory, they are not used to calculate the regression results in Table 4.4 and no fitted values are displayed in Figure 6.2.
} 
coefficients are biased too. Indeed, such a correlation is discussed in Chapter 4.5.2 and is considered to be possible. Therefore, the results in Table 4.4 could - in an extreme case - just imply that PTM is a good indicator of the existence of different qualities. Even if this case is not likely for the dairy markets, it illuminates the possible problems with regard to fitted values in Figure 6.2. A further general problem is that PTM may prove the existence of a markup but a markup can also exist without observing PTM. This is the case when the (residual) demand elasticity in the destination country is constant. This situation may be most likely when no competitors exist in the destination country, since the results in Chapter 4.5.2 show that PTM is mainly caused by the EU's existence as a competitor. However, because the destination-specific results for WMP also show that PTM takes place in almost all single destinations analyzed, this problem seems to be negligible in our dataset. Moreover, another observation suggests that the fitted values may be not as bad in indicating market power as might be supposed. When the fitted values are compared with New Zealand's import market shares, a correlation coefficient of 0.33 is exhibited. Although this value is not significant ( $p$-value $=0.24$ ), it is more promising than the lack of correlation in the case of the RDEs.

Nonetheless, since both indicators of market power in Figure 6.2 face limitations, we prefer using them to define a possible range for the markup. The actual markup should at least be as high as the minimum of both the UV surcharge and the absolute value of the significantly negative RDE. Conversely, the actual markup should not exceed the minimum of both the UV surcharge and the fitted value of the PTM model.

However, there is one clear similarity between the approaches. When the results are compared across the products, they do not change a lot - this holds true in both approaches. For the residual demand approach, this applies for the average RDE and the share of significant RDEs. In the case of the non-destination-specific version of the oligopolistic PTM model, this is true for the PTM and competitor coefficient. There is only one exception: SMP. For SMP, a non-destination-specific PTM does not take place, but the RDE estimates imply the same degree of market power as for the other products. When the market for SMP is compared to the other markets, there are only two noticeable differences. Firstly, SMP can be expected to be more homogeneous and secondly, the US - as a third foreign competitor - is active in the market. 


\subsection{Implications for the international dairy markets}

The results for both the pricing-to-market approach as well as the residual demand approach support the existence of market power for New Zealand, and therefore for Fonterra. Essentially, the extent of this market power seems to be moderate. When all destination-product combinations are considered, $56 \%$ of the RDE estimates are significantly negative with an average that implies an optimal markup of $8.6 \%$ of the price. These values can - in general - be expected to be conservative, that is, they are probably biased downwards. In comparison, the unit value series for the destination countries shows, on average, a surcharge on the SMC (UV surcharge) of 13.7\%. While this value can (in parts) be influenced by quality premiums, the PTM results prove the existence of a markup for almost all destination countries - at least for WMP.

\section{Figure 6.3: Comparison of the optimal markup implied by the RDE estimates}

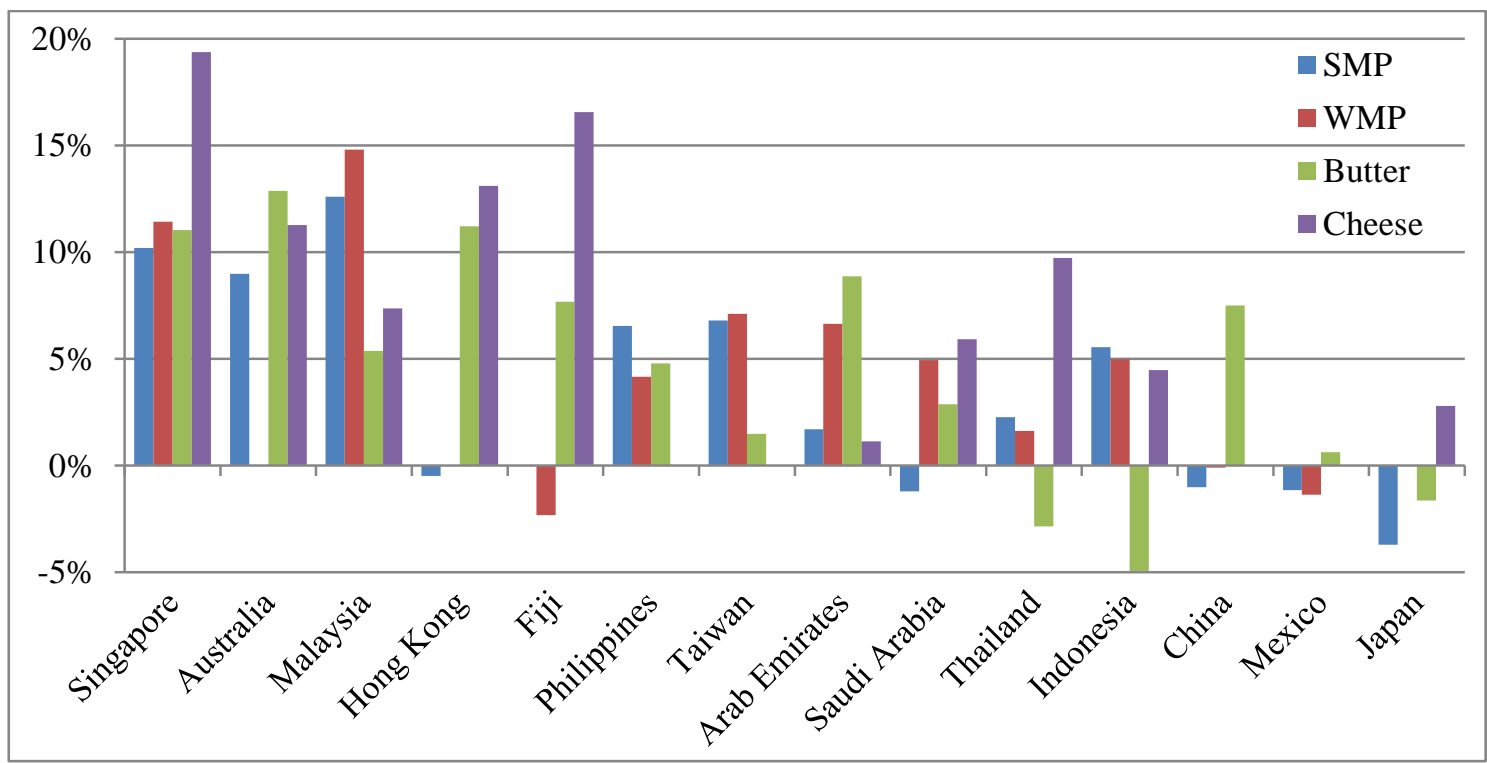

Source: own calculations

The degree of market power seems to be rather different across the destination countries - although this is not as pronounced in the PTM results as it is in the residual demand results. In contrast, the product analyzed is of less importance. This fact is illustrated in Figure 6.3. The figure depicts the optimal markups implied by the RDE estimates for all destination countries ${ }^{31}$, with estimates available for at least three products. A lot of the RDE estimates vary only slightly for a given destination country. In general, this pattern of market power across the destination countries is hard to explain. Observable facts that should theoretically be helpful for this task - such as New Zealand's import market share or those of the competitors - do not offer an explanation. This is true for the pat-

\footnotetext{
${ }^{31}$ The destination countries are sorted according to the average optimal markup.
} 
tern generated by the RDE estimates and also - to a lesser extent - for the pattern that arises when the PTM approach is considered. This leads to the conclusion that the degree of market power in a certain destination country should be caused by some different, unobservable and qualitative factors. Such factors could include the perceived degree of differentiation, buyer loyalty, distribution channels used, historical roots of the suppliers, transparency in the market and so on. Conversely, the actual degree of differentiation should be rather low. The products analyzed are typically standardized and therefore very homogeneous.

The limiting element with regard to Fonterra's market power is essentially the competition from Australia, and to a lesser extent the competition from the EU. Nonetheless, the import market shares of both competitors are often similar in the destination countries analyzed. Therefore, the larger importance of Australia for the degree of Fonterra's market power could stem from products perceived as being more similar or the usage of similar distribution channels. This probably explains why Fonterra is trying to gain a foothold in the Australian dairy industry. This is done, for example, by holding an ownership stake of $50 \%$ in the Australian dairy company Bonlac. However, other competitors hardly seem to play any role. The US is only important in the case of SMP and for a limited number of destinations; domestic competitors in the destination country are, in the majority of cases, not important. In the case of the US, Fonterra can probably keep down the competition, since it exports a huge proportion of the US's SMP by itself. As already discussed in Chapter 5.5, this is due to an agreement with Dairy America. The products of the domestic competitors in the destination countries can, however, be expected to differ to those of New Zealand with respect to quality, safety and functionality. This is due to the fact that most of the important destination countries do not have a well-developed dairy value chain. The degree of self-sufficiency is often well below one hundred percent and many farmers produce for their own use.

The results of the oligopolistic PTM model show that Fonterra uses its existing markup in order to smooth out changes in the marginal cost to a certain degree. Such changes in marginal cost in the destination country's currency can be caused by changes of Fonterra's overall marginal cost or by changes in the bilateral exchange rate. However, while Fonterra widely smoothes out changes in the marginal cost when the EU's marginal cost does not change, it more or less renounces a smoothing when the EU's marginal cost changes at the same time and to the same degree. The latter happens, for example, when the destination country's currency changes its worth against all other currencies. This 
behavior helps in conserving import market shares in the destination countries while staying on a similar markup level in the long-term ${ }^{32}$.

This kind of PTM behavior that is detected in Chapter 4.5.2 has some consequences for the international integration of the dairy markets and transmission of price signals. Obviously the price levels in the destination countries can be quite different. When the estimates of the RDE are compared across the destination countries, the smallest and largest values differ by nineteen percentage points. Furthermore, changes in the marginal cost are not proportionally transmitted into price signals. When only the marginal cost in New Zealand changes - for example, due to a drought -, this leads to price changes that may only equal around $60 \%$ of the change in the marginal cost. Since this also causes a smaller effect on the trade quantities, the competitor's marginal cost cannot be expected to also change proportionally. Conversely, under perfect competition the trade quantities would change until the marginal cost of New Zealand and the EU are equal again, when measured in a common currency. However, in the case of PTM, the marginal cost of New Zealand and the EU can be expected to be more loosely connected. This can further cause different price levels in New Zealand and the EU - even if the countries charge the same price in the destination countries in which they compete against each other. Since 2007, there are indeed huge price differences (at least partially) in the overall export prices for Oceania (New Zealand and Australia) and the EU. The less pronounced differences up to 2007 could be explained by considering that the European Commission could have based the amount of the flexible export refunds on the prices in Oceania.

\footnotetext{
${ }^{32}$ This is additionally supported by the CUSUM tests of the residual demand model that in almost all cases cannot reject the null hypothesis of stable parameters such as the RDE.
} 